\title{
Cochrane
}

Library

Cochrane Database of Systematic Reviews

\section{Diuretics for respiratory distress syndrome in preterm infants} (Review)

Stewart A, Brion LP, Soll R

Stewart A, Brion LP, Soll R.

Diuretics for respiratory distress syndrome in preterm infants.

Cochrane Database of Systematic Reviews 2011, Issue 12. Art. No.: CD001454.

DOI: 10.1002/14651858.CD001454.pub3.

www.cochranelibrary.com 
TABLE OF CONTENTS

HEADER

ABSTRACT

PLAIN LANGUAGE SUMMARY

BACKGROUND

OBJECTIVES

METHODS

RESULTS

DISCUSSION

AUTHORS' CONCLUSIONS

ACKNOWLEDGEMENTS

\section{REFERENCES}

\section{CHARACTERISTICS OF STUDIES}

\section{DATA AND ANALYSES}

Analysis 1.1. Comparison 1 Routine diuretic administration versus placebo, no treatment or PRN diuretic administration, Outcome 1 Death.

Analysis 1.2. Comparison 1 Routine diuretic administration versus placebo, no treatment or PRN diuretic administration, Outcome 2 Clinically significant PDA.

Analysis 1.3. Comparison 1 Routine diuretic administration versus placebo, no treatment or PRN diuretic administration, Outcome 3 Hypovolemic shock.

Analysis 1.4. Comparison 1 Routine diuretic administration versus placebo, no treatment or PRN diuretic administration, Outcome 4 Change in plasma volume $(\mathrm{ml} / \mathrm{kg})$ from 48 to 96 hours of life.

Analysis 1.5. Comparison 1 Routine diuretic administration versus placebo, no treatment or PRN diuretic administration, Outcome 5 Change in cardiovascular stability index from 48 to 96 hours of life.

Analysis 1.6. Comparison 1 Routine diuretic administration versus placebo, no treatment or PRN diuretic administration, Outcome 6 Dobutamine infusion rate (micrograms $/ \mathrm{kg} / \mathrm{min}$ ) at the end of treatment.

Analysis 1.7. Comparison 1 Routine diuretic administration versus placebo, no treatment or PRN diuretic administration, Outcome 7 Dopamine infusion rate (micrograms $/ \mathrm{kg} / \mathrm{min}$ ) at the end of treatment.

Analysis 1.8. Comparison 1 Routine diuretic administration versus placebo, no treatment or PRN diuretic administration, Outcome 8 Change in colloid infusion rate $(\mathrm{ml} / \mathrm{kg} / \mathrm{hour})$ at the end of treatment.

Analysis 1.9. Comparison 1 Routine diuretic administration versus placebo, no treatment or PRN diuretic administration, Outcome 9 Failure to extubate within 3 days after study entry.

Analysis 1.10. Comparison 1 Routine diuretic administration versus placebo, no treatment or PRN diuretic administration, Outcome 10 Change in peak inspiratory pressure $(\mathrm{cm} \mathrm{H2O})$ during treatment.

Analysis 1.11. Comparison 1 Routine diuretic administration versus placebo, no treatment or PRN diuretic administration, Outcome 11 Change in mean airway pressure $(\mathrm{cm} \mathrm{H} 2 \mathrm{O})$ during treatment.

Analysis 1.12. Comparison 1 Routine diuretic administration versus placebo, no treatment or PRN diuretic administration, Outcome 12 Duration of mechanical ventilation (days).

Analysis 1.13. Comparison 1 Routine diuretic administration versus placebo, no treatment or PRN diuretic administration, Outcome 13 Change in FiO2 during treatment.

Analysis 1.14. Comparison 1 Routine diuretic administration versus placebo, no treatment or PRN diuretic administration, Outcome 14 Change in alveolar-arterial 02 gradient $(\mathrm{mm} \mathrm{Hg})$ during treatment.

Analysis 1.15. Comparison 1 Routine diuretic administration versus placebo, no treatment or PRN diuretic administration, Outcome 15 BPD.

Analysis 1.16. Comparison 1 Routine diuretic administration versus placebo, no treatment or PRN diuretic administration, Outcome 16 Death or BPD.

Analysis 1.17. Comparison 1 Routine diuretic administration versus placebo, no treatment or PRN diuretic administration, Outcome 17 Duration of oxygen supplementation (days).

Analysis 1.18. Comparison 1 Routine diuretic administration versus placebo, no treatment or PRN diuretic administration, Outcome $18 \mathrm{IVH}$

Analysis 1.19. Comparison 1 Routine diuretic administration versus placebo, no treatment or PRN diuretic administration, Outcome 19 Severe IVH (grade III or IV).

Analysis 1.20. Comparison 1 Routine diuretic administration versus placebo, no treatment or PRN diuretic administration, Outcome 20 Duration of hospitalization (days). 
Analysis 1.21. Comparison 1 Routine diuretic administration versus placebo, no treatment or PRN diuretic administration, Outcome 21 Significant handicap at one year (major neurologic defect and/or MDI/PDI <50).

Analysis 1.22. Comparison 1 Routine diuretic administration versus placebo, no treatment or PRN diuretic administration, Outcome 22 Oligoanuria (urine output $<1 \mathrm{ml} / \mathrm{kg} / \mathrm{hour}$ ).

Analysis 1.23. Comparison 1 Routine diuretic administration versus placebo, no treatment or PRN diuretic administration, Outcome 23 Hyponatremia (sodium < $130 \mathrm{mM} / \mathrm{L}$ ).

Analysis 1.24. Comparison 1 Routine diuretic administration versus placebo, no treatment or PRN diuretic administration, Outcome 24 Hyperkalemia (potassium > $6.5 \mathrm{mM} / \mathrm{L}$ ).

Analysis 2.1. Comparison 2 Routine diuretic administration versus placebo or no treatment, Outcome 1 Death.

Analysis 2.2. Comparison 2 Routine diuretic administration versus placebo or no treatment, Outcome 2 Clinically significant PDA.

Analysis 2.3. Comparison 2 Routine diuretic administration versus placebo or no treatment, Outcome 3 Hypovolemic shock. .. Analysis 2.4. Comparison 2 Routine diuretic administration versus placebo or no treatment, Outcome 4 Failure to extubate within 3 days after study entry.

Analysis 2.5. Comparison 2 Routine diuretic administration versus placebo or no treatment, Outcome 5 Change in peak inspiratory pressure $(\mathrm{cm} \mathrm{H} 2 \mathrm{O})$ during treatment.

Analysis 2.6. Comparison 2 Routine diuretic administration versus placebo or no treatment, Outcome 6 Change in mean airway pressure $(\mathrm{cm} \mathrm{H} 2 \mathrm{O})$ during treatment.

Analysis 2.7. Comparison 2 Routine diuretic administration versus placebo or no treatment, Outcome 7 Duration of mechanical ventilation (days).

Analysis 2.8. Comparison 2 Routine diuretic administration versus placebo or no treatment, Outcome 8 Change in FiO2 during treatment.

Analysis 2.9. Comparison 2 Routine diuretic administration versus placebo or no treatment, Outcome 9 Change in alveolararterial $\mathrm{O} 2$ gradient $(\mathrm{mm} \mathrm{Hg})$ during treatment.

Analysis 2.10. Comparison 2 Routine diuretic administration versus placebo or no treatment, Outcome 10 BPD.

Analysis 2.11. Comparison 2 Routine diuretic administration versus placebo or no treatment, Outcome 11 Death or BPD. ......

Analysis 2.12. Comparison 2 Routine diuretic administration versus placebo or no treatment, Outcome 12 Duration of oxygen supplementation (days).

Analysis 2.13. Comparison 2 Routine diuretic administration versus placebo or no treatment, Outcome 13 IVH. ......................

Analysis 2.14. Comparison 2 Routine diuretic administration versus placebo or no treatment, Outcome 14 Severe IVH (grade III or IV).

Analysis 2.15. Comparison 2 Routine diuretic administration versus placebo or no treatment, Outcome 15 Duration of hospitalization (days).

Analysis 2.16. Comparison 2 Routine diuretic administration versus placebo or no treatment, Outcome 16 Significant handicap at one year (major neurologic defect and/or MDI/PDI <50).

Analysis 2.17. Comparison 2 Routine diuretic administration versus placebo or no treatment, Outcome 17 Oligoanuria (urine output $<1 \mathrm{ml} / \mathrm{kg} /$ hour).

Analysis 2.18. Comparison 2 Routine diuretic administration versus placebo or no treatment, Outcome 18 Hyponatremia (sodium $<130 \mathrm{mM} / \mathrm{L}$ ).

Analysis 2.19. Comparison 2 Routine diuretic administration versus placebo or no treatment, Outcome 19 Hyperkalemia (potassium > $6.5 \mathrm{mM} / \mathrm{L}$ ).

Analysis 3.1. Comparison 3 PRN furosemide versus PRN chlorothiazide, Outcome 1 Death.

Analysis 3.2. Comparison 3 PRN furosemide versus PRN chlorothiazide, Outcome 2 Clinical diagnosis of PDA during the study. .

Analysis 3.3. Comparison 3 PRN furosemide versus PRN chlorothiazide, Outcome 3 Clinical diagnosis of PDA (during the study or later).

Analysis 3.4. Comparison 3 PRN furosemide versus PRN chlorothiazide, Outcome 4 BPD.

Analysis 3.5. Comparison 3 PRN furosemide versus PRN chlorothiazide, Outcome 5 Death or BPD.

Analysis 3.6. Comparison 3 PRN furosemide versus PRN chlorothiazide, Outcome 6 IVH.

Analysis 3.7. Comparison 3 PRN furosemide versus PRN chlorothiazide, Outcome 7 Duration of mechanical ventilation in survivors (days).

Analysis 3.8. Comparison 3 PRN furosemide versus PRN chlorothiazide, Outcome 8 Duration of hospitalization (days). 
[Intervention Review]

\title{
Diuretics for respiratory distress syndrome in preterm infants
}

\author{
Audra Stewart ${ }^{1}$, Luc P Brion², Roger Soll 3
}

${ }^{1}$ Neonatal-Perinatal Medicine, University of Texas Southwestern Medical Center at Dallas, Dallas, Texas, USA. 2Division of NeonatalPerinatal Medicine, University of Texas Southwestern at Dallas, Dallas, Texas, USA. ${ }^{3}$ Division of Neonatal-Perinatal Medicine, University of Vermont, Burlington, Vermont, USA

Contact address: Luc P Brion, Division of Neonatal-Perinatal Medicine, University of Texas Southwestern at Dallas, 5323 Harry Hines Boulevard, Dallas, Texas, 75390-9063, USA. Luc.Brion@UTSouthwestern.edu.

Editorial group: Cochrane Neonatal Group

Publication status and date: New search for studies and content updated (no change to conclusions), published in Issue 12, 2011.

Citation: Stewart A, Brion LP, Soll R. Diuretics for respiratory distress syndrome in preterm infants. Cochrane Database of Systematic Reviews 2011, Issue 12. Art. No.: CD001454. DOI: 10.1002/14651858.CD001454.pub3.

Copyright (c 2011 The Cochrane Collaboration. Published by John Wiley \& Sons, Ltd.

\section{A B S T R A C T}

\section{Background}

Lung edema may complicate respiratory distress syndrome (RDS) in preterm infants.

\section{Objectives}

The aim of this review was to assess the risks and benefits of diuretic administration in preterm infants with RDS.

\section{Search methods}

The standard search method of the Cochrane Neonatal Review Group was used. The Cochrane Central Register of Controlled Trials (CENTRAL, The Cochrane Library), MEDLINE and EMBASE were searched. These searches were updated in April 2003, March 2007, January 2011. In addition, the abstract books of the American Thoracic Society and Society for Pediatric Research were searched. MEDLINE and CENTRAL search was conducted using the keyword "Respiratory Distress Syndrome" alone, to find studies of medications recently classified as diuretics, such as theophylline. In addition, EMBASE, controlled-trials.com and clinicaltrials.gov searches were completed in January 2011. MEDLINE search updated to August 2011.

\section{Selection criteria}

Trials were included in which preterm infants with RDS and less than five days of age were randomly allocated to diuretic administration. Of those trials, studies were only included in which at least one of the following outcomes measures was evaluated: mortality, patent ductus arteriosus, hypovolemic shock, intraventricular hemorrhage, renal failure, duration of oxygen supplementation, duration of mechanical ventilation, need for oxygen supplementation at 28 days of life, oxygen supplementation at 36 weeks of postmenstrual age (gestational age + postnatal age), length of stay, number of rehospitalizations during the first year of life, and neurodevelopmental outcome.

\section{Data collection and analysis}

The standard method for the Cochrane Collaboration, which is described in the Cochrane Collaboration Handbook, was used. Two investigators extracted, assessed and coded separately all data for each study. Any disagreement was resolved by discussion.

\section{Main results}

Seven studies met inclusion criteria. Six studies using furosemide were done before the current era of prenatal steroids, surfactant and fluid restriction. Furosemide administration had no long-term benefits. Furosemide-induced transient improvement in pulmonary function did not outweigh an increased risk for patent ductus arteriosus and for hemodynamic instability. In one recent study, theophylline had no longterm benefits. Theophylline significantly decreased the risk of oligoanuria and transiently increased renal function, but did not significantly affect renal function at discharge or other outcomes. 


\section{Authors' conclusions}

There are no data to support routine administration of furosemide in preterm infants with RDS. Elective administration of furosemide to any patient with RDS should be carefully weighed against the risk of precipitating hypovolemia or developing a symptomatic patent ductus arteriosus. There are not enough data to support routine administration of low-dose theophylline in preterm infants with RDS.

\section{PLAIN LANGUAGE SUMMARY}

\section{Diuretics for respiratory distress syndrome in preterm infants}

There is not enough data to support the routine use of diuretics for respiratory distress syndrome in newborn babies. Diuretics are drugs that increase the production of urine by encouraging salt and water to be released from the kidneys. When newborn babies have respiratory distress syndrome (RDS), their lungs may also contain excess fluid that can cause breathing problems. Babies with RDS sometimes may also have a reduced urine output. Using diuretics in these babies may improve lung or kidney function transiently, but may also increase cardiovascular complications. The review of trials did not find enough evidence supporting the routine use of diuretics in these infants. 


\section{B A C K G R O U N D}

\section{Rationale for using diuretics in respiratory distress syndrome} (RDS):

\subsection{Lung edema in RDS:}

Interstitial and alveolar edema is a common finding in RDS (DeSa 1969).

In preterm primates with RDS, the reduction in total lung gas volume results from alveolar edema more than from atelectasis (Jackson 1990). This edema initially results mostly from inadequate clearance of fetal lung fluid and by three hours of life results mostly from proteinaceous alveolar edema.

\subsubsection{Starling equation:}

Lung edema may result in part from changes in the terms of the Starling equation (Bland 1982; Green 1982) including plasma colloid osmotic pressure, interstitial colloid osmotic pressure and transcapillary hydraulic pressure. First, colloid osmotic pressure is often low in sick infants with RDS, as a result of decreased production and increased capillary exudation (Sola 1981; Bland 1972). Second, there may be an increase in microvascular transmural pressure resulting from increased surface tension (Albert 1979) and increased pulmonary capillary pressure. The latter may result from alveolar hypoxia (Bressack 1980; Bland 1982a), an increase in pulmonary blood flow secondary to patent ductus arteriosus (Jacob 1980), an increase in left atrial pressure secondary to cardiac dysfunction, or an increase in extracellular volume secondary to excessive fluid intake or to fluid retention. Third, hyaline membranes develop by exudation of plasma proteins (Gajl-Peczalska 1964; Gitlin 1956; Wade-Evans 1962). This exudation results from high membrane permeability (Jefferies 1984; Egan 1984), which could in turn result from hyperoxia (Bland 1982a), free radicals or inflammatory mediators. Fourth, there may be a decrease in lymphatic drainage from the lungs. Lymphatic drainage in premature lambs with RDS is lower than normal, possibly due to high surface tension (Normand 1968). Autopsy of infants with RDS typically discloses dilatation of perivenous lymphatics (Lauweryns 1968). Low lymphatic drainage could also result from mechanical obstruction by interstitial emphysema or high venous pressure secondary to pneumothorax.

\subsubsection{Fluid transport across lung epithelium:}

The major mechanism of perinatal absorption of lung fluid occurs via a switch from active secretion of chloride and fluid to active, predominantly amiloride-sensitive, sodium and water reabsorption, induced by several factors including glucocorticoids and beta-adrenergic agonists (O'Brodovich 1997). Decreased Na reabsorption may contribute to lung edema in RDS (Barker 1997).

\subsubsection{Lung edema in RDS versus therapy:}

Several factors may have contributed to a decrease in the incidence and severity of lung edema in RDS during the last two decades, including fluid restriction, closure of symptomatic patent ductus arteriosus (PDA), prenatal glucocorticoids, postnatal surfactant, and limitation of lung trauma and air leak syndrome. Surfactant administration has been shown to reduce exudation or radiolabeled albumin in preterm lambs (Ikegami 1992). Administration of surfactant reduces radiologic evidence of pulmonary edema during the first days of life; nevertheless, surfactant does not prevent later development of edema in all infants (Swischuck 1996). Prophylactic surfactant administration reduced by half the use of diuretics during weeks two to four, but did not affect its utilization during the first week of life (Gortner 1991).

1.2. Relationship between lung disease and spontaneous urine output:

Patients with RDS often present with an oliguric phase, followed with a spontaneous diuretic phase (typically occurring at 24 to 72 hours) that tends to precede the improvement in lung disease (Heaf 1982; Langman 1981; Shaffer 1986; Spitzer 1981). This led to the hypothesis that diuresis-induced decrease in extracellular volume improves interstitial lung edema and severity of the lung disease. This cause-and-effect relationship between diuresis and improvement in lung disease has been challenged. First, there is often lack of association on a case-to-case basis (Shaffer 1984). Second, similar postnatal changes in body composition and diuresis occur in premature infants without RDS and in those with RDS (Tang 1997, Bidiwala 1988; Lorenz 1995). Third, surfactantmediated improvement in RDS is observed independently of diuresis (Bhat 1989).

1.3. Diuretics may accelerate lung fluid reabsorption and improve pulmonary mechanics in patients with lung edema via two types of mechanisms:

1.3.1. An immediate, diuresis-independent lung fluid reabsorption: This may result (1) from systemic venodilatation, which increases systemic vein capacitance (Dikshit 1973), (2) from decreased pulmonary shunt in the absence of any change in wedge or oncotic pressure (as described in oleic acid-induced pulmonary edema) (Ali 1979), (3) from pulmonary venodilation which decreases wedge pressure, thereby increasing transpulmonary fluid absorption (Demling 1978) or decreasing fluid filtration, and in turn decreasing lung lymph flow (Bland 1978). Furosemide-induced pulmonary vasodilation may result from an increase in prostaglandins (Lundergan 1988).

1.3.2. A delayed increase in urine output (Aufricht 1997), which reduces extracellular volume including interstitial volume (O'Donovan 1989), and may reduce afterload (Wilson 1981) and increase oncotic pressure (Sola 1981). The effects of diuretics on the kidney, in contrast with those on the lung, have been studied extensively and well characterized (Brion 1994). If diuretic administration is repeated for several days, hormonal and renal adaptation mechanisms eventually will limit the diuretic response. Addition of diuretic acting upon another segment of the nephron is often able to overcome this tolerance.

\subsection{Prevention of renal failure:}

Neonatal renal failure may occur as a complication of hypotension, hypoxemia and asphyxia. Adenosine is an important mediator of hypoxemia-related vasoconstriction (Toth-Heyn 2000). At low dose, the methylxanthine theophylline, an adenosine A1 receptor antagonist, may reverse the intrarenal vasoconstriction observed during hypoxemia (Toth-Heyn 2000). Low-dose theophylline has been proposed to reverse hypoxemia-induced renal vasoconstriction and renal failure in neonates with perinatal asphyxia (Jenik 2000; Bhat 2006) or RDS (Huet 1995).

\section{Possible side effects of diuretics:}

2.1. Furosemide has been shown to increase urinary excretion of prostaglandin E (Friedman 1978). An increase in prostaglandin 
could mediate an association between patent ductus arteriosus (PDA) and furosemide which has been observed in a retrospective study (Green 1981).

2.2. An increased diuresis may not be desirable in patients with hypovolemia or low colloid pressure. This may precipitate hypotension, pre-renal failure, drug-induced nephrotoxicity, electrolyte anomalies and metabolic alkalosis.

2.3. Long-term complications of furosemide administration (unlikely to occur with short-duration administration) include negative mineral balance, nephrocalcinosis, nephrolithiasis and hearing loss. In addition, furosemide administration may be associated with development of cholelithiasis (Randall 1992).

3. The classification of diuretics has been expanded to include three types of medications: adenosine A1 receptor antagonists (lowdose theophylline), natriuretic peptides and arginine vasopressin antagonists (Guignard 2005).

\section{O B J E C T IVES}

The aim of this study was to assess the risks and benefits of diuretic administration in preterm infants with RDS.

\section{Primary objectives:}

To assess: mortality, PDA, shock, intraventricular hemorrhage (IVH), renal failure, duration of oxygen supplementation, duration of mechanical ventilation, need for oxygen supplementation at 28 days of life, need for oxygen supplementation at 36 weeks of postmenstrual age (gestational age + postnatal age), length of stay, number of rehospitalizations during the first year of life, and longterm outcome.

\section{Secondary objectives:}

To assess at the end of randomized therapy: hemodynamic stability, oxygenation, ventilatory support, and severe fluid and electrolyte abnormalities.

\section{METHODS}

\section{Criteria for considering studies for this review}

\section{Types of studies}

Randomized controlled clinical trials in which at least one of the primary outcome variables has been analyzed.

\section{Types of participants}

Preterm infants with a postnatal age less than five days with clinical RDS.

\section{Types of interventions}

The intervention needed to include randomized allocation to: 1) the routine administration of a diuretic in the treatment group versus either placebo, no treatment or PRN in the control group; 2) the routine administration of a diuretic in the treatment group versus either placebo or no treatment in the control group;

3) the administration of one diuretic in the treatment group versus another diuretic in the control group.

Studies were considered regardless of the number of arms in the trial.

\section{Types of outcome measures}

Primary outcome measures:

1) mortality;

2) PDA;

3) hypovolemic shock;

4) intraventricular hemorrhage (IVH);

5) renal failure;

6) duration of oxygen supplementation;

7) duration of mechanical ventilation;

8) BPD (defined as need for oxygen supplementation at 28 days of life with or without radiographic findings);

9) oxygen supplementation at 36 weeks of postmenstrual $\mathrm{FiO}_{2}$ age

(i.e., gestational age + postnatal age);

10) death or BPD;

11) length of stay;

12) number of rehospitalizations during the first year of life;

13) neurodevelopmental outcome.

Secondary outcome measures:

1) hemodynamic instability;

2) oxygenation at the end of therapy: fractional inspiratory concentration of oxygen $\left(\mathrm{FiO}_{2}\right)$, alveolar-arterial oxygen gradient;

3) ventilatory support at the end of therapy: mean airway pressure, peak inspiratory pressure, failure to tolerate extubation;

4) dehydration and clinically important electrolyte anomalies.

\section{Search methods for identification of studies}

See: Cochrane Neonatal Review Group search strategy

Standard search method of the Cochrane Neonatal Review Group.

1. Published manuscripts:

The original search included MEDLINE (1966 to 1998), EMBASE (1974 to 1998) and the Cochrane Controlled Trials Register (CCTR) from The Cochrane Library, Issue 3, 1998. Search was not limited to any language.

The following keywords were used: <exp respiratory distress syndrome> and <exp diuretics>.

An additional search using MEDLINE was conducted using the keywords 'respiratory distress syndrome' and 'diuretic' in January 2001 and repeated in April 2003, March 2007, and August 2011. None of these searches yielded any additional studies for inclusion. Searches of the Cochrane Central Register of Controlled Trials (CENTRAL, The Cochrane Library, Issue 1, 2003 and Issue 1, 2007) did not yield any additional studies. Since medications newly classified as diuretics are not listed as such in MEDLINE, we repeated the 2007 and 2011 MEDLINE search using only the keyword 'respiratory distress syndrome.'

Additional searches in CENTRAL (Issue 4, 2010), EMBASE, clinicaltrials.gov and controlled-trials.com using the keywords 'respiratory distress syndrome' and 'infant' were conducted in January 2011. MEDLINE search updated in August 2011.

\section{Published abstracts:}

Search included the abstracts of the following societies:

\# American Academy of Pediatrics 1990 to 1998 (published in American Journal of Perinatology [1990 to 1995] and in Pediatrics [1996 to 1998]). Hand search of sections on Computer and other Technologies, Critical Care and Perinatal Pediatrics.

\# American Thoracic Society 1991 to 1998 (published in American Review of Respiratory Disease [1991 to 1993] and 
in American Journal of Respiratory and Critical Care Medicine [1994 to 1998]). For 1991 to 1993 and 1995 to1997 hand search of sections with a title that includes one of the following keywords: bronchopulmonary dysplasia, BPD, childhood/children, diuretic(s), edema, fluid, infant, mechanics, neonatal, pediatric(s), pulmonary function tests, or water. For 1994 (no sections) hand search of all abstracts. For 1998 search the CD-ROM using the following keywords: bumetanide, lung disease, respiratory distress, respiratory distress syndrome, diuretic, furosemide, metolazone, spironolactone, and thiazide.

\# Eastern Society for Pediatric Research 1991 to 1998 (published in Pediatric Research). For years 1991 to 1993 and 1997 to 1998 hand search of sections on Clinical Trials, Epidemiology, Neonatology, and Pulmonology. For the other years (no sections) hand search of all of the abstracts.

\# Society for Pediatric Research 1985 to 1998 (published in Pediatric Research). Search was done by hand or electronically by CD-ROM (1997 to 1998). For abstract books or CD-ROMs with keywords, we used the same keywords as described for the American Thoracic Society CD-ROM (see above). For years 1992 to 1993 (volumes 31 and 33 of Pediatric Research), no keywords are available; therefore, we hand searched the sections on Developmental Pharmacology, Neonatology-General, and Neonatal Pulmonology.

3. Database of the Neonatal Review Group of the Cochrane Collaboration:

All publications coded under diuretics as intervention were screened.

\section{Selection process:}

Only randomized controlled trials fulfilling the selection criteria described in the previous sections were selected. Selection was done separately by two investigators; any disagreement was resolved by discussion.

\section{Data collection and analysis}

Standard method for the Cochrane Collaboration described in the Cochrane Collaboration Handbook.

\section{Data extraction and entry:}

Two review authors extracted, assessed and coded separately all data for each study. Any disagreement was resolved by discussion. Any standard error of the mean was replaced by the corresponding standard deviation (SD). Mean and standard error of the mean or SD were transformed from graphical data into numerical data using a transparent millimetric ruler and an electronic spreadsheet. Each author was sent an itemized letter requesting additional information about design, patients, methods, or original outcome data (if missing, incomplete or presented in graphical form). For each study, final data were entered into RevMan by one review author and then checked by the second review author.

\section{Planned comparisons and subgroup analyses:}

Comparisons:

1) routine diuretic administration in treatment group versus placebo, no treatment or PRN diuretics in the control group;

2) routine diuretic administration in treatment group versus placebo or no treatment in the control group;

3) diuretic administration in treatment group versus administration of another diuretic in the control group.
Subgroup analyses based on:

1) gestational age (if average gestational age in various studies differs by more than four weeks);

2) postnatal age $(<24$ hours versus at least 24 hours, i.e, before diuresis or during the time of expected diuresis);

3) class of diuretic (this subgroup analysis was added in 2007).

3. Criteria for assessing the methodological quality of the studies: Standard method of the Cochrane Neonatal Review Group. The methodological quality of the studies was assessed for the risk for four types of bias (selection, performance, attrition and detection). Each study was assessed separately by two reviewers; disagreements were resolved by discussion with the other reviewer.

\section{Statistical analysis:}

The standard method of the Cochrane Neonatal Review Group, using a fixed effect model, was used. As much as possible, each variable in various studies was transformed into the same unit of measurement, and used the weighted mean difference for metaanalysis. Tests of between-study heterogeneity (chi-square analysis and ${ }^{2}$ ) were used to determine if pooling of data was appropriate; if there was inconsistency in the direction of the effect, the data from the meta-analysis was not presented.

In addition, continuous variables were transformed into treatment effect defined as change from baseline. This transformation was not possible if the initial value was not provided or if the number of patients decreased at follow-up. If individual values of change were not provided by the authors, the variance of change was estimated using Follmann's (Follmann 1992) method, described in version 3.0.2 of the Cochrane Collaboration Handbook (page 213):

$\operatorname{Var}($ change) $=\operatorname{Var}($ pretest $)+\operatorname{Var}($ posttest $)-2 \times \mathrm{SD}$ (pretest) $\times \mathrm{SD}$ (posttest) $x$ correlation (pretest, posttest), where var is the variance and SD is the standard deviation. The pretest-posttest correlation was assumed to be 0.4 , which is a conservative estimate. Sensitivity analysis was conducted by successively using a correlation coefficient of $0.3,0.4$ and 0.5 .

\section{RES U LTS}

\section{Description of studies}

Eleven studies were considered for the initial review. Four studies were eliminated because they were not randomized controlled trials. One randomized trial (Yeh 1985) was eliminated because it did not include any of the major outcomes defined for this systematic review. Thus, the initial systematic review includes six studies. Details of each study are provided in the table "Characteristics of included studies". All studies had a parallel design. Comparisons are shown as first entry in the column labeled 'Interventions'. No subcategories were used based on gestational age because the maximum range of average gestational age within each intervention group was two weeks.

The repeat search conducted in March 2007 yielded two additional randomized trials (Cattarelli 2006; Hegyi 1986). One trial was excluded because RDS was not listed as inclusion criterion (Hegyi 1986). Thus, the revised 2007 analysis was conducted with seven trials. Subgroup analysis was modified as indicated in the method section. 
The January 2011 search yielded one additional randomized trial (Greenough 1985). This trial was excluded because the age of patients was not less than five days.

\section{Belik 1987:}

Patients were randomly allocated to either receive four i.v. doses of $1 \mathrm{mg} / \mathrm{kg}$ furosemide every 12 hours, or no diuretic. After removing two infants who met criteria for exclusion (sepsis), the number of patients randomized to furosemide was 20 and the number of patients in the control group was 17. Patients were well matched. The first dose of furosemide was given at $13 \pm 4$ hours of life; patients were followed until discharge. Changes in FiO2, AaDO2 and peak inspiratory pressure from study entry until the end of the randomized treatment were assessed using Follmann's formula.

One patient in the furosemide group died of massive intracranial hemorrhage at 24 hours of life. Furosemide transiently improved oxygenation but did not affect the duration of $\mathrm{O} 2$ supplementation. Furosemide tended to reduce peak inspiratory pressure and significantly shortened the duration of mechanical ventilation (171 \pm 47 hours in the furosemide group versus $290 \pm 99$ hours in the control group, $p<0.05)$. Three patients developed a PDA in each group. Furosemide increased the urine output-to-intake ratio and resulted in diuresis occurring at 32 hours in the treated group instead of 56 hours in the control group.

Subgroup analysis in this study is limited by sample size and low power. Nevertheless, it showed that furosemide:

(1) significantly but transiently reduced peak inspiratory pressure and improved oxygenation in the 1,000 to $1,500 \mathrm{~g}$ weight range;

(2) significantly but transiently improved oxygenation in the $>1,500$ $g$ weight range, although the effect was smaller;

(3) did not significantly affect oxygenation and peak inspiratory pressure in the $<1,000 \mathrm{~g}$ birthweight range.

\section{Cattarelli 2006:}

Patients were randomly allocated to receive either i.v. theophylline $1 \mathrm{mg} / \mathrm{kg}$ daily or an equal volume of placebo for three days. Of 54 eligible patients, 50 were randomly allocated, 25 to placebo and 25 to theophylline. One patient died in the placebo group and two in the theophylline group during the first 48 hours. Patients in the two groups had similar baseline characteristics.

Several infants received other medications that could affect outcomes of interest in this review. Eight infants in the theophylline group and twelve in the control group received furosemide, 21 in each group received dopamine, nine in the theophylline group and twelve controls received dobutamine, six in the theophylline group and four controls received ibuprofen, one control received indomethacin, and eight in the theophylline group and nine controls received caffeine.

Patients in the theophylline group had a lower frequency of oligoanuria than controls, a significantly higher urine output on day one, and a lower serum creatinine concentration 24 hours after the first administration of theophylline.

At discharge, however, serum creatinine was not significantly different between the two groups. Two infants in each group developed hyponatremia (sodium $<130 \mathrm{mM} / \mathrm{L}$ ), three in the theophylline group and two in the control group developed hyperkalemia (potassium $>6.5 \mathrm{mM} / \mathrm{L}$ ). Theophylline did not significantly affect the length of stay, nor in the incidence of PDA, IVH, BPD, retinopathy of prematurity, or necrotizing enterocolitis.

\section{Green 1983:}

Patients were randomly allocated to receive either PRN furosemide or PRN chlorothiazide. Of 101 enrolled patients, two were dropped from the study, and most information is available only in the 66 patients who did receive diuretics (33 furosemide and 33 chlorothiazide). Information on the 33 patients who did not receive diuretics were pooled, regardless of randomized group assignment. Patients who received furosemide and those who received chlorothiazide were well matched (see Table). The first diuretic dose was given close to three days of age. Patients remained in the study until one of the following occurred: lack of ventilatory support or oxygen supplementation, ductal ligation, or postnatal age greater or equal to 14 days.

Of 33 patients who received furosemide, eight died, compared with 13 of 33 who received chlorothiazide. A murmur characteristic of PDA was observed in 22 patients in the furosemide group and 13 in the control group ( $p<0.05)$. During the study, 18 patients developed clinical findings of a PDA in the furosemide group and 8 in the thiazide group. Of those, 11 and 7 , respectively, underwent surgical ligation. In addition, six patients in the furosemide group were later found to have a PDA. Thus, the total number of patients developing a PDA during the initial hospital stay was 24 of 33 in the furosemide group and eight of 33 in the thiazide group.

Among survivors, the incidence of BPD was $3 / 25$ in the furosemide group and $3 / 20$ in the chlorothiazide group. Duration of mechanical ventilation was $10.5 \pm 10.3$ days and $7.3 \pm 4.6$ days, respectively (NS).

The incidence of death or BPD was 11/33 in the furosemide group and 16/33 in the chlorothiazide group. Thirteen patients developed an IVH in the furosemide group, compared with 11 in the thiazide group.

Weight loss (\% of body weight) was greater in furosemidetreated patients than in thiazide-treated patients on days 4 and 5. Urinary excretion of prostaglandin E2 slightly and transiently increased in both groups after diuretic administration on the first day. However, furosemide but not chlorothiazide administration increased urinary excretion of prostaglandin E2 on day five.

\section{Green 1988:}

Patients were randomly allocated to receive either four i.v. doses of $1 \mathrm{mg} / \mathrm{kg}$ furosemide every 12 hours, or placebo. In addition, patients in each group received PRN doses of furosemide. Thirtyfive patients were randomized to prophylactic furosemide and 34 to the control group. Patients in the two groups were well matched for most variables. Nevertheless, the rate of colloid infusion at 18 to 24 hours of life, i.e. at or before the time of entry into the study, tended to be higher in the furosemide group than in the control group (6.3 \pm $9.5 \mathrm{ml} / \mathrm{kg} /$ hour versus $3.8 \pm 6.0 \mathrm{ml} / \mathrm{kg} /$ hour). Patients were followed from study entry at 24 to 30 hours of life until day seven.

Criteria for PRN diuretic administration were not rigidly defined in the protocol. Diuretics were usually prescribed to patients with lack of pulmonary improvement and either (1) lack of spontaneous diuresis beginning on the second to fourth day of life (urine output $>$ fluid intake for at least eight hours) or (2) clinical evidence of PDA. Eleven of 35 patients in the treatment group received additional PRN furosemide during the first three days of life, versus 21 of 34 in the control group, yielding a relative risk of 0.51 (95\% confidence 
interval $[\mathrm{Cl}] 0.29$ to 0.89 ) and a risk difference of $-0.303, \mathrm{Cl}-0.528$, -0.079 ). Nevertheless, the total dose of furosemide (randomized + PRN) administered during the first 3 days of life was significantly greater in the treatment group than in the control group $(4.8 \pm$ $1.4 \mathrm{mg} / \mathrm{kg}$ versus $1.5 \pm 1.7 \mathrm{mg} / \mathrm{kg}, \mathrm{p}<0.001$ ). The dose of PRN furosemide prescribed afterwards was similar in the two groups.

The authors used paired Student t-tests and repeated measures analysis of variance for comparing serial values in the two groups; we calculated the weighted mean difference using Follmann's formula.

Mortality was not affected by randomized assignment: three patients died in each group, yielding a relative risk of $0.97(\mathrm{Cl} 0.21$ to 4.48$)$.

Mean airway pressure and alveolar-arterial $\mathrm{O} 2$ pressure gradient were similar in both groups at entry into the study, at five and at seven days of life. Values at the end of treatment (i.e., at 72 to 80 hours of life) are not available. The duration of mechanical ventilation and that of $\mathrm{O} 2$ supplementation were also similar in both groups.

The incidence of PDA was as follows: In the treatment group, 14 patients had a clinically significant PDA, eight received indomethacin and three underwent surgical ligation. In the control group, eight developed a significant PDA, five received indomethacin and one underwent surgical ligation. Furosemide tended to increase the risk for PDA, as shown by a relative risk of $1.70(\mathrm{Cl} 0.82$ to 3.53$)$ and a risk difference of $0.165(\mathrm{Cl}-0.051$ to +0.381 ). Cardiovascular stability index worsened during the study in the furosemide group but not in the control group ( $p=0.03$ by repeated measures analysis of variance; weighted mean difference $0.77, \mathrm{Cl}-0.14$ to +1.68$)$. Patients in the furosemide group had higher heart rate $(p=0.016)$ than those in the control group. The number of patients who developed shock and the number of patients receiving vasopressors are not provided. The rate of dobutamine administration needed to maintain normal blood pressure was significantly higher in the furosemide group than in the control group ( $p<0.05)$, and that of dopamine tended to be higher from 48 to 96 hours $(p<0.10)$. In both groups, the amount of colloids effectively administered decreased from $6 \mathrm{ml} / \mathrm{kg} /$ hour at 12 hours of life to $2 \mathrm{ml} / \mathrm{kg} /$ hour at 96 hours. The amount of colloid administered from 24 to 48 hours of life tended to be higher in the furosemide group than in the control group (NS). Patients in the furosemide group had significantly less increase in plasma volume between 48 hours and 96 hours of life than those in the control group (weighted mean difference $-7.7 \mathrm{ml} / \mathrm{kg}, \mathrm{Cl}-13.1$ to -2.3 ).

Patients in the furosemide group received the same amount of crystalloids as those in the control group. Systematic furosemide administration significantly increased urine output and decreased fluid balance from 24 to 96 hours, thereby increasing weight loss ( $p$ $<0.05$ by paired Student t-test; weighted mean difference $2.2 \%$ of birthweight, $\mathrm{Cl}-1.2$ to +5.6 ). Median grade of IVH was 1 (range 0 to 4 ) in the treatment group and 0 (range 0 - 4) in the control group. The incidence of IVH is not provided.

Marks 1978:

Patients were randomly allocated to receive either a single i.v. dose of $2 \mathrm{mg} / \mathrm{kg}$ furosemide or placebo. No patient received any diuretic before study entry. Seven patients were randomized to furosemide and five to placebo. Patients in the furosemide group were smaller than those in the control group (birthweight 1,707 $\pm 485 \mathrm{~g}, \mathrm{n}=7$, versus $2,286 \pm 418 \mathrm{~g}, \mathrm{n}=5$, respectively, $\mathrm{p}<0.05)$ and had significantly lower initial FiO2 $(0.49 \pm 0.01$, versus $0.61 \pm$ 0.02 , respectively $p<0.05$ ). Patients were entered into the study on average during the second day of life, and remained in the study for six hours after treatment.

The manuscript provides data on only one of the major outcomes defined for this review. One of seven patients in the furosemide group developed hypovolemic shock, compared with none of five in the control group (NS). In addition, information provided by the authors showed that no infant died in either group (KH Marks, personal communication). No echocardiographic measurements were obtained (method unavailable at the time). There was no significant difference in blood $\mathrm{paO} 2, \mathrm{pCO} 2, \mathrm{pH}$ between the two groups before and within the six hours that followed furosemide administration. Nevertheless, change scores cannot be calculated because baseline values are provided for 27 samples (not patients) in the furosemide group and 22 samples in the control group, whereas values after treatment are provided for seven and five patients, respectively. Urine output, calciuria and natriuresis increased more in the furosemide group than in the control group.

\section{Savage 1975:}

Patients were randomly allocated to receive either three doses of $1.5 \mathrm{mg} / \mathrm{kg}$ of furosemide (one each at two, six and 12 hours of age) or no treatment. Seven patients were randomized to the furosemide group and 13 to the control group; parameters were followed during the first 24 hours of life. Patients in the furosemide group had more severe RDS than those in the control group. Positive pressure was required in five of seven infants in the furosemide group (two on mechanical ventilation and three on CPAP) and three of 13 patients in the control group (all on mechanical ventilation) ( $p=0.062)$. Five of seven patients in the furosemide group required $\mathrm{Na}$ bicarbonate to correct metabolic acidosis, compared with none of 13 in the control group $(p<$ 0.001 ). No patient developed renal failure (A. Wilkinson, personal communication).

Four patients died in the furosemide group and two in the control group. No information is provided on changes or duration of mechanical ventilation and oxygen supplementation. At six hours of life, arterial pO2 in $100 \% 02$ was $143 \pm 66 \mathrm{~mm} \mathrm{Hg}(\mathrm{n}=7)$ in the furosemide group compared with $215 \pm 55 \mathrm{~mm} \mathrm{Hg}(n=11)$ in the control group (NS). Serial data on $\mathrm{pO} 2$ and pCO2 show no significant changes within 60 minutes after furosemide administration (by paired Student t-test); corresponding values are not provided in the control group. Because of baseline differences between the two groups and other limitations of this study (see Discussion), a sensitivity analysis, comparing the results of meta-analysis with and without including Savage's study was done.

\section{Yeh 1984:}

Patients were randomly allocated to receive either three i.v. doses of $1 \mathrm{mg} / \mathrm{kg}$ of furosemide at 24-hour intervals, or no diuretic. of 60 randomized patients, four were excluded from the analysis (see Methodological quality). Final analysis included 29 patients in the furosemide group and 25 in the control group. Average postnatal age at study entry was seven hours. All parameters were followed for 72 hours after study entry, except for PDA which was assessed daily until discharge. Changes in $\mathrm{FiO} 2, \mathrm{AaDO} 2$ and mean airway pressure from study entry until the end of the randomized treatment were assessed using Follmann's formula. 
Five of 29 patients in the furosemide group died (six of the original 30 ), compared with four of 27 in the control group (seven of the original 30). Extubation was unsuccessful in 16 of 29 patients in the furosemide group and 23 of 25 patients in the control group. By the end of the study, patients in the furosemide group had lower mean airway pressure than those in controls but similar FiO2 and alveolar-arterial gradient. One-year neurodevelopmental outcome was available in 26 of 30 survivors with a birthweight of 1250 grams or less. The incidence of significant handicap (defined as a major neurologic abnormality or a MDI/PDI < 50) at one year of age was $2 / 14$ in the furosemide group and $4 / 12$ in the control group.

\section{Risk of bias in included studies}

Belik 1987:

Blinding was not documented (neither for randomization, nor for intervention, nor for outcome). The authors used blocks of two (one patient in one group, the other patient in the other group) and did not use a placebo in the control group. Two infants were excluded from the analysis based on pre-determined criteria (sepsis), and a third infant in the furosemide group was eliminated from the study because of death from massive intraventricular hemorrhage at 24 hours of life. This patient was included in our analysis of the risk of death. Although no washout period was documented, it is unlikely that any received diuretics before enrollment because patients appear to all have been entered before eight hours of life.

\section{Cattarelli 2006:}

Blinding was documented for randomization, intervention and outcome. Randomization was done by computer generated numbers. Complete follow-up: yes. Theophylline or placebo was prepared by a doctor from the neonatology section, not involved in patient care, using syringes with identical appearance. The medical and nursing staff were blinded to the patient assignment.

\section{Green 1983:}

Blinding was documented for randomization, intervention and outcome. Complete follow-up: no. Of 101 enrolled patients, two were dropped from the study, and most information is only available in the 66 patients who effectively received diuretics (33 furosemide and 33 chlorothiazide). Thus, analysis could only be performed on effective treatment basis, not on intention-to-treat basis. Nevertheless, the percentage of patients receiving diuretics was the same in both groups, thereby possibly limiting bias. The main outcome selected by the authors was the analysis of shortterm clinical PDA. Data show that several patients developed a clinical PDA later in the course. Only patients who never received diuretics previously were eligible to the study.

\section{Green 1988:}

This study is free of any of the four types of bias analyzed. Blinding was documented for randomization, intervention and outcome. Furosemide and placebo were dispensed in numbered vials. All patients had complete follow-up. No patient had received diuretics before entering into the study.

\section{Marks 1978}

Blinding was documented for randomization, intervention and outcome. Drug and placebo were drawn up in the pharmacy and administered without the knowledge of the investigators. All patients were followed.

No patient received diuretics before entering the study (KH Marks, personal communication).
Savage 1975:

Blinding of randomization and outcome is not documented. There was no blinding of intervention: control patients did not receive a placebo.

No patient received diuretic before entering the study (A. Wilkinson, personal communication).

Yeh 1984:

Randomization was blind (envelopes). It is unclear whether intervention was blind: the authors do not mention whether control patients received a placebo. Four patients were excluded from the study before analysis. Of these four patients, two in the control group died within 24 hours after birth with IVH and seizures; removing these two patients from the analysis would bias the results. Blinding of outcome is not documented. Although a washout period was not documented patients were entered at seven hours of life; therefore it is unlikely that anyone received diuretics before enrollment.

\section{Effects of interventions}

For many outcomes, only one or two studies provided data that could be merged into a meta-analysis, so that only a small number of patients was included in each analysis. Therefore, it is possible that real differences due to furosemide administration could have been missed. For each analysis, the studies and the number of patients in which the particular outcome was noted.

\section{ROUTINE ADMINISTRATION OF A DIURETIC IN THE TREATMENT GROUP VERSUS EITHER PLACEBO, NO TREATMENT OR PRN ADMINISTRATION IN THE CONTROL GROUP (Comparison 01)}

This comparison included six studies (Belik 1987; Cattarelli 2006; Green 1988; Marks 1978; Savage 1975; Yeh 1984)

\section{Mortality (Outcome 1.1)}

Combined analysis of mortality data in six studies showed that 16 of 124 patients died in the diuretic group compared with 13 of 124 in the control group. No individual study showed a significant effect of diuretic therapy on mortality rate. Summary statistics showed no significant effect of diuretic therapy on mortality, but a trends towards increased mortality, with a RR of $1.35(95 \% \mathrm{Cl}$ 0.71 to 2.56$)$ and a RD of $0.04(95 \% \mathrm{Cl}-0.04$ to +0.12$)$. There was no significant heterogeneity among the studies. Because of the limitations of Savage's study (see discussion), a sensitivity analysis was done by repeating the meta-analysis after removing that study, yielding 12 deaths among 117 patients in the treatment group and 11 among 111 in the control group. This sensitivity analysis showed no significant effect of diuretic therapy on mortality, as shown by a RR of $1.07(95 \% \mathrm{Cl} 0.51$ to 2.24$)$ and a RD of $0.01(95 \% \mathrm{Cl}-0.07$ to +0.09 ).

Predetermined subgroup analyses were available for the following groups: starting during the first 24 hours, starting after at least 24 hours, loop diuretics and theophylline. The summary statistics for studies starting before 24 hours showed a non significant trend towards increased mortality (RR $1.47,95 \% \mathrm{Cl} 0.72$ to 2.97 ), whereas the summary statistics of studies starting at or after 24 hours showed no effect on mortality (RR $0.97,95 \% \mathrm{Cl} 0.21$ to 4.48 ). The subgroup of studies using furosemide did not significantly affect but tended to increase mortality, as shown by a RR of 1.30 $(95 \% \mathrm{Cl} 0.67$ to 2.52$)$ and a $\mathrm{RD}$ of $0.04(95 \% \mathrm{Cl}-0.06$ to +0.13$)$. The 
sensitivity analysis done after removing Savage's study, yielding 10 deaths among 92 patients in the treatment group and 10 among 86 in the control group, revealed that furosemide did not affect mortality, as shown by a RR of $0.98(95 \% \mathrm{Cl} 0.45$ to 2.14$)$ and a $\mathrm{RD}$ of $0.00(\mathrm{Cl}-0.10$ to +0.09$)$. In the single study conducted in the 21st century, theophylline did not significantly affect mortality (two deaths among 25 in the treated group versus one among 25 in the control), with a RR of $2.00(95 \% \mathrm{Cl} 0.19$ to 20.67$)$. However, the sample size is too small to rule out the possibility that early administration of theophylline might affect mortality.

\section{Cardiovascular system (Outcomes 1.2 to 1.6 )}

\section{Clinically significant PDA (Outcome 1.2)}

Data on clinically significant PDA were available in four studies (Yeh, Belik, Green 1988, Catarrelli). Summay statistics showed no significant effect of diuretic therapy on the risk of PDA (30 of 106 in the treatment group versus 26 of 102 in the control group), with RR of $1.11(95 \% \mathrm{Cl} 0.72$ to 1.71$)$ and RD $0.03(95 \% \mathrm{Cl}-0.09$ to +0.15$)$. Subgroup analyses were conducted on studies with randomization during the first 24 hours, those starting after at least 24 hours, those using loop diuretics and those using theophylline. None of those analyses showed any significant effect of routine diuretic administration on PDA. However, the single study using furosemide administration after 24 hours (Green 1988) showed a trend towards an increase in PDA (RR $1.70,95 \% \mathrm{Cl} 0.82$ to 3.53 ).

\section{Hemodynamic instability (Outcomes 1.3 to 1.8 )}

Data on hypovolemic shock, cardiovascular instability, dopamine requirement, dobutamine requirement and colloid requirement were each available in only one study (Marks 1978 and Green 1988) and are reported in the section on description of studies. Data from Marks study suggest that furosemide did not significantly affect the risk for hypovolemic shock (RR 4.0, $95 \% \mathrm{Cl} 0.2$ to 82.0; RD 0.2, $95 \% \mathrm{Cl}-0.3$ to +0.7$)$. Data from Green's study $(n=69)$ showed that furosemide significantly reduced the change in plasma volume during treatment in comparison with control ( $M D-7.7 \mathrm{ml} / \mathrm{kg}$, $95 \% \mathrm{Cl}-11.5$ to -3.7 ) but did not affect the change in rate of colloid infusion during treatment (MD $-0.9 \mathrm{ml} / \mathrm{kg} /$ hour, $95 \% \mathrm{Cl}-4.3$ to +2.6 ). Furosemide increased the cardiovascular stability index change $(\mathrm{MD}+0.8,95 \% \mathrm{Cl}-0.1$ to +1.7$)$ and the rate of dobutamine infusion during the treatment (WMD +3.1 micrograms $/ \mathrm{kg} / \mathrm{min}, 95 \% \mathrm{Cl}-0.6$ to +6.8 ), and tended to increase the change in dopamine infusion (MD $+2.4,95 \% \mathrm{Cl}-0.1$ to +4.9 ).

\section{Respiratory system (Outcomes 1.9 to 1.16 )}

\section{Mechanical ventilation (Outcomes 1.9 - 1.12)}

In Yeh's study, routine furosemide administration decreased the risk of failure to extubate (RR $0.65,95 \% \mathrm{Cl} 0.45$ to 0.93 and RD $-0.3,95 \% \mathrm{Cl}-0.5$ to -0.1$)$. In Belik's study, routine furosemide administration tended to reduce peak inspiratory pressure during therapy (WMD $-6.6 \mathrm{~cm} \mathrm{H} 2 \mathrm{O}, 95 \% \mathrm{Cl}-14.7$ to +1.5 ). Similarly, combined analysis of Green's and Yeh's study showed that furosemide tended to decrease mean airway pressure during treatment (weighted mean difference $(-1.2 \mathrm{~cm} \mathrm{H} 2 \mathrm{O}, 95 \% \mathrm{Cl}-2.4$ to +0.1 ). Sensitivity analysis using a correlation coefficient of 0.5 or 0.3 in Follmann's formula did not change the results.

Duration of mechanical ventilation was analyzed in two studies (Belik and Green). Combined analysis showed that furosemide significantly decreased the duration of mechanical ventilation $(-2.8$ days, $95 \% \mathrm{Cl}-4.5$ to -1.2$)$. However, test for heterogeneity was significant: furosemide significantly shortened the duration in Belik's study and did not significantly affect it in Green's study. It is unclear whether heterogeneity of response resulted from (1) the time of initiation of routine furosemide in the treatment group (13 hours in Belik's study versus 24 to 30 hours in Green's study) or (2) the amount of diuretic administration in the control group (none in Belik's study versus PRN in Green's study).

Oxygenation and oxygen requirement (Outcome 1.13 and 1.14) Combined analysis of the data on FiO2 from Belik's and Yeh's study showed that furosemide did not significantly affect the change in FiO2 during therapy (WMD $-0.05,95 \% \mathrm{Cl}-0.13$ to +0.04 ).

Data on AaDO2 were available in three studies (Balik, Yeh and Green). Overall, furosemide did not significantly affect AaDO2 (WMD $-1.6 \mathrm{~mm} \mathrm{Hg}, 95 \% \mathrm{Cl}-43.8$ to +40.5$)$. The results were heterogeneous: in Green's study (furosemide initiated at $24-30$ hours in the treatment group and given PRN in the control group), furosemide tended to worsen AaDO2; in contrast, in studies involving routine administration of furosemide before 24 hours and no diuretics in the control group (Belik and Yeh), furosemide significantly improved AaDO2 (WMD - $66.8 \mathrm{~mm} \mathrm{Hg}, 95 \% \mathrm{Cl}-131.2$ to -2.4) using a correlation coefficient of 0.4 in Follmann's formula. Nevertheless, sensitivity analysis using a correlation of 0.3 showed no significant effect of furosemide (WMD $-67 \mathrm{~mm} \mathrm{Hg}, 95 \% \mathrm{Cl}-136$ to +2).

\section{BPD (Outcome 1.15)}

Data on BPD were provided in three studies (Yeh, Belik, Cattarelli). No study showed a significant of diuretic on the risk of BPD. Summary statistics showed no significant effect of routine diuretic administration on the risk of BPD (12 of 71 in the treatment group versus 14 of 68 in the control group, RR $0.81,95 \% \mathrm{Cl} 0.41$ to 1.59 , $\mathrm{RD}-0.04,95 \% \mathrm{Cl}-0.16$ to +0.08$)$. Subgroup analyses were available for administration before 24 hours (all three studies), loop diuretics and theophylline. Furosemide did not significantly affect the risk of BPD (11 of 48 patients in the furosemide group, compared with 10 of 44 in the control group), yielding a RR of $1.02,95 \% \mathrm{Cl} 0.49$ to 2.10 and a RD of $0.00,95 \% \mathrm{Cl}-0.16$ to +0.17 . In contrast, routine theophylline administration resulted in a non significant trend towards a decrease in BPD, yielding a RR of $0.29,95 \% \mathrm{Cl} 0.04$ to 2.44 and $\mathrm{RD}-0.10,95 \% \mathrm{Cl}-0.26$ to +0.05 .

\section{Death or BPD (Outcome 1.16)}

Data on death or BPD are available in two studies (Belik, Cattarelli). The time of death was not reported in Yeh's study. Summary statistics showed no significant effect of diuretics on the risk of death or BPD ( 6 of 45 in the treatment group versus 6 of 42 in the control group, RR $0.95,95 \% \mathrm{Cl} 0.32$ to $2.76, \mathrm{RD}-0.01,95 \% \mathrm{Cl}-0.15$ to +0.13 ). Furosemide tended to increase the risk of death or BPD, as shown by a RR of $2.55,95 \% \mathrm{Cl} 0.29$ to 22.31 and a RD of $0.09,95 \% \mathrm{Cl}$ -0.10 to +0.28 . In contrast, in the single study using theophylline, diuretic administration tended to decrease the risk of BPD, RR 0.60 , $95 \% \mathrm{Cl} 0.16$ to 2.25 .

\section{Duration of oxygen supplementation (Outcome 1.17)}

Duration of oxygen supplementation was analyzed in three studies (Belik, Yeh, Green). Combined analysis ( $n=92$ patients) showed that furosemide did not affect the duration of oxygen supplementation (WMD -0.5 days, $95 \% \mathrm{Cl}-2.5$ to +1.5 ).

\section{Neurology}

Intraventricular hemorrhage (IVH) (Outcomes 1.18 and 1.19)

Data on IVH were available in three studies ( Savage, Yeh and Cattarelli). Two studies showed a trend towards a decreased risk of 
IVH and one study towards an increased risk. of IVH. IVH developed in 12 of 60 patients in the diuretic group versus 17 of 67 in the control group, yielding a RR of $0.76,95 \% \mathrm{Cl} 0.40$ to 1.44 and RD -0.06 , $95 \% \mathrm{Cl}-0.21$ to +0.08 .

Sensitivity analysis done after removing Savage's study from the analysis yielded a relative risk of $0.63(95 \% \mathrm{Cl} 0.32$ to 1.26$)$ and a risk difference of $-0.11(95 \% \mathrm{Cl}-0.27$ to +0.05$)$, suggesting a trend towards reduced risk for IVH.

Subgroup analysis of the studies using furosemide showed that IVH developed in 9 of 37 patients in the furosemide group and in 11 of 43 in the control group, yielding a relative risk of $0.90(95 \% \mathrm{Cl}$ 0.43 to 1.88$)$ and a risk difference of $-0.03(95 \% \mathrm{Cl}-0.22$ to +0.17$)$. Sensitivity analysis done after removing Savage's study from the analysis yielded a relative risk of $0.70(95 \% \mathrm{Cl} 0.31$ to 1.59$)$ and a risk difference of $-0.10(95 \% \mathrm{Cl}-0.33$ to +0.13$)$.

In Cattarelli' s study, theophylline administration tended to reduce the risk of IVH (RR $0.52,95 \% \mathrm{Cl} 0.15$ to $1.84, \mathrm{RD}-0.12,95 \% \mathrm{Cl}-0.34$ to +0.10 ) but dit not affect the risk of severe IVH (one of 23 in the treatment group versus one of 24 in the control group, RR 1.04 $95 \% \mathrm{Cl} 0.07$ to 15.72 , RD $0.00,95 \% \mathrm{Cl}-0.11$ to +0.12 ).

\section{Duration of hospitalization (Outcome 1.20)}

This variable was analyzed two studies (Yeh and Catterelli). In Yeh's routine furosemide administration tended to prolong hospitalization (MD +6.6 days, $95 \% \mathrm{Cl}-16.4$ to +29.6 ), whereas in Catarelli' s study, theophylline did not affect the duration of hospitalization (MD 0.40 days, $95 \% \mathrm{Cl}-15.62$ to +16.42 ). Summary statistics showed no significant effect of diuretic administration on duration of hospitalization ( $\mathrm{n}=103$, WMD 2.43 days, $95 \% \mathrm{Cl}-10.71$ to +15.57 )

\section{Neurodevelopmental outcome (Outcome 1.21)}

The only data available were published as an abstract (Yeh 1984) which describes one-year outcome in infants with birthweight of 1250 grams or less. Furosemide did not significantly affect the risk for significant handicap at one year of age (RR $0.43,95 \% \mathrm{Cl} 0.09$ to 1.94 and $\mathrm{RD}-0.19,95 \% \mathrm{Cl}-0.51$ to +0.13$)$.

\section{Renal and electrolytes issues (Outcomes 1.22 to 1.24)}

\section{Oligoanuria (urine output $<1 \mathrm{ml} / \mathbf{k g} /$ hour) (Outcome 1.22)}

This variable was analyzed in one study (Cattarelli 2006). One among 24 patients in the theophylline group versus four among 23 in the control group developed oligoanuria, yielding a RR of 0.13 , $95 \% \mathrm{Cl} 0.02$ to 0.96 and a RD of $-0.29,95 \% \mathrm{Cl}-0.50$ to -0.08 .

\section{Hyponatremia (sodium $<130 \mathrm{mM} / \mathrm{L}$ ) (Outcome 1.23)}

This variable was analyzed in one study (Cattarelli 2006). Two infants in each group developed hyponatremia, yielding a RR of $1.04,95 \% \mathrm{Cl} 0.16$ to 6.80 , and a RD of $0.00,95 \% \mathrm{Cl}-0.16$ to +0.16 .

\section{Hyperkalemia (potassium > $6.5 \mathrm{mM} / \mathrm{L}$ ) (Outcome 1.24)}

This variable was analyzed in one study (Cattarelli 2006). Three infants among 24 infants in the theophylline group versus two among 23 in the control group developed hyperkalemia, yielding a RR of $1.57,95 \% \mathrm{Cl} 0.29$ to 8.53 and a RD of $0.05,95 \% \mathrm{Cl}-0.13$ to +0.22 .

ROUTINE ADMINISTRATION OF A DIURETIC IN THE TREATMENT GROUP VERSUS EITHER PLACEBO OR NO TREATMENT IN THE CONTROL GROUP (COMPARISON 2)

This comparison included five studies (Belik 1987; Cattarelli 2006; Marks 1978; Savage 1975; Yeh 1984). We present in this section only data that differ from section one, i.e., after eliminating data from Green 1988's study.

\section{Mortality (Outcome 2.1)}

Among the five studies reporting data on mortality, none showed a significant effect of routine diuretic administration. Summary statistics showed no significant effect, but a trend towards an increased risk, with a RR of $1.47,95 \% \mathrm{Cl} 0.72$ to 2.97 ; RD $0.05,95 \% \mathrm{Cl}$ -0.04 to +0.15$)$.

Subgroup analyses were available for studies starting before 24 hours of age, studies on loop diuretics and studies on theophylline. For loop diuretics, summary statistics showed a tend towards increase mortality, with a RR of $1.41(95 \% \mathrm{Cl} 0.67$ to 2.95$)$ and a RD of $0.06(95 \% \mathrm{Cl}-0.07$ to +0.19$)$. Sensitivity analysis done after removing Savage's study showed no effect of furosemide on mortality ( 7 deaths among 57 patients in the treatment group versus 7 among 52 in the control group), as shown by a RR of $0.98(95 \% \mathrm{Cl} 0.39$ to $2.44)$ and a RD of $-0.00(95 \% \mathrm{Cl}-0.13$ to +0.19$)$.

\section{CARDIOVASCULAR SYSTEM}

\section{Clinically significant PDA (Outcome 2.2)}

Data on clinically significant PDA were available in Belik's and Yeh's study. A significant PDA developed in 10 of 48 patients in the furosemide group and 13 of 44 in the control group, yielding a RR of $0.72(95 \% \mathrm{Cl} 0.38$ to 1.38$)$ and a RD of $-0.08(95 \% \mathrm{Cl}-0.25$ to +0.08$)$.

\section{Mechanical ventilation}

Change in mean airway pressure (Outcome 2.6)

Data from Yeh's study showed that furosemide tended to reduce mean airway pressure (MD $-1.3 \mathrm{~cm} \mathrm{H} 2 \mathrm{O}(95 \% \mathrm{Cl}-2.8$ to +0.2$)$.

\section{Oxygen requirement (Outcomes 2.08 and 2.12)}

Data on $\mathrm{AaDO} 2$ are discussed in the subgroup analysis of the previous section. Duration of oxygen supplementation was analyzed in two studies (Belik and Yeh). Furosemide did not affect the duration of oxygen supplementation (WMD - 0.2 days, $95 \% \mathrm{Cl}-2.4$ to +2.0$)$.

\section{ADMINISTRATION OF ONE DIURETIC IN THE TREATMENT GROUP VERSUS ANOTHER DIURETIC IN THE CONTROL GROUP (COMPARISON 3)}

Only one study was entered into this comparison (Green 1983).

\section{Mortality (Outcome 3.1)}

Furosemide tended to decrease mortality compared with hydrochlorothiazide, as shown by a RR of $0.62(95 \% \mathrm{Cl} 0.29$ to 1.29$)$ and a risk difference of $-0.15(95 \% \mathrm{Cl}-0.37$ to +0.07$)$.

\section{Clinical diagnosis of PDA (Outcomes 3.2 and 3.3)}

Furosemide significantly increased the risk for clinically significant PDA during the study as defined by the authors, as shown by a RR of $2.25(95 \% \mathrm{Cl} 1.14$ to 4.44$)$ and a RD of $0.30(95 \% \mathrm{Cl} 0.08$ to 0.53$)$. It also increased the risk for significant PDA during the hospitalization, as shown by a RR of $3.00(95 \% \mathrm{Cl} 1.58$ to 5.68$)$ and a RD of $0.485(95 \% \mathrm{Cl}$ 0.27 to +0.70$)$.

Duration of mechanical ventilation (Outcome 3.7)

Furosemide did not affect the duration of mechanical ventilation (MD 3.2 days, $95 \% \mathrm{Cl}-1.3$ to +7.7 ).

Clinical outcomes (Outcomes 3.4 to 3.6 ) 
Among survivors, furosemide tended to reduce the risk for BPD, with a RR of $0.80(95 \% \mathrm{Cl} 0.18$ to 3.54$)$ and a RD of $-0.03(95 \% \mathrm{Cl}-0.23$ to +0.17 ).

Furosemide tended to reduce the risk for death or BPD, with a RR of $0.69(95 \% \mathrm{Cl} 0.38$ to 1.25$)$ and a RD of $-0.15(95 \% \mathrm{Cl}-0.39$ to +0.08$)$.

Furosemide tended to increase the risk for IVH, with a RR of 1.18 $(95 \% \mathrm{Cl} 0.62$ to 2.25$)$ and a RD of $0.06(95 \% \mathrm{Cl}-0.17$ to +0.29$)$.

\section{Duration of hospitalization (Outcomes 3.8)}

Furosemide tended to shorten the duration of hospitalization (MD -8.0 days, $95 \% \mathrm{Cl}-33.3$ to +17.3$)$.

\section{DISCUSSION}

1. Limitations of the studies available for this review:

All available studies for this review are small sample size, single center studies. Because of this small sample size, one cannot rule out the possibility that some changes could occur with diuretic administration but were missed.

For instance, one cannot exclude that diuretic administration, whether using furosemide or theophylline, could increase the risk of mortality.

Most studies available for this review were done between 1975 and 1988. Since then, major changes have occurred in obstetrical management of prematurity and in neonatal intensive care. The only study done in the 21st century is Cattarelli 2006, which used theophylline.

No analyzable data are available about oxygen requirement at 36 weeks of postmenstrual age, and number of rehospitalizations during the first year of life. Some studies (e.g., Marks, Savage) provide only minimal amount of analyzable data.

Marks' study is limited by baseline differences between the two groups: patients in the furosemide group had a lower gestational age and lower FiO2 than controls (see table of included studies). This study suggests that administering a single dose of furosemide on the second day of life, compared with placebo, has no effects on echocardiographic signs of PDA and on blood gas analyses. Nevertheless, the sample size is insufficient to assess the riskbenefit ratio of furosemide.

Savage's study is limited by two factors:

(1) differences in baseline characteristics between the two groups, including the following: severity of lung disease and need for sodium bicarbonate (See results)

(2) possibility of less than optimal treatment conditions, suggested by lack of mechanical ventilation in two of six patients who died (both patients in the furosemide group)

Therefore, a sensitivity analysis for death was performed - the only available parameter for Savage's study - by excluding this study from the meta-analysis. In addition, this study used very high doses of furosemide over a short period, $4.5 \mathrm{mg} / \mathrm{kg}$ in 10 hours, which potentially could have led to a risk of hearing loss.

In the first study by Green (Green 1983) analysis on an intention-totreat basis was not possible, because the authors do not provide the number of patients initially randomized to each group.

In the second study by Green (Green 1988) the rate of colloid infusion at 18 to 24 hours of life, i.e. at or before the time of entry into the study, tended to be higher in the furosemide group than in the control group. This suggests that the former group may have more hypovolemia than control group even before initiating furosemide.

\section{Summary}

Comparison of routine diuretic with placebo, PRN diuretic or no treatment showed the following:

(1) no significant change, but a trend towards increased mortality;

(2) no significant change in risk of PDA;

(3) a trend towards an increased risk of hypovolemic shock, hemodynamic instability, and less plasma volume increase during treatment;

(4) a significant decrease in risk of failure to extubate within the end of treatment and a trend toward a decrease in peak pressure and mean airway pressure;

(5) a significant decrease in duration of mechanical ventilation, which was only observed in studies in which routine furosemide was initiated before 24 hours of life and in which control patients did not receive PRN furosemide;

(6) no overall change in $\mathrm{FiO} 2$ or $\mathrm{AaDO} 2$. However, furosemide significantly improved the AaDO2 gradient in studies in which routine furosemide was initialed before 24 hours of life and in which control patients did not receive PRN furosemide;

(7) no change in the risk of BPD or in the duration of oxygen supplementation, but a trend toward an increase in the risk of death or BPD;

(8) no change in the risk of severe IVH, with a trend towards a decreased risk for IVH (any grade);

(9) no change in duration of hospitalization;

(10) no change in the risk of significant handicap at one year of age in the smallest infants.

In addition to the above, comparison of routine diuretic administration with placebo or no treatment showed the following: (1) no significant change, but a trend towards increased mortality;

(2) no effect on the risk of PDA;

(3) no significant effect on mean airway pressure at the end of treatment;

(4) an improvement in $\mathrm{AaDO} 2$ by the end of treatment;

(5) no change in duration of oxygen requirement.

A single study comparing PRN furosemide (first dose at an average of 2.8 to 2.9 days of life) with PRN chlorothiazide showed the following:

(1) a trend toward a decrease in the risk of death and the risk for combined mortality-BPD;

(2) no change in risk of BPD and risk of IVH;

(3) a significant increase in the risk for clinically significant PDA;

(4) a significant increase in weight loss, urine output and in urine excretion of prostaglandin E2.

These data are consistent with a prostaglandin E2-induced increased incidence in PDA.

\section{Interpretation and limitations of this review:}

3.1. Limitations:

This review was done according to the recommendations of the Cochrane Collaboration, using sensitivity analysis as necessary. The method used for data analysis used two assumptions that could not be verified because there was no access to the original data. First, it was assumed that data had a parametric distribution; this may not be correct for duration of hospitalization, duration of mechanical ventilation; for these variables, the standard deviation was often larger than half the mean value, suggesting that data may be skewed to the right. Second, it was assumed that the pretest- 
posttest correlation of 0.4 (0.3 to 0.5 ) for assessing changes in $\mathrm{FiO} 2, \mathrm{AaDO} 2$, mean airway pressure, and peak inspiratory pressure. This may have yielded underestimation of differences. Indeed, in Green 1988 study, the mean difference did not reach significance for weight loss and for cardiovascular stability index, whereas the authors had found a significant difference by Student t-test or by repeated measures analysis of variance. Thus, this approach may have yielded conservative results, i.e., differences among treated and control groups may be underestimated..

The total number of patients is small. This is even more critical for many of the outcome variables (e.g., long-term development), which were not obtained in all studies.

Heterogeneity in design, timing of the study and medication administered needs to be taken into consideration. Some effects of diuretics are similar (increased urine output), whereas many effects are not (Guignard 2005). This is further addressed in the next section.

\subsection{Interpretation:}

Analysis of the studies available for this review shows that the administration of diuretics to patients with RDS did not significantly change mortality, BPD, IVH or long-term outcome. Because of small sample size one cannot rule out the possibility that diuretic administration might increase the risk of mortality by $35 \%$.

The only benefits of furosemide, i.e., transiently improved oxygenation and failure to extubate within three days, did not outweigh the risk for serious cardiovascular side-effects, i.e., hypovolemia requiring increased doses of vasopressor therapy and hemodynamically significant PDA. Nevertheless, the effects of furosemide on plasma volume in patients with RDS (Green 1988) contrast with lack of such an effect in patients with CLD (O'Donovan 1989; Segar 1997). The effects on plasma volume observed in the Green study may have been in part due to difference in hemodynamic instability at the time of study entry, as shown by a trend towards a greater need for colloid administration in the furosemide group than in the control group. Benefits were observed only in studies starting before 24 hours of life, i.e., before the expected diuretic phase, whereas cardiovascular side effects were observed in studies starting after 24 hours. Nevertheless, the relationship between timing of furosemide administration and its effects may not have been causal; only a prospective randomized trial could have tested this hypothesis.

Routine theophylline administration resulted in a transient increase in renal function, including a decreased risk for oligoanuria, lower plasma creatinine, higher estimated glomerular filtration rate, increased urine output. Theophylline administration did not significantly affect other outcomes. Although theophylline tended to increase the risk of mortality and reduce that of BPD, neither reached statistical significance, and the study was not powered for analysis of these outcomes.

In summary, in studies available for this review, benefits of routine administration of furosemide to patients with RDS did not outweigh the risks of hypovolemia and of symptomatic PDA. Studies available for this systematic review were all done before the introduction of several factors that may have contributed to a decrease in pulmonary edema in RDS. Thus, routine administration of furosemide for treating lung edema in preterm infants with RDS before five days of life is contraindicated. Although all studies but one available for this review assessed only furosemide, the use of other diuretics would also carry the risk of hypovolemia. The single study conducted in the 21st century showed that low-dose theophylline administration in patients with RDS transiently improves renal function, but provides no evidence for improvement in long-term outcome.

Elective administration of diuretics in patients with RDS should be carefully weighed against potential side effects.

\section{AUTHORS' CONCLUSIONS}

\section{Implications for practice}

There are no data to support routine administration of furosemide in preterm infants with RDS. Elective administration of furosemide to any patient with RDS should be carefully weighed against the risk of precipitating hypovolemia or developing a symptomatic patent ductus arteriosus. There are not enough data to support routine administration of low-dose theophylline in preterm infants with RDS.

\section{Implications for research}

Additional studies are required to determine the short and longterm risk -benefit ratio of low-dose theophylline in patients with RDS.

\section{ACKNOWLEDGEMENTS}

Michael C. McQueen was a co-author of the first version of this systematic review (Soll 1992).

We wish to thank Dr. Mark and Dr. Wilkinson for providing us with additional information.

Editorial support of the Cochrane Neonatal Review Group has been funded with Federal funds from the Eunice Kennedy Shriver National Institute of Child Health and Human Development National Institutes of Health, Department of Health and Human Services, USA, under Contract No. HHSN267200603418C. 
R E F E R E N C E S

\section{References to studies included in this review}

Belik 1987 \{published data only\}

* Belik J, Spitzer AR, Clark BJ, Gewitz MH, Fox WW. Effect of early furosemide administration in neonates with respiratory distress syndrome. Pediatric Pulmonology 1987;3:219-25.

Belik J, Spitzer AR, Clark BJ, Gewitz MH, Fox WW. Furosemide therapy prior to spontaneous diuresis: Acute improvement in respiratory distress syndrome (RDS). Pediatric Research 1983; 17:304A.

\section{Cattarelli 2006 \{published data only\}}

Cattarelli D, Spandrio M, Gasparoni A, Bottino R, Offer C, Chirico G. A randomised, double blind, placebo controlled trial of the effect of theophylline in prevention of vasomotor nephropathy in very preterm neonates with respiratory distress syndrome. Archives of Disease in Childhood Fetal Neonatal Edition 2006;91:F80-4.

\section{Green 1983 \{published data only\}}

* Green TP, Thompson TR, Johnson DE, Lock JE. Diuresis and pulmonary function in premature infants with respiratory distress syndrome. Journal of Pediatrics 1983;103:618-23.

Green TP, Thompson TR, Johnson DE, Lock JE. Furosemide promotes patent ductus arteriosus in premature infants with the respiratory-distress syndrome. New England Journal of Medicine 1983;308:743-8.

\section{Green 1988 \{published data only\}}

Green TP, Johnson DE, Bass JL, Landrum BG, Ferrara TB, Thompson TR. Prophylactic furosemide in severe respiratory distress syndrome: A blinded prospective study. Pediatric Research 1986;20:430A

* Green TP, Johnson DE, Bass JL, Landrum BG, Ferrara TB, Thompson TR. Prophylactic furosemide in severe respiratory distress syndrome: Blinded prospective study. Journal of Pediatrics 1988;112:605-12.

\section{Marks 1978 \{published data only\}}

Marks KH, Berman W, Friedman Z, Whitman V, Lee C, Maisels MJ. Furosemide in hyaline membrane disease. Pediatrics 1978;62:785-8.

\section{Savage 1975 \{published data only\}}

Savage MO, Wilkinson AR, Baum JD, Roberton NRC. Furosemide in respiratory distress syndrome. Archives of Disease in Childhood 1975;50:709-13.

\section{Yeh 1984 \{published data only\}}

Yeh TF, Raval D, Henek T, Pildes RS. One year follow-up of small premature infants $<=1250$ grams after early furosemide therapy. Pediatric Research 1984;18:357A.

* Yeh TF, Shibli A, Leu ST, Raval D, Pildes RS. Early furosemide therapy in premature infants ( $<=2000 \mathrm{gm}$ ) with respiratory distress syndrome: A randomized controlled trial. Journal of Pediatrics 1984;105:603-9.

\section{References to studies excluded from this review}

Durand 1987 \{published data only\}

Durand DJ, Goodman A, Ray P, Ballard RA, Clyman RI. Theophylline treatment in the extubation of infants weighing less than 1,250 grams: a controlled trial. Pediatrics 1987;80:684-8.

Graff 1985 \{published and unpublished data\}

Graff M, Novo R, Smith C, Hiatt M, Hegyi T. The effect of furosemide on compliance in acute and chronic pulmonary failure. Pediatric Research 1985;19:405A.

Green 1981 \{published data only\}

Green TP, Thompson TR, Johnson D, Lock JE. Furosemide use in premature infants and appearance of patent ductus arteriosus. American Journal of Diseases of Children 1981;135:239-43.

\section{Greenough 1985 \{published data only\}}

Greenough A, Elias-Jones A, Pool J, Morley CJ, Davis JA. The therapeutic actions of theophylline in preterm ventilated infants. Early Human Development 1985;12:15-22.

Hegyi 1986 \{published data only\}

Hegyi T, Hiatt IM, Stile IL, Zolfaghari S. Effects of postnatal aminophylline on the course of respiratory distress syndrome in premature infants. Clinical Therapeutics 1986;8:439-49.

\section{Laubscher 1998 \{published data only\}}

Laubscher B, Greenough A, Dimitriou G. Comparative effects of theophylline and caffeine on respiratory function of prematurely born infants. Early Human Development 1998;50:185-92.

\section{Moylan 1975 \{published data only\}}

Moylan FMB, O'Connell KC, Todres ID, Shannon DC. Edema of the pulmonary interstitium in infants and children. Pediatrics 1975;55:783-7.

Tulassay 1986 \{published data only\}

Tulassay T, Seri I. Acute oliguria in preterm infants with hyaline membrane disease: interaction of dopamine and furosemide. Acta Paediatrica Scandinavica 1986;75:420-4.

Yeh 1985 \{published data only\}

Yeh TF, Raval D, John E, Pildes RS. Renal response to frusemide in preterm infants with respiratory distress syndrome during the first three postnatal days. Archives of Disease in Childhood 1985;60:621-626

\section{Zanardo 1995 \{published data only\}}

Zanardo V, Dani C, Trevisanuto D, Meneghetti S, Guglielmi A, Zacchello G, Cantarutti F. Methylxanthines increase renal calcium excretion in preterm infants. Biology of the Neonate 1995;68:169-74. 


\section{Additional references}

\section{Albert 1979}

Albert RK, Lakshminarayan S, Hildebrandt J, Kirk W, Butler J. Increased surface tension favors pulmonary edema formation in anesthesized dogs' lungs. Journal of Clinical Investigation 1979;63:1015-18.

\section{Ali 1979}

Ali J, Chernicki W, Wood LDH. Effect of furosemide in canine low-pressure pulmonary edema. Journal of Clinical Investigation 1979;64:1494-1504.

\section{Aufricht 1997}

Aufricht C, Votava F, Marx M, Frenzel K, Simbruner G. Intratracheal furosemide in infants after cardiac surgery: its effects on lung mechanics and urinary output, and its levels in plasma and tracheal aspirate. Intensive Care Medicine 1997;23:992-7.

\section{Barker 1997}

Barker PM, Gowen CW, Lawson EE, Knowles MR. Decreased sodium absorption across nasal epithelium of very premature infants with respiratory distress syndrome. Journal of Pediatrics 1997;130:373-7.

\section{Bhat 1989}

Bhat R, John E, Diaz-Blanco JE, Ortega R, Fornell L, Vidyasagar D. Surfactant therapy and spontaneous diuresis. Journal of Pediatrics 1989;114:443-7.

\section{Bhat 2006}

Bhat MA, Shah ZA, Makhdoomi MS, Mufti MH. Theophylline for renal function in term neonates with perinatal asphyxia: a randomized, placebo-controlled trial. Journal of Pediatrics 2006;149:180-4.

\section{Bidiwala 1988}

Bidiwala KS, Lorenz JM, Kleinman LI. Renal function correlates of postnatal diuresis in preterm infants. Pediatrics 1988;82:50-8.

\section{Bland 1972}

Bland RD. Cord blood total protein level as a screening aid for the idiopathic respiratory distress syndrome. New England Journal of Medicine 1972;287:9-13.

\section{Bland 1978}

Bland RD, McMillan DD, Bressack MA. Decreased pulmonary transvascular fluid filtration in awake newborn lambs after intravenous furosemide. Journal of Clinical Investigation 1978;62:601-9.

\section{Bland 1982}

Bland RD. Edema formation in the newborn lung. Clinics in Perinatology 1982;9:593-610.

\section{Bland 1982a}

Bland RD, Hansen TA, Hazinski TA, Haberken CM, Bressack MA. Studies of lung fluid balance in newborn lambs. Annal NY Acadademy of Sciences 1982;384:126-45.

\section{Bressack 1980}

Bressack MA, Bland RD. Alveolar hypoxia increases fluid filtration in unanesthetized newborn lambs. Circulation Research 1980;46:111-6.

\section{Brion 1994}

Brion LP, Satlin LM, Edelmann CM Jr. Renal disease. In: Avery GB, Fletcher MA, MacDonald MG editor(s). Neonatology: Pathophysiology and Management of the Newborn. 4. Philadelphia: JB Lippincott Co., 1994:792-886.

\section{Demling 1978}

Demling RH, Will JA. The effect of furosemide on the pulmonary transvascular fluid filtration rate. Critical Care Medicine 1978;6:317-9.

\section{DeSa 1969}

DeSa DJ. Pulmonary fluid content in infants with respiratory distress. Journal of Pathology 1969;97:469-79.

\section{Dikshit 1973}

Dikshit K, Vyden JK, Forrester JS, Chatterjee K, Prakash R, Swan HJ. Renal and extrarenal hemodynamic effects of furosemide in congestive heart failure after acute myocardial infarction. New England Journal of Medicine 1973;288:1087-90.

\section{Egan 1984}

Egan EA, Dillon WP, Zorn S. Fetal lung liquid absorption and alveolar epithelial solute permeability in surfactant deficient, breathing fetal lambs. Pediatric Research 1984;18:566-70.

\section{Follmann 1992}

Follmann D, Elliott P, Suh I, Cutler J. Variance imputation for overviews of clinical trials with continuous response. Journal of Clinical Epidemiology 1992;45:769-73.

\section{Friedman 1978}

Friedman Z, Demers LM, Marks KH, Uhrmann S, Maisels MJ. Urinary excretion of prostaglandin $\mathrm{E}$ following the administration of furosemide and indomethacin to sick lowbirth-weight infants. Journal of Pediatrics 1978;93:512-5.

\section{Gajl-Peczalska 1964}

Gajl-Peczalska K. Plasma protein composition of hyaline membrane in the newborn as studied by immunofluorescence. Archives of Disease in Childhood 1964;39:226-31.

\section{Gitlin 1956}

Gitlin D, Craig JM. The nature of the hyaline membrane in asphyxia of the newborn. Pediatrics 1956;17:64-71.

\section{Gortner 1991}

Gortner L, Bernsau U, Hellwege HH, Hieronimi G, Jorch G, Reiter HL. Does prophylactic use of surfactant change drug utilization in very premature infants during the neonatal period?. Developmental Pharmacology and Therapeutics 1991;16:1-16.

\section{Green 1982}

Green TP. The use of diuretics in infants with the respiratory distress syndrome. Seminars in Perinatology 1982;6:172-80. 


\section{Guignard 2005}

Guignard JP. Diuretics. Yaffe SJ, Aranda JV. Neonatal and Pediatric Pharmacology. Therapeutic Principles in Practice. Third Edition. Philadelphia, PA: Lippincott Williams \& Wilkins, 2005:595-611.

\section{Heaf 1982}

Heaf DP, Belik J, Spitzer AR, Gewitz MH, Fox WW. Changes in pulmonary function during the diuretic phase of respiratory distress syndrome. Journal of Pediatrics 1982;101:103-7.

\section{Huet 1995}

Huet F, Semana D, Grimaldi M, Guignard JP, Gouyon JB. Effects of theophylline on renal insufficiency in neonates with respiratory distress syndrome. Intensive Care Medicine 1995;21:511-4.

\section{Ikegami 1992}

Ikegami M, Jobe AH, Tabor BL, Rider ED, Lewis JF. Lung albumin recovery in surfactant-treated preterm ventilated lambs. American review of Respiratory Disease 1992;145:1005-8.

\section{Jackson 1990}

Jackson C, Mackenzie A, Chi E, Standaert T, Truog W, Hodson W. Mechanisms for reduced total lung capacity at birth and during hyaline membrane disease in premature newborn monkeys. American Review of Respiratory Disease 1990;142:413-9.

\section{Jacob 1980}

Jacob J, Gluck L, DiSessa T, Edwards D, Kulovich M, Kurlinski J, Merritt TA, Friedman WF. The contribution of PDA in the neonate with severe RDS. Journal of Pediatrics 1980;96:79-87.

\section{Jefferies 1984}

Jefferies AL, Coates G, O'Brodovich H. Pulmonary epithelial permeability in hyaline-membrane disease. New England Journal of Medicine 1984;311:1075-80.

\section{Jenik 2000}

Jenik AG, Ceriani Cernadas JM, Gorenstein A, Ramirez JA, Vain N, Armadans M, Ferraris JR. A randomised doubleblind, placebo-controlled trial of the effects of prophylactic theophylline on renal function in term neonates with perinatal asphyxia. Pediatrics 2000;105:E45.

\section{Langman 1981}

Langman CB, Engle WD, Baumgart S, Fox WW, Polin RA. The diuretic phase of respiratory distress syndrome and its relationship to oxygenation. Journal of Pediatrics 1981;98:462-6.

\section{Lauweryns 1968}

Lauweryns JM, Claesseus S, Boussauw L. The pulmonary lymphatics in neonatal hyaline membrane disease. Pediatrics 1968;41:917-30.

\section{Lorenz 1995}

Lorenz JM, Kleinman LI, Ahmed G, Markarian K. Phases of fluid and electrolyte homeostasis in the extremely low birth weight infant. Pediatrics 1995;96:484-9.

\section{Lundergan 1988}

Lundergan CF, Fitzpatrick TM, Rose JC, Ramwell PW, Kott PA. Effect of cyclo-oxygenase inhibition on the pulmonary vasodilatory response to furosemide. Journal of Pharmacology and Experimental Therapeutics 1988;246:102-6.

\section{Normand 1968}

Normand ICS, Reynolds EOR, Strang LB, Wigglesworth JS. Flow and protein concentration of lymph from lungs of lambs developing hyaline membrane disease. Archives of Disease in Childhood 1968;43:334-9.

\section{O'Brodovich 1997}

O'Brodovich HM. Respiratory distress syndrome: The importance of effective transport. Journal of Pediatrics 1997;130:342-4.

\section{O'Donovan 1989}

O'Donovan BH, Bell EF. Effects of furosemide on body water compartments in infants with bronchopulmonary dysplasia. Pediatric Research 1989;26:121-4.

\section{Randall 1992}

Randall LH, Shaddy RE, Sturtevant JE, Reid BS, Molteni RA. Cholelithiasis in infants receiving furosemide: a prospective study of the incidence and one-year follow-up. Journal of Perinatology 1992;12:107-11.

\section{Segar 1997}

Segar JL, Chemtob S, Bell EF. Changes in body water compartments with diuretic therapy in infants with chronic lung disease. Early Human Development 1997;48:99-107.

\section{Shaffer 1984}

Shaffer SG, Glenski JA, Callenbach JC, Hall FK, Sheehan MB, Thibeault DW, Hall RT. Postnatal diuresis and respiratory distress syndrome in infants receiving mechanical ventilation. American Journal of Perinatology 1984;1:203-7.

\section{Shaffer 1986}

Shaffer SG, Bradt SK, Hall RT. Postnatal changes in total body water and extracellular volume in the preterm infant with respiratory distress syndrome. Journal of Pediatrics 1986;109:509-14.

\section{Sola 1981}

Sola A, Gregory GA. Colloid osmotic pressure of normal newborns and premature infants. Critical Care Medicine 1981;9:568-72.

\section{Spitzer 1981}

Spitzer AR, Fox WW, Delivoria-Papadopoulos M. Maximum diuresis- a factor in predicting recovery from respiratory distress syndrome and the development of bronchopulmonary dysplasia. Journal of Pediatrics 1981;98:476-9.

\section{Swischuck 1996}

Swischuk LE, Shetty BP, John SD. The lungs in immature infants: how important is surfactant therapy in preventing chronic lung problems?. Pediatric Radiology 1996;26:508-11. 


\section{Tang 1997}

Tang W, Ridout D, Modi N. Influence of respiratory distress syndrome on body composition after preterm birth. Archives of Disease in Childhood. Fetal and Neonatal Edition 1997;77:F28F31.

\section{Toth-Heyn 2000}

Toth-Heyn P, Drukker A, Guignard JP. The stressed neonatal kidney: from pathophysiology to clinical management of neonatal vasomotor nephropathy. Pediatric Nephrology 2000;14:227-39.

\section{Wade-Evans 1962}

Wade-Evans T. The formation of pulmonary hyaline membranes in the newborn baby. Archives of Disease in Childhood 1962;37:470-80.

\section{Wilson 1981}

Wilson JR, Reichek N, Dunkman WB, Goldberg S. Effect of diuresis on the performance of the failing left ventricle in man. American Journal of Medicine 1981;70:234-9.

\section{CHARACTERISTICS OF STUDIES}

Characteristics of included studies [ordered by study ID]

\section{References to other published versions of this review}

\section{Brion 1999}

Brion LP, Soll RF. Diuretics for respiratory distress syndrome in preterm infants. Cochrane Database of Systematic Reviews 1999, Issue 3. [DOI: 10.1002/14651858.CD001454.pub2]

\section{Brion 2001}

Brion LP, Soll RF. Diuretics for respiratory distress syndrome in preterm infants. Cochrane Database of Systematic Reviews 2001, Issue 2. [DOI: 10.1002/14651858.CD001454.pub2]

\section{Brion 2008}

Brion LP, Soll RF. Diuretics for respiratory distress syndrome in preterm infants.. Cochrane Database of Systematic Reviews 2008, Issue 1. [DOI: 10.1002/14651858.CD001454.pub2]

* Indicates the major publication for the study

Belik 1987

Methods

Blinding of randomization: No. Thirty-nine infants were entered into the study. Within each of 3 birthweight categories ( $<1,000 \mathrm{~g}, 1,000-1,500 \mathrm{~g}$ and $>1,500 \mathrm{~g})$, patients were randomized by blocks of 2 : within each block, one patient was randomly allocated to treatment or control, and the other patient was entered into the other group. The method of randomization is not documented.

Blinding of intervention: no. Control patients did not receive a placebo.

Complete follow-up: No. Three infants were excluded from the analysis. Of 39 randomized infants, 2 infants had an exclusion criterion described in the protocol of the study, i.e., proven sepsis (one in the treatment group, one in the control group). The third infant (treatment group) died of massive intracranial hemorrhage at 24 hours of life. Thus, after removing two infants who met criteria for exclusion, the number of patients randomized to furosemide was 20 and the number of patients in the control group was 17.

Blinding of outcome: not documented

Parallel design

Washout period: not documented.

Participants

Total number of patients entered into the study: 39

Entry criteria: (1) Prematurity (2) postnatal age < 24 hours (3) RDS defined as grunting, intercostal retractions, cyanosis in room air, and reticulogranular appearance with air bronchogram on chest radiograms (4) FiO2 $>0.4$ to maintain pAO2 $>50$ torr.

Exclusion criteria: Sepsis, renal failure (serum creatinine $>1.8 \mathrm{mg} / \mathrm{dl}$ )

Data are provided on 19 infants in the furosemide group and 17 in the control group. Patients were enrolled between January and December 1982. Maternal steroid administration occurred in 3 patients in the treatment group and 1 in the control group. All patients in the treatment group and 16 in the control group required mechanical ventilation. Average gestational ages were $30.8 \pm 2.6$ weeks in the treatment group and 30.6 \pm 2.5 weeks in the control group. Average weights were $1459 \pm 462 \mathrm{~g}$ and $1468 \pm 482$ $\mathrm{g}$, respectively. The first dose of furosemide was administered at $13 \pm 4$ hours of life. Maternal steroid administration occurred in 3 experimental infants and in 1 control. There was no significant difference between the treatment and control group for the following variables: gender distribution, location of birth, incidence of cesarean section, Apgar scores at 1 and 5 minutes, and baseline urine output to intake ratio $(\mathrm{O} / \mathrm{I})$, $\mathrm{FiO} 2$, alveolar-arterial $\mathrm{O} 2$ gradient, and peak inspiratory pressure.

Average fluid intake was similar in the two groups: 88 and $85 \mathrm{ml} / \mathrm{kg} /$ day, respectively, on the first day, 106 and $101 \mathrm{ml} / \mathrm{kg} /$ day on the second day and 133 and $133 \mathrm{ml} / \mathrm{kg} /$ day on the third day. 
Belik 1987 (Continued)

All patients were followed until discharge.

Interventions $\quad$ Four doses of furosemide versus control.

Patients were randomly allocated to receive either four doses of $1 \mathrm{mg} / \mathrm{kg}$ furosemide every 12 hours intravenously (treatment group, $n=21$ ), or no diuretic (control group, $n=18$ ).

\section{Outcomes}

Major outcomes: urine output to intake ratio (O/I) per 8-hour period, ventilator requirement, duration of oxygen therapy

Other outcomes: survival, echocardiographic signs of PDA, clinically significant PDA.

One of 20 patients in the furosemide group died of massive intracranial hemorrhage at 24 hours; all the other randomized patients survived. Patients in the furosemide group had significantly higher $\mathrm{O} / \mathrm{I}$ than those in the control group between 32 and 48 hours. Diuresis (defined as $0 / 1>1$ ) occurred at 32 hours in the furosemide group and 56 hours in the control group. In the treatment group, FiO2 was transiently lower than in the control group at 32-56 hours of life, alveolar-arterial 02 gradient was lower at 40 and 48 hours, and peak inspiratory pressure was lower at 32 hours and $48-64$ hours. The average duration of 02 therapy (12 days) was not significant between the 2 groups. Two patients in the furosemide group and one in the control group required 02 for $>1$ month. The duration of mechanical ventilation was significantly shorter in the treated group than in the control group ( $171 \pm 47$ vs $290 \pm 94$ hours, respectively, $\mathrm{p}<0.05)$.

Three patients in each group developed a murmur suggestive of PDA. No patient in the treatment group and one in the control group required treatment for a decompensated PDA. Echocardiographic data were similar in the two groups.

Subgroup analysis showed higher $\mathrm{O} / \mathrm{I}$ in treatment group than in control group among infants weighing $1,000-1,500 \mathrm{~g}$ and those weighing $>1,500 \mathrm{~g}$ but not in those weighing $<1,000 \mathrm{~g}$. Among patients weighing 1,000-1500 g substantial differences were observed between treatment and control groups in FiO2, alveolar-arterial gradient and peak inspiratory pressure. Among those weighing 1,500-2,000 g only minimal differences occurred between the two groups. No differences were observed among those weighing $<1,000 \mathrm{~g}$.

Notes The authors used two-way analysis of variance followed by Scheffe post-hoc test.

\section{Risk of bias}

\begin{tabular}{lll}
\hline Bias & Authors' judgement & Support for judgement \\
\hline $\begin{array}{l}\text { Random sequence genera- } \\
\text { tion (selection bias) }\end{array}$ & Unclear risk & The method of randomization is not documented \\
\hline $\begin{array}{l}\text { Allocation concealment } \\
\text { (selection bias) }\end{array}$ & High risk & $\begin{array}{l}\text { Blinding of randomization: No. Thirty-nine infants were entered into the study. } \\
\text { Within each of } 3 \text { birthweight categories }(<1,000 \mathrm{~g}, 1,000-1,500 \mathrm{~g} \text { and }>1,500 \mathrm{~g}), \\
\text { patients were randomized by blocks of } 2: \text { within each block, one patient was } \\
\text { randomly allocated to treatment or control, and the other patient was entered } \\
\text { into the other group. }\end{array}$ \\
\hline
\end{tabular}

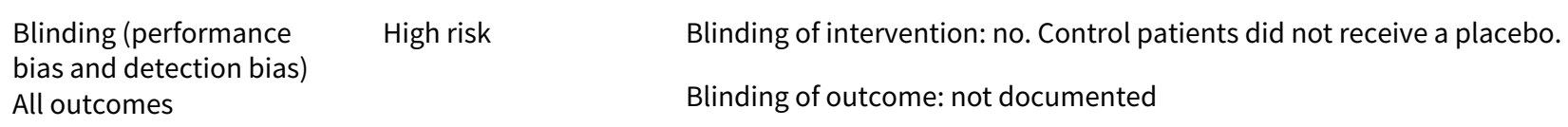

$\begin{array}{ll}\begin{array}{l}\text { Incomplete outcome data } \\ \text { (attrition bias) }\end{array} & \begin{array}{l}\text { Complear risk } \\ \text { All outcomes }\end{array} \\ & \begin{array}{l}\text { randomized infants, } 2 \text { infants had an exclusion criterion described in the pro- } \\ \text { tocol of the study, i.e., proven sepsis (one in the treatment group, one in the } \\ \text { control group). The third infant (treatment group) died of massive intracranial } \\ \text { hemorrhage at } 24 \text { hours of life. Thus, after removing two infants who met crite- } \\ \text { ria for exclusion, the number of patients randomized to furosemide was } 20 \text { and } \\ \text { the number of patients in the control group was } 17 .\end{array}\end{array}$




\section{Cattarelli 2006}

Methods Blinding of randomization: yes. Randomization was done by computer.

Blinding of intervention: yes. Theophylline or placebo was prepared by a doctor from the neonatology section, not involved in patient care, using syringes with identical appearance.

Complete follow-up: yes.

Blindness of outcome: yes.

The medical and nursing staff were blinded to the patient assignment.

Of 54 eligible patients, 50 were entered into the study and randomly allocated to placebo or to theo-
phylline.
Entry criteria: Inborn preterm neonates $<=32$ weeks gestational age, RDS within 6 hours of life, needing
mechanical ventilation or nasal continuous positive airway pressure.
Exclusion criteria: kidney and/or urinary tract congenital abnormalities, congenital heart defects, pre-
natal exposure to inhibitors of angiotensin converting enzyme or non-steroidal anti-inflammatory
drugs (NSAIDs), and chromosomal disorders or multiple malformations.
Patients assigned to placebo $(n=25)$ had an average gestational age of $28.7 \pm 1.6$ weeks and a birth-
weight of $1157 \pm 354$ g. Patients assigned to theophylline $(n=25)$ had an average gestational age of
$28.7 \pm 2.0$ weeks and an average birthweight of $1192 \pm 378 \mathrm{~g}$.

Interventions

Patients in the treatment group were allocated to receive i.v. theophylline $1 \mathrm{mg} / \mathrm{kg}$ daily; controls were allocated to receive an equal volume of placebo ( $5 \%$ dextrose in water) for three days. The first dose was given soon after it had been confirmed that inclusion criteria had been met.

Outcomes

Death, BPD, Death or BPD, PDA, IVH, severe IVH, oligoanuria (urine output $<1 \mathrm{ml}$ per kg per hour), serial measurements of urine output, serial serum creatinine values, blood urea nitrogen, hyponatremia, hyperkalemia, periventricular leukomalacia, retinopathy of prematurity, necrotizing enterocolitis, length of stay.

Notes

Several infants received other medications that could affect outcomes of interest in this review. Eight infants in the theophylline group and twelve in the control group received furosemide, 21 in each group received dopamine, nine in the theophylline group and twelve controls received dobutamine, six in the theophylline group and four controls received ibuprofen, one control received indomethacin, and eight in the theophylline group and nine controls received caffeine.

\section{Risk of bias}

\begin{tabular}{lll}
\hline Bias & Authors' judgement & Support for judgement \\
\hline $\begin{array}{l}\text { Random sequence genera- } \\
\text { tion (selection bias) }\end{array}$ & Low risk & Randomization was done by computer \\
\hline $\begin{array}{l}\text { Allocation concealment } \\
\text { (selection bias) }\end{array}$ & Low risk & Blinding of randomization: yes \\
\hline $\begin{array}{l}\text { Blinding (performance } \\
\text { bias and detection bias) } \\
\text { All outcomes }\end{array}$ & Low risk & $\begin{array}{l}\text { Blinding of intervention: yes. Theophylline or placebo was prepared by a doc- } \\
\text { tor from the neonatology section, not involved in patient care, using syringes } \\
\text { with identical appearance. }\end{array}$ \\
& $\begin{array}{l}\text { Blindness of outcome: yes. The medical and nursing staff were blinded to the } \\
\text { patient assignment. }\end{array}$
\end{tabular}

Incomplete outcome data Low risk Complete follow-up: yes
(attrition bias)
All outcomes


Green 1983 (Continued)

Blinding of intervention: yes. Diuretic solutions were prepared in the pharmacy and were only identified by patient name and number.

Complete follow-up: no. Of 128 infants with RDS, 27 were ineligible either because they were older than 72 hours or had already received a diuretics. Of 101 enrolled patients, 2 were dropped from the study, one because of coarctation of the aorta and the other because of inaudible heart sounds secondary to severe lung disease. Most information is available only in 66 of the randomized patients, i.e., those who effectively received diuretics (33 furosemide and 33 chlorothiazide). Thus, intention-to-treat analysis is not possible.

Blinding of outcome: yes

Parallel design

Washout period: adequate. Only patients who never received diuretics previously were eligible to the study.

Participants

Total number of patients entered into the study: 99

Entry criteria: Birthweight $<2,500$ g, RDS, mechanical ventilation, postnatal age $<72$ hours.

Exclusion criteria: previous diuretic treatment, known or suspected cardiac or renal disease.

Patients were entered into the study between December 1979 and June 1981, at which time 99 infants had completed the study. The exact number of patients enrolled in each group is not provided. Patients who did not receive diuretics had an average gestational age of $31.4 \pm 2.4$ weeks and a birthweight of $1668 \pm 484 \mathrm{~g}$. Their mean airway pressure, $11.8 \pm 4.3 \mathrm{~cm} \mathrm{H} 2 \mathrm{O}$, was lower than in those who received diuretics, $15.0 \pm 4.7 \mathrm{~cm} \mathrm{H} 2 \mathrm{O}(\mathrm{p}<0.001)$.

Among patients who received diuretics, average gestational ages were $30.3 \pm 2.8$ weeks in the furosemide group and $30.8 \pm 2.8$ weeks in the thiazide group. Average birthweights were $1481 \pm 471 \mathrm{~g}$ and $1532 \pm 500 \mathrm{~g}$, respectively. The mean ages at the time of administration of the first dose of diuretic were, respectively, $2.8 \pm 1.0$ and $2.9 \pm 1.4$ days. Mean airway pressure $(15 \mathrm{~cm} \mathrm{HO})$ was similar in the two groups. In patients showing no pulmonary improvement, clinical PDA was treated with diuretics and surgical ligation; indomethacin was not used. Fluid intake was restricted to $60-80 \mathrm{ml} / \mathrm{kg} /$ day in intubated patients. Patients were treated in servo-controlled isolettes.

Patients remained in the study until extubation, ductal ligation or 14 days of age, whichever came first.

Interventions

PRN furosemide vs PRN chlorothiazide.

Patients were randomly allocated to the furosemide group or the thiazide group. The numbers by group at randomization are not given by the authors. Criteria for diuretic administration were not rigidly defined in the protocol. Beginning on the second to fourth day of life, a diuretic was usually prescribed by the attending neonatologist if the patient had not initiated spontaneous diuresis (urine output $>$ fluid intake for at least 8 hours) and was not showing satisfactory pulmonary improvement. In addition, patients with clinical evidence of PDA and lack of pulmonary improvement received diuretics as indicated.

Diuretic solutions were prepared in the pharmacy in vials identified only by patient and number. Concentrations of furosemide $(1 \mathrm{mg} / \mathrm{ml})$ and chlorothiazide $(20 \mathrm{mg} / \mathrm{ml})$ were based on furosemide-tochlorothiazide equivalency. In most circumstances, the dosage administered was $1 \mathrm{ml} / \mathrm{kg} /$ dose. Twenty of 33 furosemide-treated patients received multiple doses, and 21 of 33 chlorothiazide-treated patients received multiple doses. The average total volume of diuretic solution received was $3.8 \pm 4.3 \mathrm{ml} / \mathrm{kg}$ in the furosemide group and $4.8 \pm 3.5 \mathrm{ml} / \mathrm{kg}$ in the thiazide group.

Outcomes

Major outcome variable: PDA (NEJM), survival (J Pediatr).

Other outcome variables: incidence of ductal ligation, urinary prostaglandin E excretion after diuretic administration, incidence of IVH, duration of mechanical ventilation. Among the 33 patients who did not receive diuretics, 6 died, 10 developed a PDA, and 3 developed an intraventricular hemorrhage. Other outcomes are provided only in the 66 patients who were prescribed diuretics, i.e., 33 patients in each group. Eight patients died in the furosemide group and 13 in the thiazide group.

A murmur characteristic of PDA was observed in 22 patients in the furosemide group and 13 in the control group $(p<0.05)$. During the study, 18 patients developed clinical findings of a PDA in the furosemide group and 8 in the thiazide group $(\mathrm{p}<0.05)$. Of those, 11 and 7 , respectively, underwent surgical ligation. In addition, 6 patients in the furosemide group were later found to have a PDA; thus, the total number of patients developing a PDA during the initial hospital stay was 24 in the furosemide group and 8 in the thiazide group. Weight loss (\% of body weight) was greater in furosemide-treated patients than in thiazide-treated patients on days 4 and 5 . Urinary excretion of prostaglandin E slightly and transient- 
ly increased in both groups after diuretic administration on the first day. However, furosemide but not chlorothiazide administration after day 5 doubled urinary excretion of prostaglandin E2.

Thirteen developed an IVH in the furosemide group, compared with 11 in the thiazide group. Among survivors, duration of mechanical ventilation was $10.5 \pm 10.3$ days and $7.3 \pm 4.6$ days, respectively (NS).

Notes

The study was designed as (1) a sequential analysis of PDA scores in pairs of furosemide-treated and chlorothiazide-treated patients (NEJM) and (2) multivariate analysis of factors associated with survival (J Pediatr).

Multivariate analysis showed that better survival was related to increasing birthweight, lower initial mean airway pressure, lack of IVH and furosemide usage. PDA was related to birthweight and furosemide usage. IVH was related to low birthweight but not to furosemide.

The routes of administration of furosemide and chlorothiazide are not mentioned in the manuscript.

\begin{tabular}{lll}
\hline Risk of bias & & \\
\hline Bias & Authors' judgement & Support for judgement \\
\hline $\begin{array}{l}\text { Random sequence genera- } \\
\text { tion (selection bias) }\end{array}$ & Low risk & Randomization was done by computer \\
\hline $\begin{array}{l}\text { Allocation concealment } \\
\text { (selection bias) }\end{array}$ & Low risk & Blinding of randomization: yes \\
\hline $\begin{array}{l}\text { Blinding (performance } \\
\text { bias and detection bias) } \\
\text { All outcomes }\end{array}$ & Low risk & $\begin{array}{l}\text { Blinding of intervention: yes. Diuretic solutions were prepared in the pharma- } \\
\text { cy and were only identified by patient name and number. } \\
\text { Blinding of outcome: yes }\end{array}$ \\
\hline $\begin{array}{l}\text { Incomplete outcome data } \\
\text { (attrition bias) } \\
\text { All outcomes }\end{array}$ & High risk & $\begin{array}{l}\text { Complete follow-up: no. Of 128 infants with RDS, 27 were ineligible either be- } \\
\text { cause they were older than } 72 \text { hours or had already received a diuretics. Of } 101 \\
\text { enrolled patients, } 2 \text { were dropped from the study, one because of coarctation } \\
\text { of the aorta and the other because of inaudible heart sounds secondary to se- } \\
\text { vere lung disease. Most information is available only in } 66 \text { of the randomized } \\
\text { patients, i.e., those who effectively received diuretics (33 furosemide and } 33 \\
\text { chlorothiazide). }\end{array}$
\end{tabular}

\section{Green 1988}

Methods Blinding of randomization: yes. Method of randomization is not provided.

Blinding of intervention: yes. Furosemide and placebo was dispensed in numbered vials.

Complete follow-up: yes

Blinding of outcome: yes

Parallel design

Washout period: yes. No patient had received diuretics before entering into the study.

\section{Participants}

Total number of patients entered into the study: 69

Entry criteria: birthweight $<2,500 \mathrm{~g}$, clinical diagnosis of RDS with radiographic confirmation, need for mechanical ventilation, postnatal age $<30$ hours

Exclusion criteria: previous diuretic treatment, known or suspected cardiac or renal disease Thirty-five patients were randomized to furosemide prophylaxis and thirty-four to the control group. Gestational ages were $31.5 \pm 2.3$ weeks in the treatment group and $31.3 \pm 2.3$ weeks in the control group Mean birthweights were $1.66 \pm 0.41 \mathrm{~kg}$ and $1.63 \pm 0.45 \mathrm{~kg}$, respectively. Patients in the furosemide group received the first dose of furosemide at 24 hours (maximum 30 hours for outpatients) of life. Both groups had similar Apgar scores at 1 and 5 minutes, mean airway pressure, alveolar-arterial 02 gradient and cardiovascular stability index. Nevertheless, the rate of colloid infusion at 18-24 hours of life, i.e. at or before the time of entry into the study, tended to be higher in the furosemide group than in the control group (6.3 $\pm 9.5 \mathrm{ml} / \mathrm{kg} / \mathrm{hour} v \mathrm{~s} 3.8 \pm 6.0 \mathrm{ml} / \mathrm{kg} / \mathrm{hour}$ ). Fluid intake (crystalloids) was $60-80 \mathrm{ml} /$ $\mathrm{kg} /$ day initially and maintained at $80-100 \mathrm{ml} / \mathrm{kg} /$ day during mechanical ventilation. Patients with hy- 
potension or poor peripheral perfusion received 5-10 $\mathrm{ml} / \mathrm{kg}$ colloids followed if needed by dobutamine or dopamine. Patients were treated in radiant warmers until completion of initial stabilization and procedures, and then in incubators.

Patients remained in the study until day 7 .

Interventions Prophylactic and PRN furosemide vs PRN furosemide

Patients were randomly allocated to the prophylactic furosemide group $(n=35)$ or to the control group $(n=34)$. Patients in the prophylactic furosemide group received four doses of $1 \mathrm{~m} / \mathrm{kg}$ of furosemide every 12 hours starting at 24 hours of life (maximum 30 hours for outpatients) with additional PRN doses of furosemide. Patients in the control group received similar doses of placebo ( $0.9 \%$ saline); in addition, they received PRN doses of furosemide. Indications for PRN doses included (1) edema or oliguria $(<1 \mathrm{ml} / \mathrm{kg} /$ hour for 2-3 hours) in the presence of poor or deteriorating pulmonary function or (2) congestive heart failure defined as cardiomegaly on chest radiography, with hepatosplenomegaly or peripheral edema.

However, the total dose of furosemide administered during the first 3 days of life was significantly greater in the treatment group than in the control group $(4.8 \pm 1.4 \mathrm{mg} / \mathrm{kg}$ vs $1.5 \pm 1.7 \mathrm{mg} / \mathrm{kg}, \mathrm{p}<0.001)$. The dose of furosemide prescribed afterwards was similar in the two groups.

Outcomes

Major outcome: mean airway pressure on day 7 , incidence of hemodynamic instability, requirement for inotropic therapy, hypovolemia, mortality.

Other outcomes: PRN furosemide administration, incidence of PDA, urine output, plasma volume (Evans blue distribution volume) at 48 and 96 hours, IVH.

Three patients died in each group. Eleven of 35 patients in the treatment group received additional PRN furosemide during the first 3 days of life, compared with 21 of 34 in the control group $(p<0.05)$. Mean airway pressure and alveolar-arterial pressure gradient were similar in both groups at 5 and 7 days of age.

Cardiovascular stability index worsened during the study in the furosemide group but not in the control group. Patients in the furosemide group had higher heart rate and required a higher rate of dobutamine administration than those in the control group. The incidence of PDA was as follows: In the treatment group, 14 patients had a clinically significant PDA, 8 received indomethacin and 3 underwent surgical ligation. In the control group, 8 developed a significant PDA, 5 received indomethacin and one underwent surgical ligation.

Patients in the furosemide group had higher urine output than controls. At 96 hours of life, patients in the furosemide group had a greater \% loss from birthweight than controls $(9.9 \pm 7.2 \%$ vs $6.0 \pm 7.7 \%$, respectively, $\mathrm{p}<0.05)$. In both groups, the amount of colloids effectively administered decreased from $6 \mathrm{ml} / \mathrm{kg} /$ hour at 12 hours of life to $2 \mathrm{ml} / \mathrm{kg} /$ hour at 96 hours. Patients in the furosemide group had less increase in plasma volume between 48 hours and 96 hours of life than those in the control group (7.8 \pm 12.0 vs $0.1 \pm 10.7 \mathrm{ml} / \mathrm{kg}, \mathrm{p}<0.02)$.

Median grade of IVH was 1 (range 0-4) in the treatment group and 0 (range $0-4$ ) in the control group.

Notes

The study design included sequential analysis of mean airway pressure on day 7 . The study was terminated after enrolling 50 patients, because an interim analysis showed a strong suggestion of adverse cardiovascular effects in the treatment group.

\section{Risk of bias}

Bias Authors' judgement Support for judgement

Random sequence genera- Unclear risk Method of randomization is not provided
tion (selection bias)
tion (selection bias)

\begin{tabular}{|c|c|c|}
\hline $\begin{array}{l}\text { Allocation concealment } \\
\text { (selection bias) }\end{array}$ & Low risk & Blinding of randomization: yes \\
\hline $\begin{array}{l}\text { Blinding (performance } \\
\text { bias and detection bias) } \\
\text { All outcomes }\end{array}$ & Low risk & $\begin{array}{l}\text { Blinding of intervention: yes. Furosemide and placebo was dispensed in num- } \\
\text { bered vials. Blinding of outcome: yes }\end{array}$ \\
\hline $\begin{array}{l}\text { Incomplete outcome data } \\
\text { (attrition bias) }\end{array}$ & Low risk & Complete follow-up: yes \\
\hline
\end{tabular}


Green 1988 (Continued)

All outcomes

Marks 1978

Blinding of randomization: yes. Randomization was done using a random sampling of numbers.
Blinding of intervention: yes. Drug and placebo were drawn up in the pharmacy and administered with-
out the knowledge of the investigators.
Complete follow-up: yes
Blinding of outcome: yes
Parallel design
Washout period: no patients received diuretics before entering the study.

Participants

Total number of patients entered into the study: 12

Entry criteria: RDS, postnatal age $<72$ hours, peripheral edema, $\mathrm{FiO} 2>0.4$ to maintain $\mathrm{pO} 2>50$ torr.

Exclusion criteria: not documented

Seven infants were randomized to furosemide and 5 to placebo. Mean gestational ages were $32.1 \pm 2.5$ weeks in the furosemide group and $34.8 \pm 1.2$ weeks in the control group $(p<0.05)$. Mean birthweights were significantly lower in the furosemide group, $1,707 \pm 485 \mathrm{~g}$, than in the control group, 2,286 $\pm 418 \mathrm{~g}$ $(p<0.05)$. Postnatal ages were $31 \pm 9$ hours and $36 \pm 14$ hours, respectively. Patients in the furosemide group had a lower initial FiO2 than those in the control group $(0.49 \pm 0.01$, vs. $0.61 \pm 0.02$, respectively, $\mathrm{p}<0.05)$. In each group, 4 patients received continuous positive airway pressure (CPAP) and 1 received mechanical ventilation. Blood gases were similar in the 2 groups before treatment.

The protocol specified indications to start CPAP and mechanical ventilation, and progressive increase in fluid intake from the first to the third day $(65,80$ and $100 \mathrm{ml} / \mathrm{kg} /$ day on the first, second and third day, respectively). Patients in the furosemide group received $81 \pm 9 \mathrm{ml} / \mathrm{kg} /$ day, compared with $71 \pm 12 \mathrm{ml}$ $\mathrm{kg} /$ day in the control group. Ventilatory settings and $\mathrm{FiO} 2$ were not modified during the study. The study lasted from the time of baseline observation until 6 hours after drug administration.

$\begin{array}{ll}\text { Interventions } & \text { Single dose of furosemide vs placebo } \\ & \text { Patients were randomized to receive either a single dose of } 2 \mathrm{mg} / \mathrm{kg} \text { of furosemide intravenously ( } \mathrm{n}=7 \text { ), } \\ & \text { or placebo ( } 5 \% \text { glucose in } 0.225 \% \text { sodium chloride, } n=5) .\end{array}$

Outcomes Blood gases, urine output, echographic measurement of the PDA.

There was no significant different difference in blood p02, $\mathrm{pCO} 2$ and pH between the two groups after treatment.

Echocardiographic measurements were not different between the two groups (data not provided in the manuscript).

Patients in the furosemide group but not those in the control group developed after treatment an increase in urine output, natriuresis and calciuria. One patient in the furosemide group developed acute hypovolemia (hypotension, metabolic acidosis and a rise in hematocrit), which was treated with colloid administration.

Notes

\section{Risk of bias}

\begin{tabular}{lll}
\hline Bias & Authors' judgement & Support for judgement \\
\hline $\begin{array}{l}\text { Random sequence genera- } \\
\text { tion (selection bias) }\end{array}$ & Low risk & Randomization was done using a random sampling of numbers \\
\hline $\begin{array}{l}\text { Allocation concealment } \\
\text { (selection bias) }\end{array}$ & Low risk & Blinding of randomization: yes \\
\hline $\begin{array}{l}\text { Blinding (performance } \\
\text { bias and detection bias) }\end{array}$ & Low risk & $\begin{array}{l}\text { Blinding of intervention: yes. Drug and placebo were drawn up in the pharma- } \\
\text { cy and administered without the knowledge of the investigators. }\end{array}$
\end{tabular}


Marks 1978 (Continued)
All outcomes
Blinding of outcome: yes

Incomplete outcome data Low risk
(attrition bias)

(attrition bias)

All outcomes

Savage 1975

Methods Blinding of randomization: not documented. The method of randomization is not provided.

Blinding of intervention: no. Control patients did not receive a placebo.

Complete follow-up: yes

Blinding of outcome: not documented

Parallel design

Washout period: no patient received diuretic before entering the study.

Total number of patients entered into the study: 20
Entry criteria: RDS
Exclusion criteria: not documented
Seven infants were randomized to furosemide and 13 to the control group. Mean gestational ages were
$31.7 \pm 3.4$ weeks in the furosemide group and $31.8 \pm 2.6$ weeks in the control group. Mean birthweights
were $1830 \pm 97 \mathrm{~g}$ and $1616 \pm 420 \mathrm{~g}$, respectively. The first dose of diuretics was given at 2 hours of life.
Patients in the furosemide group had more severe RDS than those in the control group. Positive pres-
sure was required in 5 of 7 infants in the furosemide group ( 2 on mechanical ventilation and 3 on CPAP)
and 3 of 13 patients in the control group (all on mechanical ventilation) $(p=0.062)$. Five of 7 patients in
the furosemide group required Na bicarbonate to correct metabolic acidosis, compared with none in
the control group ( $p<0.001)$. Fluid intake was similar in the 2 groups: 51 ml $/ \mathrm{kg} / \mathrm{day}$ (range $29-79)$ in the
furosemide group and $48 \mathrm{ml} / \mathrm{kg} /$ day (range $35-61$ ) in the control group. Average calcium intake in the
furosemide group was three times as high as in the control group.
Patients were followed during the first 24 hours of life.

Interventions Three doses of furosemide vs control

Patients were randomly assigned to either receive 3 doses of $1.5 \mathrm{mg} / \mathrm{kg}$ of furosemide intravenously, one each at 2, 6 and 12 hours of age $(n=7)$, or no treatment $(n=13)$.

Outcomes Outcome variables included blood gas analyses, mortality and fluid balance. No information is provided on mean airway pressure, duration of mechanical ventilation or $\mathrm{O} 2$ administration. Four patients died in the furosemide group, and 2 in the control group. At 6 hours of life, arterial blood pO2 in $100 \% 02$ was $163 \pm 66 \mathrm{~mm} \mathrm{Hg}(\mathrm{n}=7)$ in the furosemide group, compared with $215 \pm 55 \mathrm{~mm} \mathrm{Hg}$ $(n=11)$ in the control group (NS).

Patients in the furosemide group had significantly higher urine output, natriuresis and calciuria than those in the control group. No patient developed renal failure. The 2 patients in the furosemide group who did not receive sodium and calcium supplements had higher natriuresis and calciuria than patients in the control group. Blood pO2 and pCO2 did not change significantly in the treatment group after furosemide administration.

Notes Values of blood PO2 and PCO2 before and after treatment are provided in the furosemide group but no comparable data are provided in the control group.

\section{Risk of bias}

Bias Authors' judgement Support for judgement

Random sequence genera- Unclear risk The method of randomization is not provided

tion (selection bias) 
Savage 1975 (Continued)

Allocation concealment Unclear risk Blinding of randomization: not documented
(selection bias)

Blinding (performance

bias and detection bias)

All outcomes
High risk

Blinding of intervention: no. Control patients did not receive a placebo. Blinding of outcome: not documented

Incomplete outcome data Low risk

Complete follow-up: yes

(attrition bias)

All outcomes

Yeh 1984

Blinding of randomization: yes. Sixty envelopes were prepared and kept under the control of an inde-
pendent observer.
Blinding of intervention: unclear. Control patients were treated similarly to experimental patients but
did not receive furosemide. The authors do not mention whether control patients received a placebo.
Complete follow-up: no. Sixty patients were randomized. Four patients were excluded from the study
before analysis: 2 patients (one in each group) with group B streptococcus sepsis, and 2 patients in the
control group who died within 24 hours after birth with IVH and seizures.
Blinding of outcome: not documented
Parallel design
Washout period: not documented

Participants

Total number of patients entered into the study: 60

Entry criteria: Birthweight maximum $2000 \mathrm{~g}$, clinical and radiologic evidence of RDS, mechanical ventilation within 4 hours of age, normal blood pressure and good peripheral capillary filling.

Exclusion criteria: not defined in the protocol.

Final analysis included 29 patients randomized to furosemide and 27 randomized to the control group. Average gestational ages were $30.5 \pm 2.6$ weeks in the furosemide group and $30.7 \pm 1.9$ weeks in the control group. Birth weights were $1257 \pm 343 \mathrm{~g}$ and $1277 \pm 286 \mathrm{~g}$, respectively. Postnatal ages at study entry were $7.3 \pm 3.5$ hours and $7.0 \pm 3.5$ hours, respectively. Mean airway pressure, $\mathrm{FiO} 2$ and alveolar-arterial $\mathrm{O} 2$ gradient were similar in both groups.

Fluid intake increased daily from $80 \mathrm{ml} / \mathrm{kg}$ /day on the first day to $150 \mathrm{ml} / \mathrm{kg} /$ day on the fifth day, with an additional $20 \mathrm{ml} / \mathrm{kg} /$ day for patients on phototherapy. Fluid intake was similar in the 2 groups. Patients were treated in servocontrolled incubators.

All parameters were followed for 72 hours after study entry. In addition, patients were assessed clinically for PDA until discharge from the hospital.

Interventions

Three doses of furosemide vs control.

Patients were randomly assigned to receive either 3 doses of $1 \mathrm{mg} / \mathrm{kg}$ of furosemide intravenously at approximately 24 -hour intervals $(n=30)$, or no furosemide $(n=30)$.

Outcomes

\begin{abstract}
Major outcome: failure to extubate at 72 hours
Other outcomes: incidence of BPD (defined as respiratory distress with radiographic changes of at least stage 3 from Northway classification), incidence of clinical PDA, incidence of IVH, mean airway pressure, $\mathrm{FiO} 2$.

Five of 29 patients in the furosemide group died ( 6 of the original 30), compared with 4 of 27 in the control group ( 7 of the original 30). Sixteen of 29 patients in the furosemide group and 23 in the control group failed extubation within 72 hours after initiation of the study. Mean airway pressure at the end of the study was significantly lower in the furosemide group than in the control group, but FiO2 and alveolar-arterial gradient were similar. Clinical diagnosis of PDA was made in 10 of 29 patients in the furosemide group and 12 of 27 in the control group. BPD developed in 9 of 29 patients in the furosemide group and 9 of 27 patients in the control group. Duration of $\mathrm{O} 2$ therapy, time to regain weight and duration of hospitalization were not significantly different between the 2 groups. IVH was observed in 7 of 29 patients in the furosemide group ( 7 of the 30 initially enrolled patients) and 8 of 27 (10 of the 30 initially enrolled patients) in the control group. During the study, patients in the
\end{abstract}


Yeh 1984 (Continued)

furosemide group had higher urine output, fractional excretions of sodium and chloride but not potassium than those in the control group. At the end of the study, patients in the furosemide group had lost a higher percentage of body weight than those in the control group.

\begin{tabular}{|c|c|c|}
\hline Notes & No echographic result & are presented. Treatment for PDA is not documented. \\
\hline \multicolumn{3}{|l|}{ Risk of bias } \\
\hline Bias & Authors' judgement & Support for judgement \\
\hline $\begin{array}{l}\text { Random sequence genera- } \\
\text { tion (selection bias) }\end{array}$ & Low risk & $\begin{array}{l}\text { Sixty envelopes were prepared and kept under the control of an independent } \\
\text { observer. }\end{array}$ \\
\hline $\begin{array}{l}\text { Allocation concealment } \\
\text { (selection bias) }\end{array}$ & Low risk & Blinding of randomization: yes \\
\hline $\begin{array}{l}\text { Blinding (performance } \\
\text { bias and detection bias) } \\
\text { All outcomes }\end{array}$ & Unclear risk & $\begin{array}{l}\text { Blinding of intervention: unclear. Control patients were treated similarly to ex- } \\
\text { perimental patients but did not receive furosemide. The authors do not men- } \\
\text { tion whether control patients received a placebo. Blinding of outcome: not } \\
\text { documented }\end{array}$ \\
\hline $\begin{array}{l}\text { Incomplete outcome data } \\
\text { (attrition bias) } \\
\text { All outcomes }\end{array}$ & Unclear risk & $\begin{array}{l}\text { Complete follow-up: no. Sixty patients were randomized. Four patients were } \\
\text { excluded from the study before analysis: } 2 \text { patients (one in each group) with } \\
\text { group B streptococcus sepsis, and } 2 \text { patients in the control group who died } \\
\text { within } 24 \text { hours after birth with IVH and seizures. }\end{array}$ \\
\hline
\end{tabular}

\section{Characteristics of excluded studies [ordered by study ID]}

\begin{tabular}{ll}
\hline Study & Reason for exclusion \\
\hline Durand 1987 & Respiratory distress syndrome was not listed as inclusion criterion \\
\hline Graff 1985 & Not a controlled study \\
\hline Green 1981 & Retrospective study \\
\hline Greenough 1985 & Enrollment criteria included infants less than 10 days of age \\
\hline Hegyi 1986 & Respiratory distress syndrome was not listed as inclusion criterion \\
\hline Laubscher 1998 & Respiratory distress syndrome was not listed as inclusion criterion \\
\hline Moylan 1975 & Not a randomized study \\
\hline Tulassay 1986 & Not a randomized study \\
\hline Yeh 1985 & No assessment of any of the major outcome variables selected for this systematic review \\
\hline Zanardo 1995 & Enrollment criteria included either apnea or respiratory distress syndrome
\end{tabular}


DATA AND ANALYSES

Comparison 1. Routine diuretic administration versus placebo, no treatment or PRN diuretic administration

\begin{tabular}{|c|c|c|c|c|}
\hline Outcome or subgroup title & $\begin{array}{l}\text { No. of } \\
\text { studies }\end{array}$ & $\begin{array}{l}\text { No. of } \\
\text { partici- } \\
\text { pants }\end{array}$ & Statistical method & Effect size \\
\hline 1 Death & 6 & & $\begin{array}{l}\text { Risk Ratio (M-H, Fixed, 95\% } \\
\mathrm{Cl})\end{array}$ & Subtotals only \\
\hline 1.1 All & 6 & 248 & $\begin{array}{l}\text { Risk Ratio (M-H, Fixed, 95\% } \\
\mathrm{Cl} \text { ) }\end{array}$ & $1.35[0.71,2.56]$ \\
\hline 1.2 Postnatal age $<24$ hours & 4 & 167 & $\begin{array}{l}\text { Risk Ratio (M-H, Fixed, 95\% } \\
\mathrm{Cl} \text { ) }\end{array}$ & $1.47[0.72,2.97]$ \\
\hline 1.3 Postnatal age at least 24 hours & 2 & 81 & $\begin{array}{l}\text { Risk Ratio (M-H, Fixed, 95\% } \\
\mathrm{Cl} \text { ) }\end{array}$ & $0.97[0.21,4.48]$ \\
\hline 1.4 Loop diuretics & 5 & 198 & $\begin{array}{l}\text { Risk Ratio (M-H, Fixed, 95\% } \\
\mathrm{Cl} \text { ) }\end{array}$ & $1.30[0.67,2.52]$ \\
\hline 1.5 Theophylline & 1 & 50 & $\begin{array}{l}\text { Risk Ratio (M-H, Fixed, 95\% } \\
\mathrm{Cl} \text { ) }\end{array}$ & $2.0[0.19,20.67]$ \\
\hline 1.6 Sensitivity & 5 & 228 & $\begin{array}{l}\text { Risk Ratio (M-H, Fixed, 95\% } \\
\mathrm{Cl} \text { ) }\end{array}$ & $1.07[0.51,2.24]$ \\
\hline 2 Clinically significant PDA & 4 & & $\begin{array}{l}\text { Risk Ratio (M-H, Fixed, 95\% } \\
\mathrm{Cl} \text { ) }\end{array}$ & Subtotals only \\
\hline 2.1 All & 4 & 208 & $\begin{array}{l}\text { Risk Ratio (M-H, Fixed, 95\% } \\
\mathrm{CI})\end{array}$ & $1.11[0.72,1.71]$ \\
\hline 2.2 Postnatal age $<24$ hours & 3 & 139 & $\begin{array}{l}\text { Risk Ratio (M-H, Fixed, 95\% } \\
\mathrm{Cl} \text { ) }\end{array}$ & $0.86[0.50,1.48]$ \\
\hline 2.3 Postnatal age at least 24 hours & 1 & 69 & $\begin{array}{l}\text { Risk Ratio (M-H, Fixed, 95\% } \\
\text { Cl) }\end{array}$ & $1.7[0.82,3.53]$ \\
\hline 2.4 Loop diuretics & 3 & 161 & $\begin{array}{l}\text { Risk Ratio (M-H, Fixed, 95\% } \\
\mathrm{Cl})\end{array}$ & $1.08[0.67,1.73]$ \\
\hline 2.5 Theophylline & 1 & 47 & $\begin{array}{l}\text { Risk Ratio (M-H, Fixed, 95\% } \\
\mathrm{CI} \text { ) }\end{array}$ & $1.25[0.44,3.54]$ \\
\hline 3 Hypovolemic shock & 1 & 12 & $\begin{array}{l}\text { Risk Ratio (M-H, Fixed, 95\% } \\
\mathrm{Cl} \text { ) }\end{array}$ & $4.0[0.20,82.01]$ \\
\hline 3.1 Postnatal age at least 24 hours & 1 & 12 & $\begin{array}{l}\text { Risk Ratio (M-H, Fixed, 95\% } \\
\mathrm{Cl} \text { ) }\end{array}$ & $4.0[0.20,82.01]$ \\
\hline $\begin{array}{l}4 \text { Change in plasma volume }(\mathrm{ml} / \mathrm{kg}) \text { from } 48 \text { to } \\
96 \text { hours of life }\end{array}$ & 1 & 69 & $\begin{array}{l}\text { Mean Difference (IV, Fixed, } \\
95 \% \mathrm{CI})\end{array}$ & $-7.7[-11.74,-3.66]$ \\
\hline 4.1 Postnatal age at least 24 hours & 1 & 69 & $\begin{array}{l}\text { Mean Difference (IV, Fixed, } \\
95 \% \mathrm{CI})\end{array}$ & $-7.7[-11.74,-3.66]$ \\
\hline
\end{tabular}




\begin{tabular}{|c|c|c|c|c|}
\hline Outcome or subgroup title & $\begin{array}{l}\text { No. of } \\
\text { studies }\end{array}$ & $\begin{array}{l}\text { No. of } \\
\text { partici- } \\
\text { pants }\end{array}$ & Statistical method & Effect size \\
\hline $\begin{array}{l}5 \text { Change in cardiovascular stability index } \\
\text { from } 48 \text { to } 96 \text { hours of life }\end{array}$ & 1 & 69 & $\begin{array}{l}\text { Mean Difference (IV, Fixed, } \\
95 \% \mathrm{CI})\end{array}$ & $0.77[-0.14,1.68]$ \\
\hline 5.1 Postnatal age at least 24 hours & 1 & 69 & $\begin{array}{l}\text { Mean Difference (IV, Fixed, } \\
95 \% \mathrm{Cl} \text { ) }\end{array}$ & $0.77[-0.14,1.68]$ \\
\hline $\begin{array}{l}6 \text { Dobutamine infusion rate (micrograms } / \mathrm{kg} / \\
\mathrm{min} \text { ) at the end of treatment }\end{array}$ & 1 & 69 & $\begin{array}{l}\text { Mean Difference (IV, Fixed, } \\
95 \% \mathrm{CI})\end{array}$ & $3.10[-0.62,6.82]$ \\
\hline 6.1 Postnatal age at least 24 hours & 1 & 69 & $\begin{array}{l}\text { Mean Difference (IV, Fixed, } \\
95 \% \mathrm{Cl} \text { ) }\end{array}$ & $3.10[-0.62,6.82]$ \\
\hline $\begin{array}{l}7 \text { Dopamine infusion rate (micrograms } / \mathrm{kg} / \\
\mathrm{min} \text { ) at the end of treatment }\end{array}$ & 1 & 69 & $\begin{array}{l}\text { Mean Difference (IV, Fixed, } \\
95 \% \mathrm{CI} \text { ) }\end{array}$ & $2.41[-0.07,4.89]$ \\
\hline 7.1 Postnatal age at least 24 hours & 1 & 69 & $\begin{array}{l}\text { Mean Difference (IV, Fixed, } \\
95 \% \mathrm{CI})\end{array}$ & $2.41[-0.07,4.89]$ \\
\hline $\begin{array}{l}8 \text { Change in colloid infusion rate }(\mathrm{ml} / \mathrm{kg} / \text { hour }) \\
\text { at the end of treatment }\end{array}$ & 1 & 69 & $\begin{array}{l}\text { Mean Difference (IV, Fixed, } \\
95 \% \mathrm{Cl})\end{array}$ & $-0.86[-4.30,2.58]$ \\
\hline 8.1 Postnatal age at least 24 hours & 1 & 69 & $\begin{array}{l}\text { Mean Difference (IV, Fixed, } \\
95 \% \mathrm{CI})\end{array}$ & $-0.86[-4.30,2.58]$ \\
\hline $\begin{array}{l}9 \text { Failure to extubate within } 3 \text { days after study } \\
\text { entry }\end{array}$ & 1 & 56 & $\begin{array}{l}\text { Risk Ratio (M-H, Fixed, 95\% } \\
\mathrm{Cl} \text { ) }\end{array}$ & $0.65[0.45,0.93]$ \\
\hline 9.1 Postnatal age $<24$ hours & 1 & 56 & $\begin{array}{l}\text { Risk Ratio (M-H, Fixed, 95\% } \\
\mathrm{Cl})\end{array}$ & $0.65[0.45,0.93]$ \\
\hline $\begin{array}{l}10 \text { Change in peak inspiratory pressure }(\mathrm{cm} \\
\mathrm{H} 2 \mathrm{O}) \text { during treatment }\end{array}$ & 1 & 36 & $\begin{array}{l}\text { Mean Difference (IV, Fixed, } \\
95 \% \mathrm{Cl} \text { ) }\end{array}$ & $-6.62[-14.74,1.50]$ \\
\hline 10.1 Postnatal age $<24$ hours & 1 & 36 & $\begin{array}{l}\text { Mean Difference (IV, Fixed, } \\
95 \% \mathrm{CI} \text { ) }\end{array}$ & $-6.62[-14.74,1.50]$ \\
\hline $\begin{array}{l}11 \text { Change in mean airway pressure }(\mathrm{cm} \mathrm{H} 2 \mathrm{O}) \\
\text { during treatment }\end{array}$ & 2 & 125 & $\begin{array}{l}\text { Mean Difference (IV, Fixed, } \\
95 \% \mathrm{Cl} \text { ) }\end{array}$ & $-1.16[-2.42,0.09]$ \\
\hline 11.1 Postnatal age $<24$ hours & 1 & 56 & $\begin{array}{l}\text { Mean Difference (IV, Fixed, } \\
95 \% \mathrm{Cl} \text { ) }\end{array}$ & $-1.30[-2.81,0.21]$ \\
\hline 11.2 Postnatal age at least 24 hours & 1 & 69 & $\begin{array}{l}\text { Mean Difference (IV, Fixed, } \\
95 \% \mathrm{CI})\end{array}$ & $-0.85[-3.11,1.41]$ \\
\hline 12 Duration of mechanical ventilation (days) & 2 & 105 & $\begin{array}{l}\text { Mean Difference (IV, Fixed, } \\
95 \% \mathrm{CI})\end{array}$ & $-2.83[-4.49,-1.17]$ \\
\hline 12.1 Postnatal age $<24$ hours & 1 & 36 & $\begin{array}{l}\text { Mean Difference (IV, Fixed, } \\
95 \% \mathrm{CI} \text { ) }\end{array}$ & $-5.0[-7.06,-2.94]$ \\
\hline 12.2 Postnatal age at least 24 hours & 1 & 69 & $\begin{array}{l}\text { Mean Difference (IV, Fixed, } \\
95 \% \mathrm{CI} \text { ) }\end{array}$ & $1.20[-1.61,4.01]$ \\
\hline
\end{tabular}




\begin{tabular}{|c|c|c|c|c|}
\hline Outcome or subgroup title & $\begin{array}{l}\text { No. of } \\
\text { studies }\end{array}$ & $\begin{array}{l}\text { No. of } \\
\text { partici- } \\
\text { pants }\end{array}$ & Statistical method & Effect size \\
\hline 13 Change in FiO2 during treatment & 2 & 92 & $\begin{array}{l}\text { Mean Difference (IV, Fixed, } \\
95 \% \mathrm{CI})\end{array}$ & $-0.05[-0.13,0.03]$ \\
\hline 13.1 Postnatal age $<24$ hours & 2 & 92 & $\begin{array}{l}\text { Mean Difference (IV, Fixed, } \\
95 \% \mathrm{CI})\end{array}$ & $-0.05[-0.13,0.03]$ \\
\hline $\begin{array}{l}14 \text { Change in alveolar-arterial } 02 \text { gradient } \\
(\mathrm{mm} \mathrm{Hg}) \text { during treatment }\end{array}$ & 3 & 161 & $\begin{array}{l}\text { Mean Difference (IV, Fixed, } \\
95 \% \mathrm{CI})\end{array}$ & $-1.62[-43.75,40.51]$ \\
\hline 14.1 Postnatal age $<24$ hours & 2 & 92 & $\begin{array}{l}\text { Mean Difference (IV, Fixed, } \\
95 \% \mathrm{CI})\end{array}$ & $-66.81[-131.24,-2.37]$ \\
\hline 14.2 Postnatal age at least 24 hours & 1 & 69 & $\begin{array}{l}\text { Mean Difference (IV, Fixed, } \\
95 \% \mathrm{CI})\end{array}$ & $47.06[-8.62,102.74]$ \\
\hline 15 BPD & 3 & & $\begin{array}{l}\text { Risk Ratio (M-H, Fixed, 95\% } \\
\text { Cl) }\end{array}$ & Subtotals only \\
\hline 15.1 All & 3 & 139 & $\begin{array}{l}\text { Risk Ratio (M-H, Fixed, 95\% } \\
\mathrm{Cl})\end{array}$ & $0.81[0.41,1.59]$ \\
\hline 15.2 Postnatal age $<24$ hours & 3 & 139 & $\begin{array}{l}\text { Risk Ratio (M-H, Fixed, 95\% } \\
\mathrm{Cl})\end{array}$ & $0.81[0.41,1.59]$ \\
\hline 15.3 Loop diuretics & 2 & 92 & $\begin{array}{l}\text { Risk Ratio (M-H, Fixed, 95\% } \\
\mathrm{Cl})\end{array}$ & $1.02[0.49,2.10]$ \\
\hline 15.4 Theophylline & 1 & 50 & $\begin{array}{l}\text { Risk Ratio (M-H, Fixed, 95\% } \\
\mathrm{Cl})\end{array}$ & $0.29[0.04,2.44]$ \\
\hline 16 Death or BPD & 2 & & $\begin{array}{l}\text { Risk Ratio (M-H, Fixed, 95\% } \\
\text { Cl) }\end{array}$ & Subtotals only \\
\hline 16.1 All & 2 & 87 & $\begin{array}{l}\text { Risk Ratio (M-H, Fixed, 95\% } \\
\text { Cl) }\end{array}$ & $0.95[0.32,2.76]$ \\
\hline 16.2 Postnatal age $<24$ hours & 2 & 87 & $\begin{array}{l}\text { Risk Ratio (M-H, Fixed, 95\% } \\
\mathrm{Cl} \text { ) }\end{array}$ & $0.95[0.32,2.76]$ \\
\hline 16.3 Loop diuretics & 1 & 37 & $\begin{array}{l}\text { Risk Ratio (M-H, Fixed, 95\% } \\
\mathrm{Cl} \text { ) }\end{array}$ & $2.55[0.29,22.31]$ \\
\hline 16.4 Theophylline & 1 & 50 & $\begin{array}{l}\text { Risk Ratio (M-H, Fixed, 95\% } \\
\mathrm{Cl} \text { ) }\end{array}$ & $0.6[0.16,2.25]$ \\
\hline $\begin{array}{l}17 \text { Duration of oxygen supplementation } \\
\text { (days) }\end{array}$ & 3 & 161 & $\begin{array}{l}\text { Mean Difference (IV, Fixed, } \\
95 \% \mathrm{CI})\end{array}$ & $-0.50[-2.51,1.50]$ \\
\hline 17.1 Postnatal age $<24$ hours & 2 & 92 & $\begin{array}{l}\text { Mean Difference (IV, Fixed, } \\
95 \% \mathrm{CI} \text { ) }\end{array}$ & $-0.22[-2.40,1.96]$ \\
\hline 17.2 Postnatal age at least 24 hours & 1 & 69 & $\begin{array}{l}\text { Mean Difference (IV, Fixed, } \\
95 \% \mathrm{CI})\end{array}$ & $-2.10[-7.28,3.08]$ \\
\hline
\end{tabular}




\begin{tabular}{|c|c|c|c|c|}
\hline Outcome or subgroup title & $\begin{array}{l}\text { No. of } \\
\text { studies }\end{array}$ & $\begin{array}{l}\text { No. of } \\
\text { partici- } \\
\text { pants }\end{array}$ & Statistical method & Effect size \\
\hline $18 \mathrm{IVH}$ & 3 & & $\begin{array}{l}\text { Risk Ratio (M-H, Fixed, 95\% } \\
\mathrm{CI})\end{array}$ & Subtotals only \\
\hline 18.1 All & 3 & 127 & $\begin{array}{l}\text { Risk Ratio (M-H, Fixed, 95\% } \\
\mathrm{Cl} \text { ) }\end{array}$ & $0.76[0.40,1.44]$ \\
\hline 18.2 Postnatal age $<24$ hours & 3 & 127 & $\begin{array}{l}\text { Risk Ratio (M-H, Fixed, 95\% } \\
\mathrm{Cl} \text { ) }\end{array}$ & $0.76[0.40,1.44]$ \\
\hline 18.3 Loop diuretics & 2 & 80 & $\begin{array}{l}\text { Risk Ratio (M-H, Fixed, 95\% } \\
\mathrm{Cl} \text { ) }\end{array}$ & $0.90[0.43,1.88]$ \\
\hline 18.4 Theophylline & 1 & 47 & $\begin{array}{l}\text { Risk Ratio (M-H, Fixed, 95\% } \\
\mathrm{Cl} \text { ) }\end{array}$ & $0.52[0.15,1.84]$ \\
\hline 18.5 Sensitivity & 2 & 107 & $\begin{array}{l}\text { Risk Ratio (M-H, Fixed, 95\% } \\
\mathrm{Cl} \text { ) }\end{array}$ & $0.63[0.32,1.26]$ \\
\hline 19 Severe IVH (grade III or IV) & 1 & 47 & $\begin{array}{l}\text { Risk Ratio (M-H, Fixed, 95\% } \\
\mathrm{Cl} \text { ) }\end{array}$ & $1.04[0.07,15.72]$ \\
\hline 19.1 All studies & 1 & 47 & $\begin{array}{l}\text { Risk Ratio (M-H, Fixed, 95\% } \\
\mathrm{Cl} \text { ) }\end{array}$ & $1.04[0.07,15.72]$ \\
\hline 20 Duration of hospitalization (days) & 2 & & $\begin{array}{l}\text { Mean Difference (IV, Fixed, } \\
95 \% \mathrm{CI})\end{array}$ & Subtotals only \\
\hline 20.1 All & 2 & 103 & $\begin{array}{l}\text { Mean Difference (IV, Fixed, } \\
95 \% \mathrm{CI} \text { ) }\end{array}$ & $2.43[-10.71,15.57]$ \\
\hline 20.2 Postnatal age $<24$ hours & 2 & 103 & $\begin{array}{l}\text { Mean Difference (IV, Fixed, } \\
95 \% \mathrm{CI} \text { ) }\end{array}$ & $2.43[-10.71,15.57]$ \\
\hline 20.3 Loop diuretics & 1 & 56 & $\begin{array}{l}\text { Mean Difference (IV, Fixed, } \\
95 \% \mathrm{CI} \text { ) }\end{array}$ & $6.60[-16.38,29.58]$ \\
\hline 20.4 Theophylline & 1 & 47 & $\begin{array}{l}\text { Mean Difference (IV, Fixed, } \\
95 \% \mathrm{CI} \text { ) }\end{array}$ & $0.40[-15.62,16.42]$ \\
\hline $\begin{array}{l}21 \text { Significant handicap at one year (major } \\
\text { neurologic defect and/or MDI/PDI <50) }\end{array}$ & 1 & 26 & $\begin{array}{l}\text { Risk Ratio (M-H, Fixed, 95\% } \\
\mathrm{Cl})\end{array}$ & $0.43[0.09,1.94]$ \\
\hline 21.1 Postnatal age $<24$ hours & 1 & 26 & $\begin{array}{l}\text { Risk Ratio (M-H, Fixed, 95\% } \\
\mathrm{Cl})\end{array}$ & $0.43[0.09,1.94]$ \\
\hline 22 Oligoanuria (urine output $<1 \mathrm{ml} / \mathrm{kg} /$ hour) & 1 & & $\begin{array}{l}\text { Risk Ratio (M-H, Fixed, 95\% } \\
\mathrm{Cl})\end{array}$ & Subtotals only \\
\hline 22.1 All & 1 & 47 & $\begin{array}{l}\text { Risk Ratio (M-H, Fixed, 95\% } \\
\mathrm{Cl} \text { ) }\end{array}$ & $0.13[0.02,0.96]$ \\
\hline 22.2 Theophylline & 1 & 47 & $\begin{array}{l}\text { Risk Ratio (M-H, Fixed, 95\% } \\
\text { Cl) }\end{array}$ & $0.13[0.02,0.96]$ \\
\hline
\end{tabular}




\begin{tabular}{lllll}
\hline Outcome or subgroup title & $\begin{array}{l}\text { No. of } \\
\text { studies }\end{array}$ & $\begin{array}{l}\text { No. of } \\
\text { partici- } \\
\text { pants }\end{array}$ & Statistical method & Effect size \\
\hline 23 Hyponatremia (sodium $<130 \mathrm{mM} / \mathrm{L})$ & 1 & 47 & $\begin{array}{l}\text { Risk Ratio (M-H, Fixed, 95\% } \\
\text { Cl) }\end{array}$ & $1.04[0.16,6.80]$ \\
\hline 23.1 All & 1 & 47 & $\begin{array}{l}\text { Risk Ratio (M-H, Fixed, 95\% } \\
\text { Cl) }\end{array}$ & $1.04[0.16,6.80]$ \\
\hline 24 Hyperkalemia (potassium $>6.5 \mathrm{mM} / \mathrm{L})$ & 1 & 47 & $\begin{array}{l}\text { Risk Ratio (M-H, Fixed, 95\% } \\
\text { Cl) }\end{array}$ & $1.57[0.29,8.53]$ \\
\hline 24.1 All & 1 & 47 & $\begin{array}{l}\text { Risk Ratio (M-H, Fixed, 95\% } \\
\text { Cl) }\end{array}$ & $1.57[0.29,8.53]$ \\
\hline
\end{tabular}

Analysis 1.1. Comparison 1 Routine diuretic administration versus placebo, no treatment or PRN diuretic administration, Outcome 1 Death.

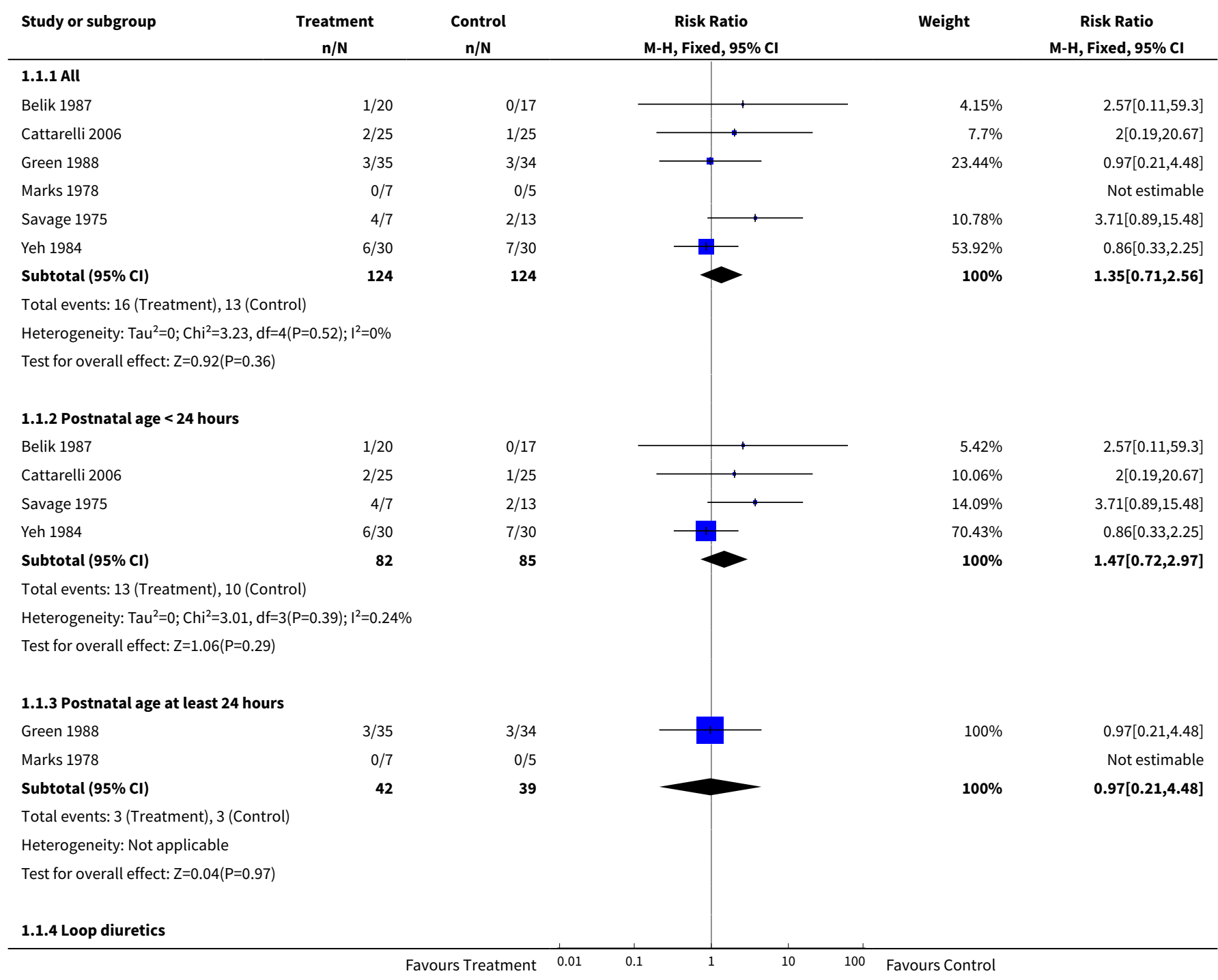




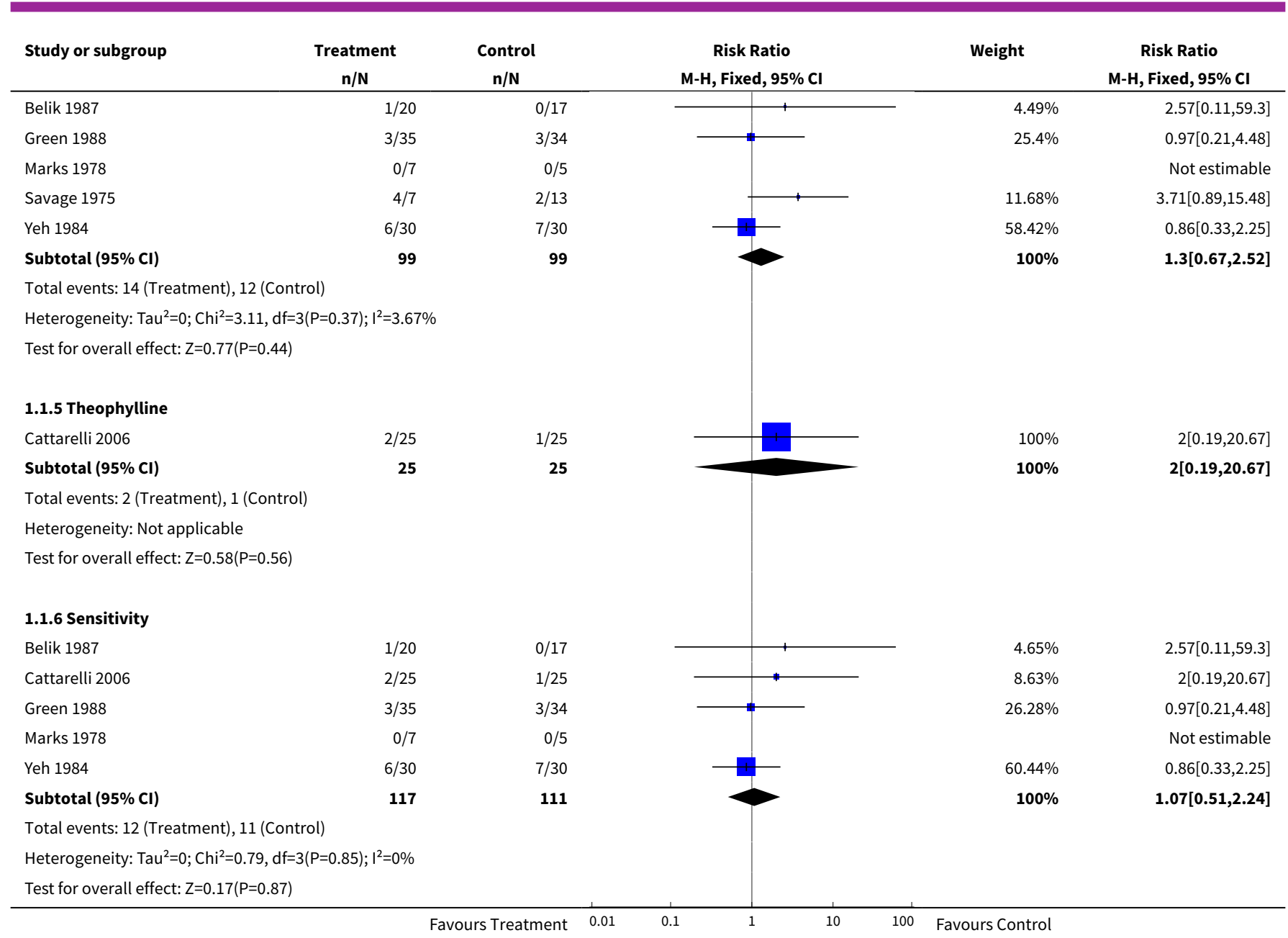

Analysis 1.2. Comparison 1 Routine diuretic administration versus placebo, no treatment or PRN diuretic administration, Outcome 2 Clinically significant PDA.

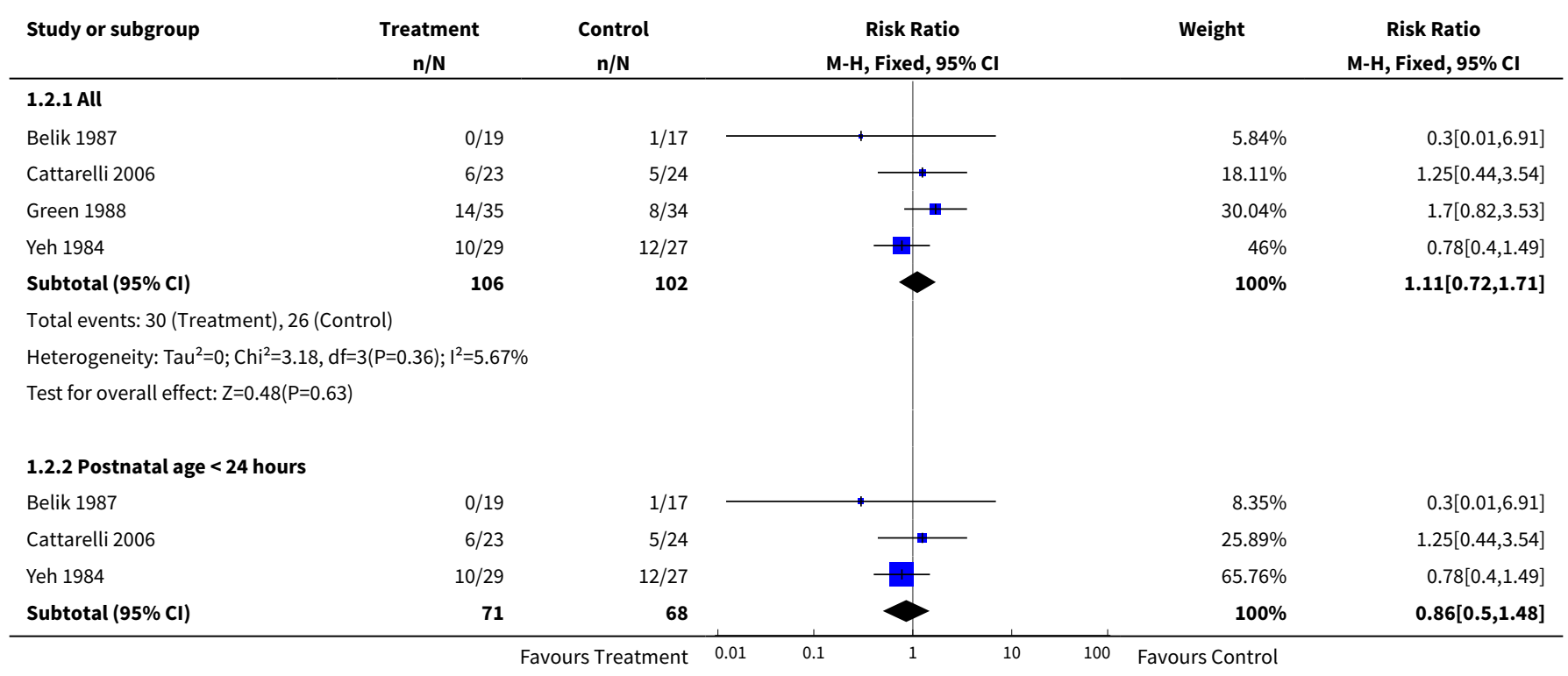




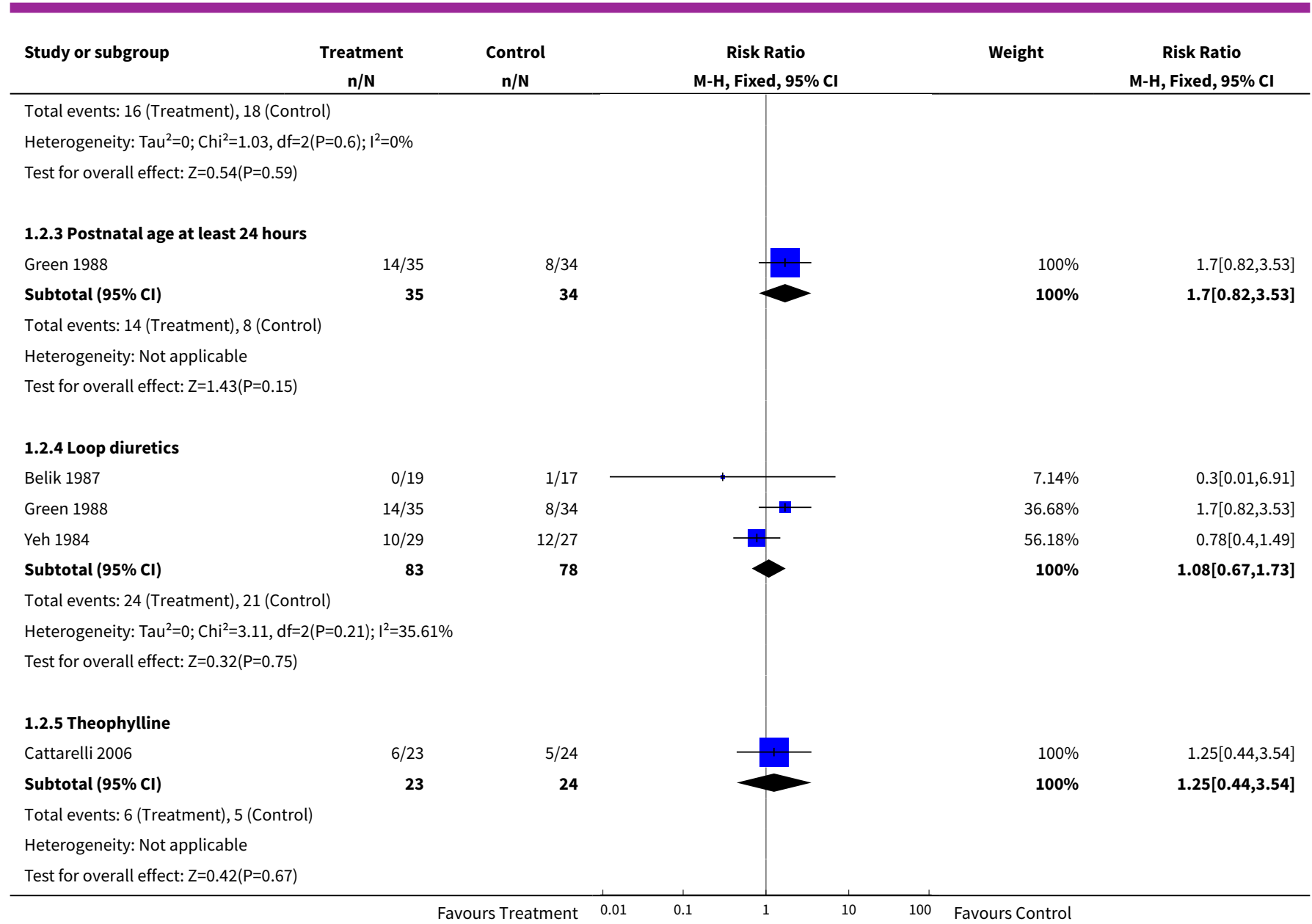

Analysis 1.3. Comparison 1 Routine diuretic administration versus placebo, no treatment or PRN diuretic administration, Outcome 3 Hypovolemic shock.

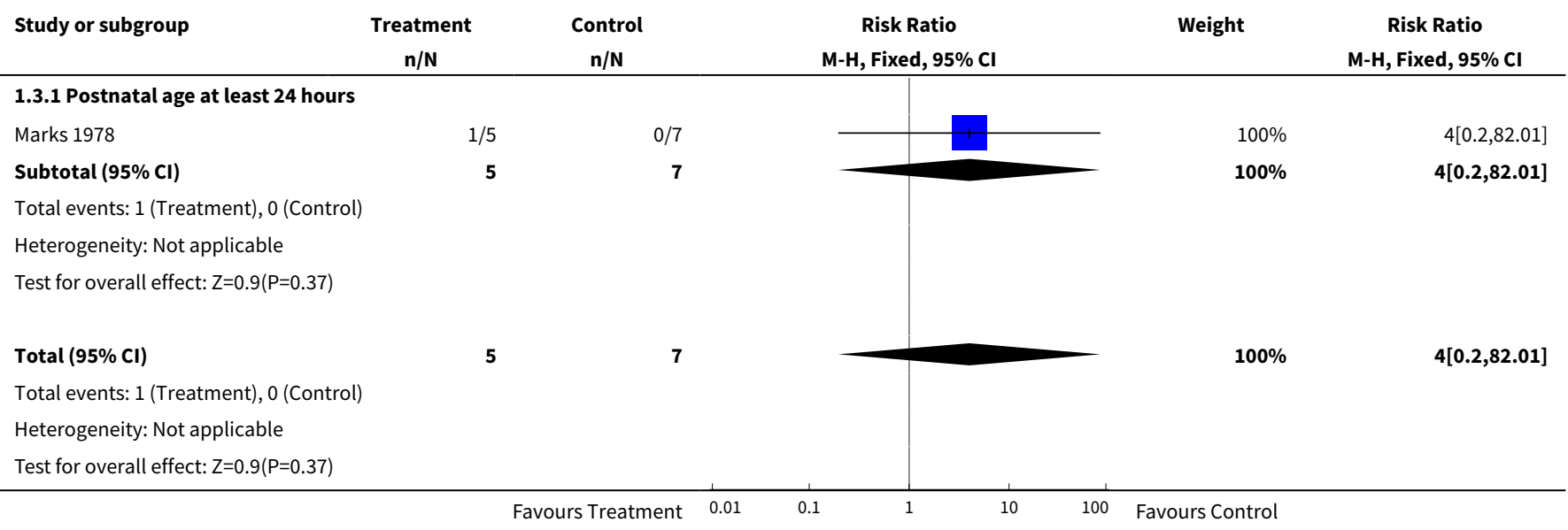


Analysis 1.4. Comparison 1 Routine diuretic administration versus placebo, no treatment or PRN diuretic administration, Outcome 4 Change in plasma volume (ml/kg) from 48 to 96 hours of life.

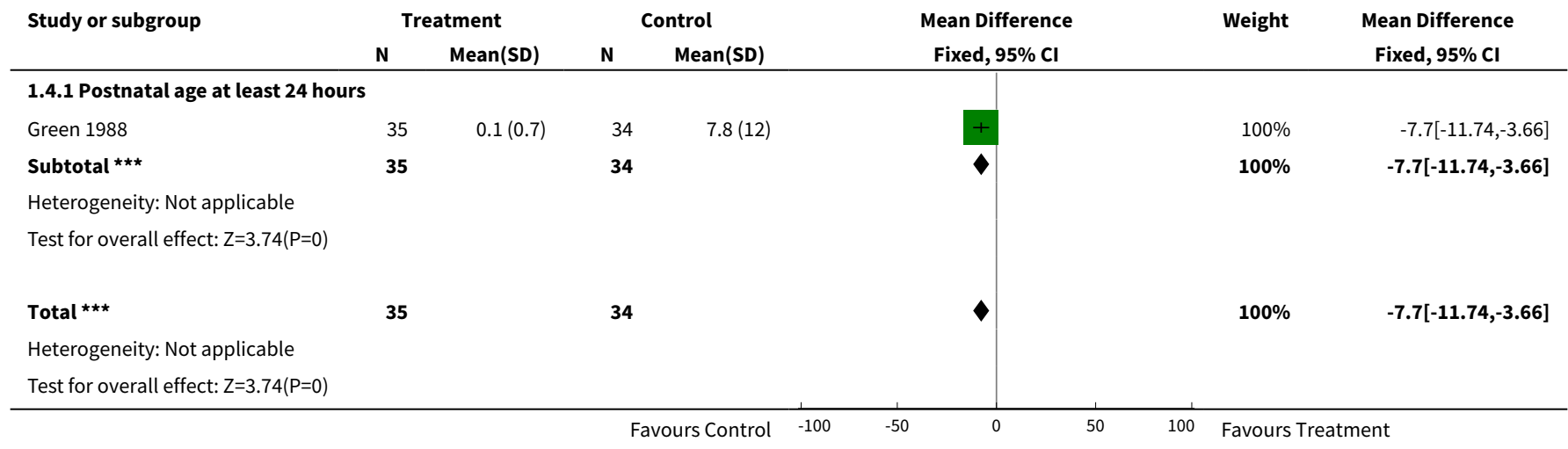

Analysis 1.5. Comparison 1 Routine diuretic administration versus placebo, no treatment or PRN diuretic administration, Outcome 5 Change in cardiovascular stability index from 48 to 96 hours of life.

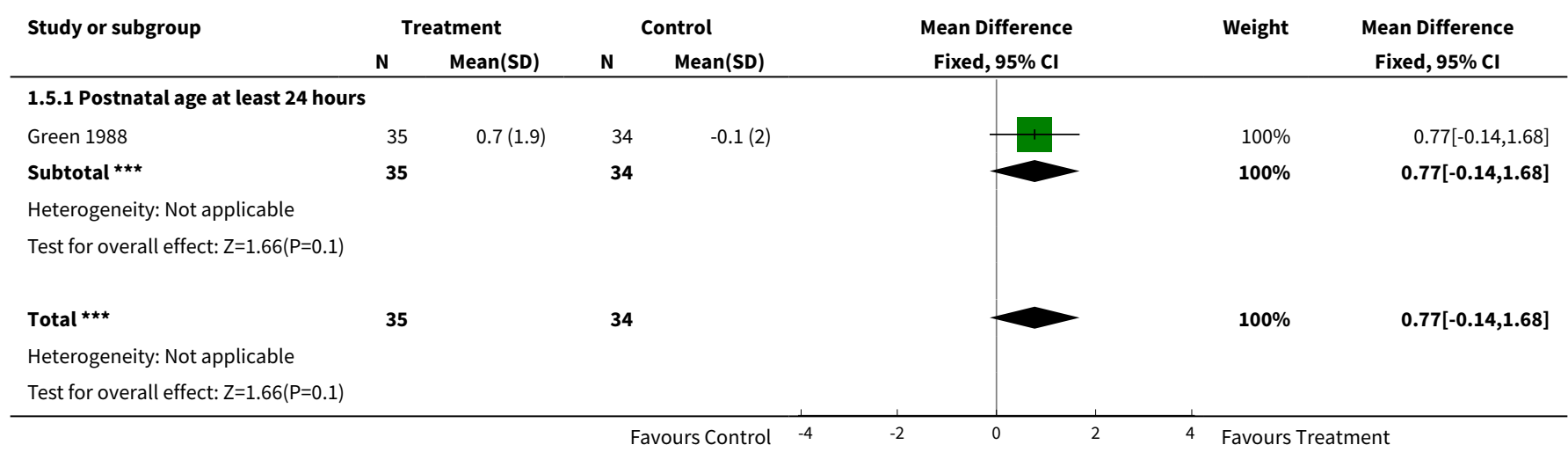

Analysis 1.6. Comparison 1 Routine diuretic administration versus placebo, no treatment or PRN diuretic administration, Outcome 6 Dobutamine infusion rate (micrograms/kg/min) at the end of treatment.

\begin{tabular}{|c|c|c|c|c|c|c|c|}
\hline \multirow[t]{2}{*}{ Study or subgroup } & \multicolumn{2}{|c|}{ Treatment } & \multicolumn{2}{|c|}{ Control } & \multirow{2}{*}{$\begin{array}{c}\text { Mean Difference } \\
\text { Fixed, } 95 \% \mathrm{Cl}\end{array}$} & \multirow[t]{2}{*}{ Weight } & \multirow{2}{*}{$\begin{array}{c}\text { Mean Difference } \\
\text { Fixed, } 95 \% \mathrm{Cl}\end{array}$} \\
\hline & $\mathbf{N}$ & Mean(SD) & $\mathbf{N}$ & Mean(SD) & & & \\
\hline \multicolumn{8}{|c|}{ 1.6.1 Postnatal age at least 24 hours } \\
\hline Green 1988 & 35 & $7.1(9.3)$ & 34 & $4(6.3)$ & & $100 \%$ & $3.1[-0.62,6.82]$ \\
\hline 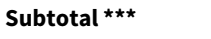 & 35 & & 34 & & & $100 \%$ & $3.1[-0.62,6.82]$ \\
\hline \multicolumn{8}{|c|}{ Heterogeneity: Not applicable } \\
\hline \multicolumn{8}{|c|}{ Test for overall effect: $Z=1.63(P=0.1)$} \\
\hline Total $\star \star \star ~$ & 35 & & 34 & & & $100 \%$ & $3.1[-0.62,6.82]$ \\
\hline \multicolumn{8}{|c|}{ Heterogeneity: Not applicable } \\
\hline \multicolumn{8}{|c|}{ Test for overall effect: $Z=1.63(P=0.1)$} \\
\hline & & & Favo & Treatment & 0 & Favours & \\
\hline
\end{tabular}


Analysis 1.7. Comparison 1 Routine diuretic administration versus placebo, no treatment or PRN diuretic administration, Outcome 7 Dopamine infusion rate (micrograms $/ \mathrm{kg} / \mathrm{min}$ ) at the end of treatment.

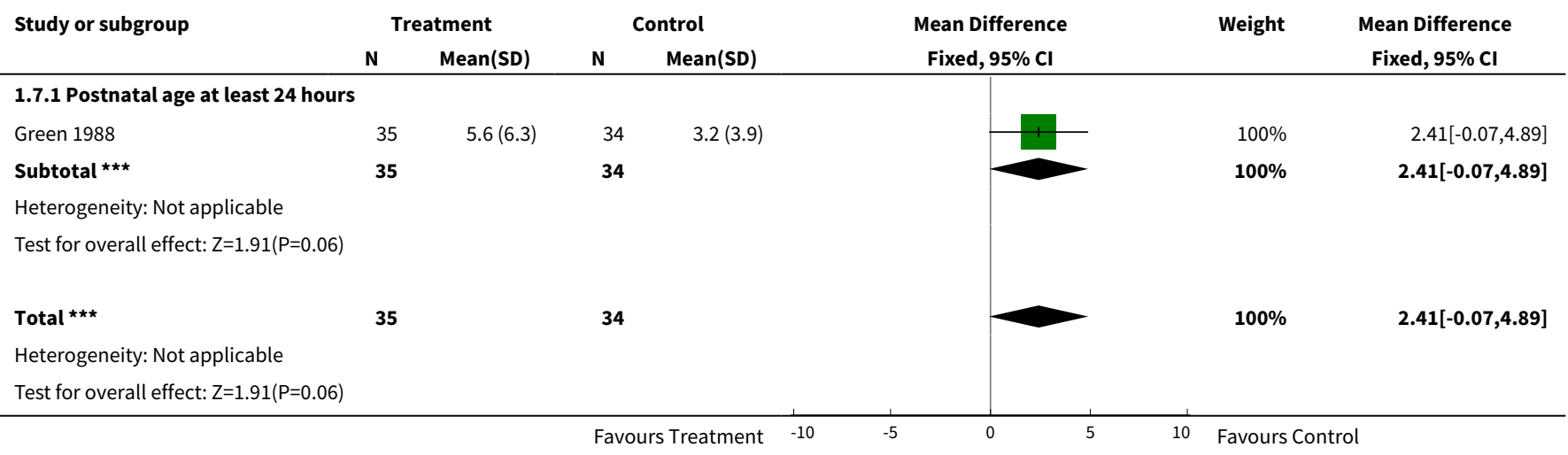

Analysis 1.8. Comparison 1 Routine diuretic administration versus placebo, no treatment or PRN diuretic administration, Outcome 8 Change in colloid infusion rate $(\mathrm{ml} / \mathrm{kg} / \mathrm{hour})$ at the end of treatment.

\begin{tabular}{|c|c|c|c|c|c|c|c|}
\hline \multirow[t]{2}{*}{ Study or subgroup } & \multicolumn{2}{|c|}{ Treatment } & \multicolumn{2}{|c|}{ Control } & \multirow{2}{*}{$\begin{array}{c}\text { Mean Difference } \\
\text { Fixed, } 95 \% \mathrm{Cl}\end{array}$} & \multirow[t]{2}{*}{ Weight } & \multirow{2}{*}{$\begin{array}{c}\text { Mean Difference } \\
\text { Fixed, } 95 \% \mathrm{Cl}\end{array}$} \\
\hline & $\mathbf{N}$ & Mean(SD) & $\mathbf{N}$ & Mean(SD) & & & \\
\hline \multicolumn{8}{|c|}{ 1.8.1 Postnatal age at least 24 hours } \\
\hline Green 1988 & 35 & $-3(8.9)$ & 34 & $-2.1(5.3)$ & & $100 \%$ & $-0.86[-4.3,2.58]$ \\
\hline 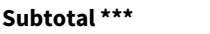 & 35 & & 34 & & & $100 \%$ & $-0.86[-4.3,2.58]$ \\
\hline \multicolumn{8}{|c|}{ Heterogeneity: $\mathrm{Tau}^{2}=0 ; \mathrm{Chi}^{2}=0, \mathrm{df}=0(\mathrm{P}<0.0001) ; \mathrm{I}^{2}=100 \%$} \\
\hline \multicolumn{8}{|c|}{ Test for overall effect: $Z=0.49(P=0.62)$} \\
\hline 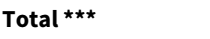 & 35 & & 34 & & & $100 \%$ & $-0.86[-4.3,2.58]$ \\
\hline \multicolumn{8}{|c|}{ Heterogeneity: $\mathrm{Tau}^{2}=0 ; \mathrm{Chi}^{2}=0, \mathrm{df}=0(\mathrm{P}<0.0001) ; \mathrm{I}^{2}=100 \%$} \\
\hline Test for overall effect & & & & & & & \\
\hline
\end{tabular}

Analysis 1.9. Comparison 1 Routine diuretic administration versus placebo, no treatment or PRN diuretic administration, Outcome 9 Failure to extubate within 3 days after study entry.

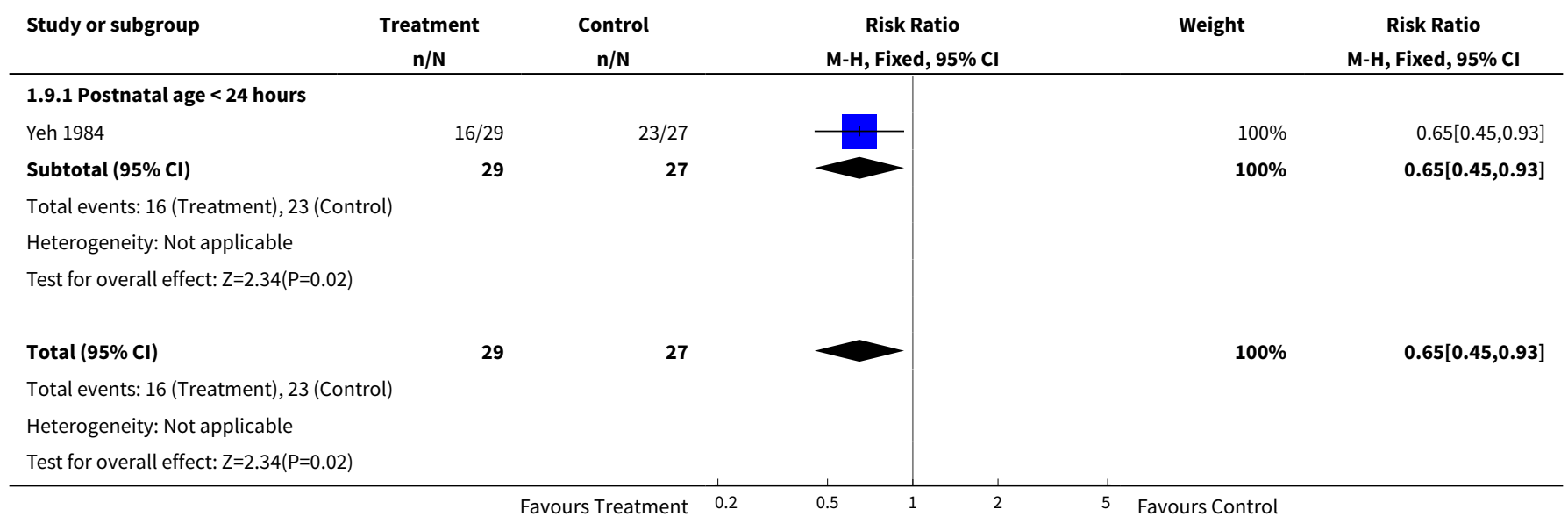


Analysis 1.10. Comparison 1 Routine diuretic administration versus placebo, no treatment or PRN diuretic administration, Outcome 10 Change in peak inspiratory pressure $(\mathrm{cm} \mathrm{H} 2 \mathrm{O})$ during treatment.

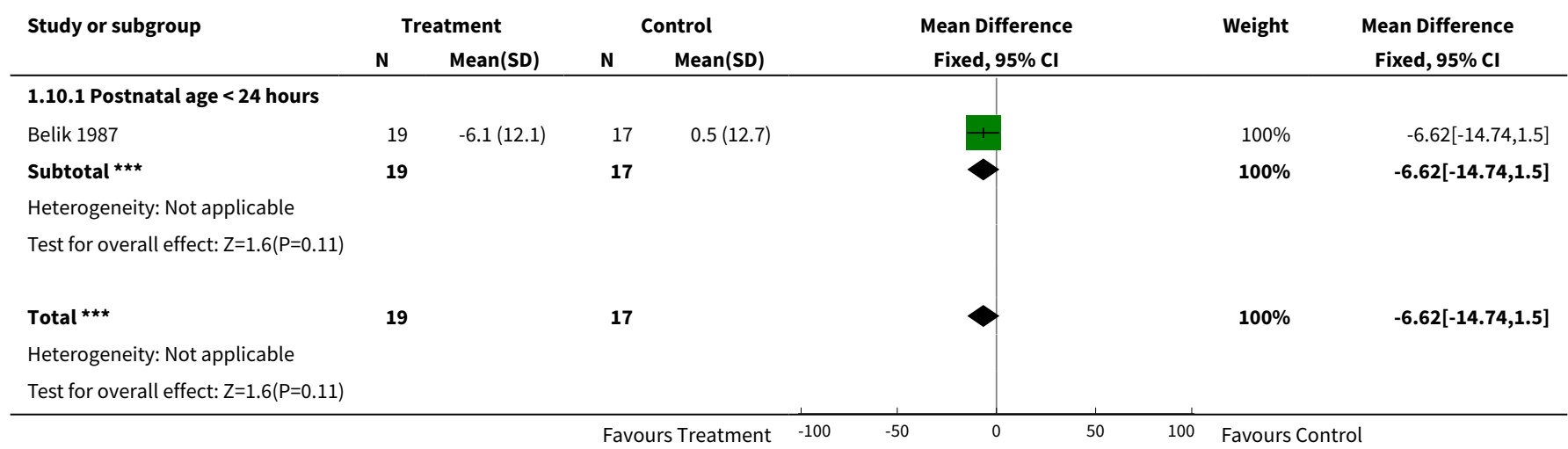

Analysis 1.11. Comparison 1 Routine diuretic administration versus placebo, no treatment or PRN diuretic administration, Outcome 11 Change in mean airway pressure $(\mathrm{cm} \mathrm{H2O})$ during treatment.

\begin{tabular}{|c|c|c|c|c|c|c|c|}
\hline \multirow[t]{2}{*}{ Study or subgroup } & \multicolumn{2}{|c|}{ Treatment } & \multicolumn{2}{|c|}{ Control } & \multirow{2}{*}{$\begin{array}{c}\text { Mean Difference } \\
\text { Fixed, } 95 \% \mathrm{Cl}\end{array}$} & \multirow[t]{2}{*}{ Weight } & \multirow{2}{*}{$\begin{array}{c}\text { Mean Difference } \\
\text { Fixed, } 95 \% \mathrm{Cl}\end{array}$} \\
\hline & $\mathbf{N}$ & $\operatorname{Mean}(S D)$ & $\mathbf{N}$ & Mean(SD) & & & \\
\hline \multicolumn{8}{|c|}{ 1.11.1 Postnatal age $<24$ hours } \\
\hline Yeh 1984 & 29 & $-2.4(3.5)$ & 27 & $-1.1(2.1)$ & & $69.25 \%$ & $-1.3[-2.81,0.21]$ \\
\hline 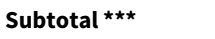 & 29 & & 27 & & & $69.25 \%$ & $-1.3[-2.81,0.21]$ \\
\hline \multicolumn{8}{|c|}{ Heterogeneity: Not applicable } \\
\hline \multicolumn{8}{|c|}{ Test for overall effect: $Z=1.69(P=0.09)$} \\
\hline \multicolumn{8}{|c|}{ 1.11.2 Postnatal age at least 24 hours } \\
\hline Green 1988 & 35 & $-6.8(5)$ & 34 & $-6(4.6)$ & I & $30.75 \%$ & $-0.85[-3.11,1.41]$ \\
\hline Subtotal ${ }^{\star \star \star}$ & 35 & & 34 & & & $30.75 \%$ & $-0.85[-3.11,1.41]$ \\
\hline \multicolumn{8}{|c|}{ Heterogeneity: Not applicable } \\
\hline \multicolumn{8}{|c|}{ Test for overall effect: $Z=0.74(P=0.46)$} \\
\hline \multicolumn{8}{|c|}{ Heterogeneity: $\operatorname{Tau}^{2}=0 ; \mathrm{Chi}^{2}=0.11, \mathrm{df}=1(\mathrm{P}=0.75) ; \mathrm{I}^{2}=0 \%$} \\
\hline \multicolumn{8}{|c|}{ Test for overall effect: $Z=1.81(P=0.07)$} \\
\hline \multicolumn{8}{|c|}{ Test for subgroup differences: $\mathrm{Chi}^{2}=0.11, \mathrm{df}=1(\mathrm{P}=0.75), \mathrm{I}^{2}=0 \%$} \\
\hline & & & Favo & Treatment & 0 & Favours & \\
\hline
\end{tabular}

Analysis 1.12. Comparison 1 Routine diuretic administration versus placebo, no treatment or PRN diuretic administration, Outcome 12 Duration of mechanical ventilation (days).

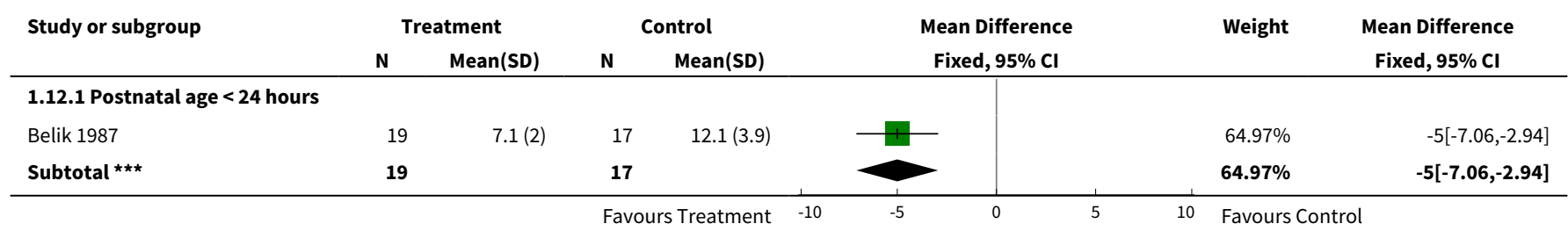




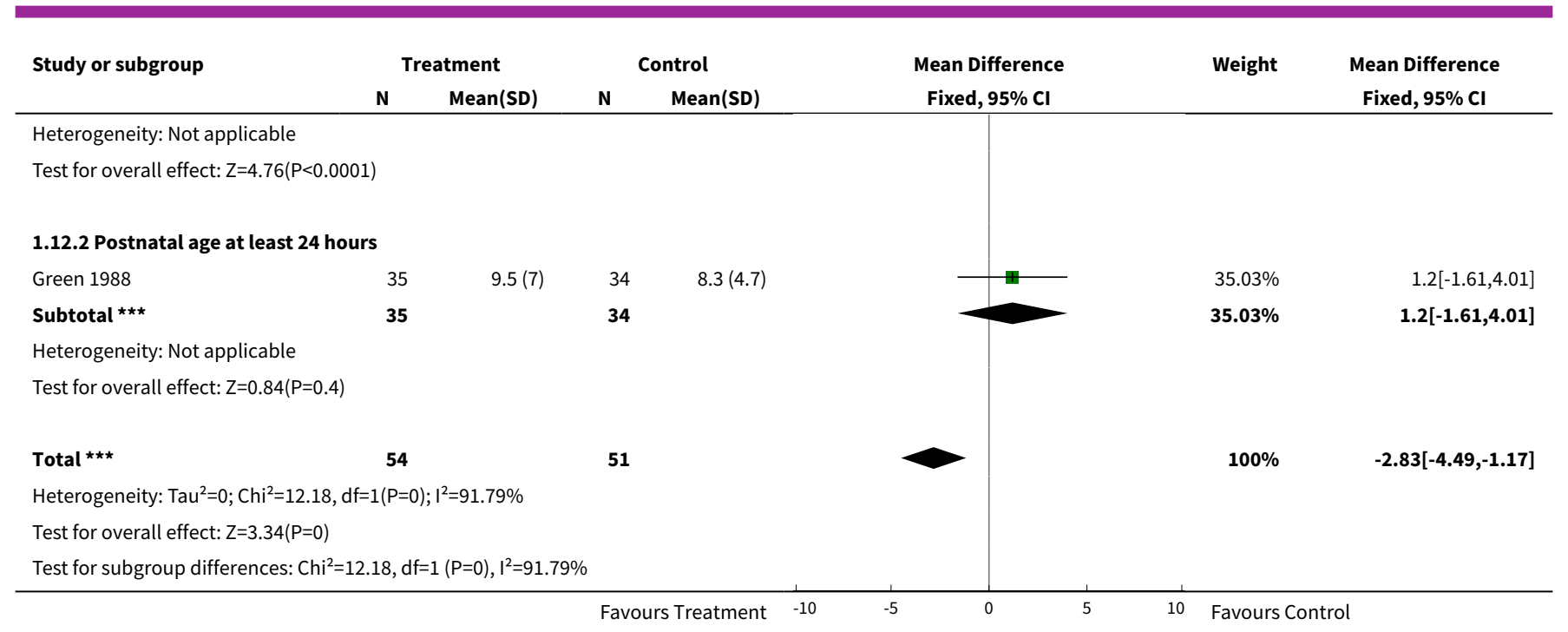

Analysis 1.13. Comparison 1 Routine diuretic administration versus placebo, no treatment or PRN diuretic administration, Outcome 13 Change in FiO2 during treatment.

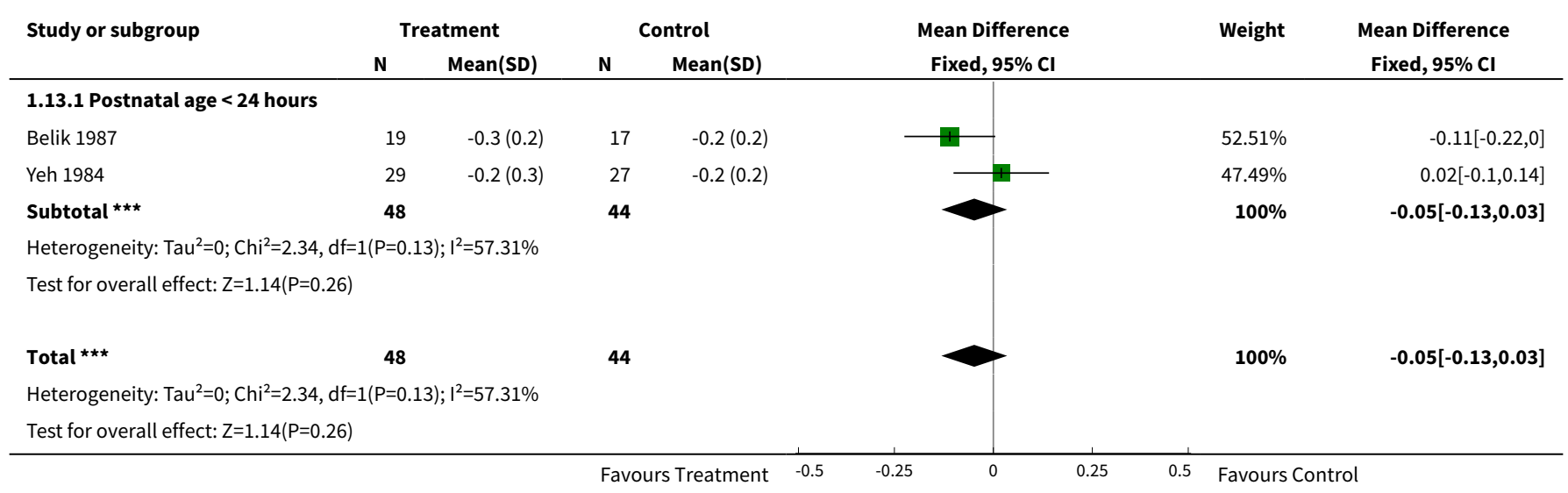

Analysis 1.14. Comparison 1 Routine diuretic administration versus placebo, no treatment or PRN diuretic administration, Outcome 14 Change in alveolar-arterial 02 gradient ( $\mathrm{mm} \mathrm{Hg}$ ) during treatment.

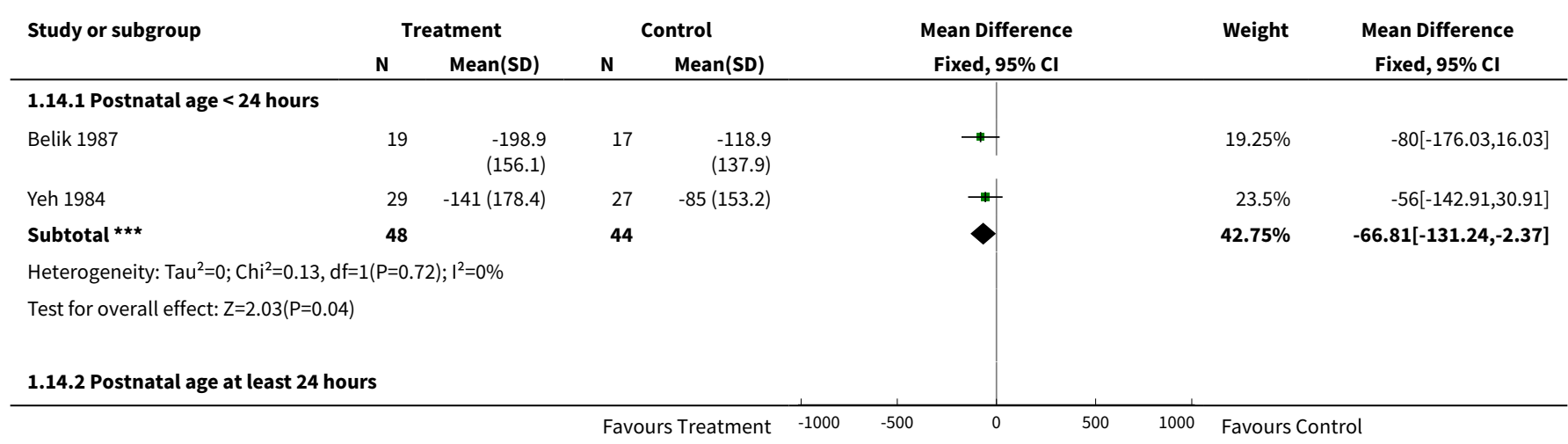




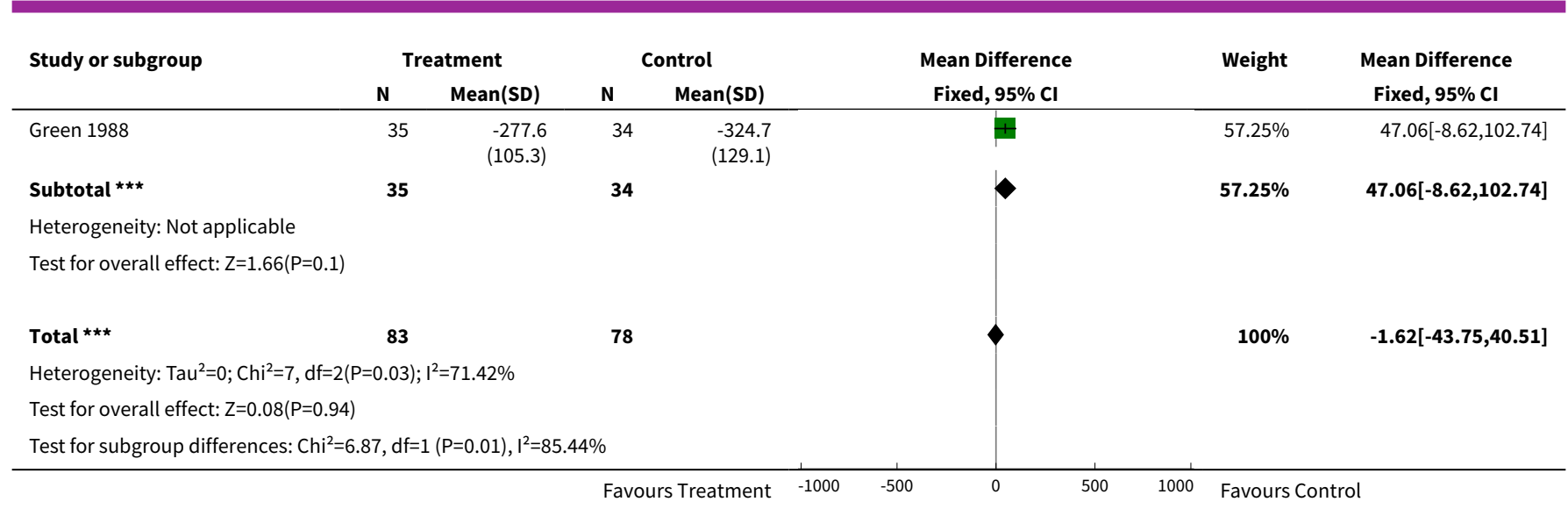

Analysis 1.15. Comparison 1 Routine diuretic administration versus placebo, no treatment or PRN diuretic administration, Outcome 15 BPD.

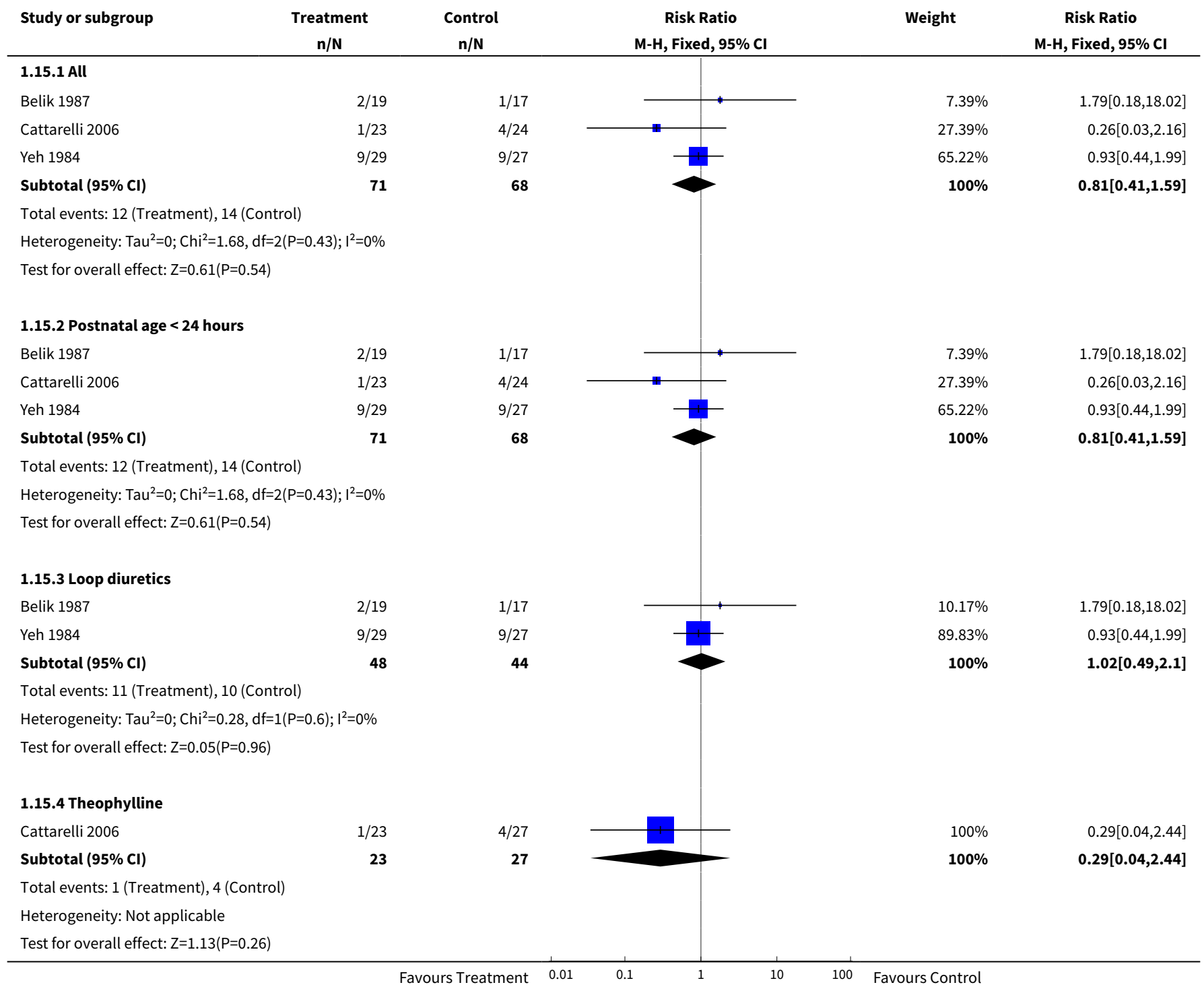


Analysis 1.16. Comparison 1 Routine diuretic administration versus placebo, no treatment or PRN diuretic administration, Outcome 16 Death or BPD.

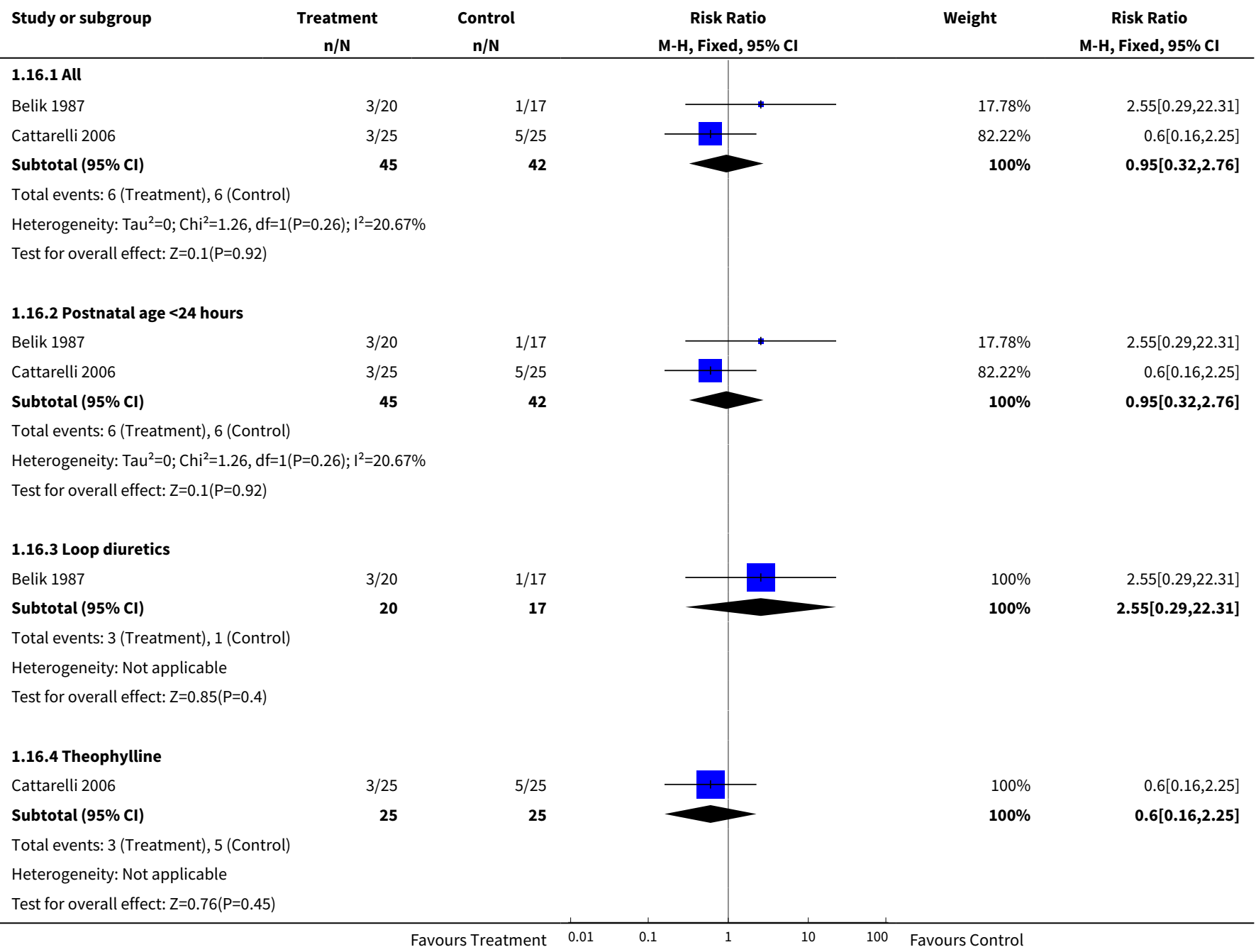

Analysis 1.17. Comparison 1 Routine diuretic administration versus placebo, no treatment or PRN diuretic administration, Outcome 17 Duration of oxygen supplementation (days).

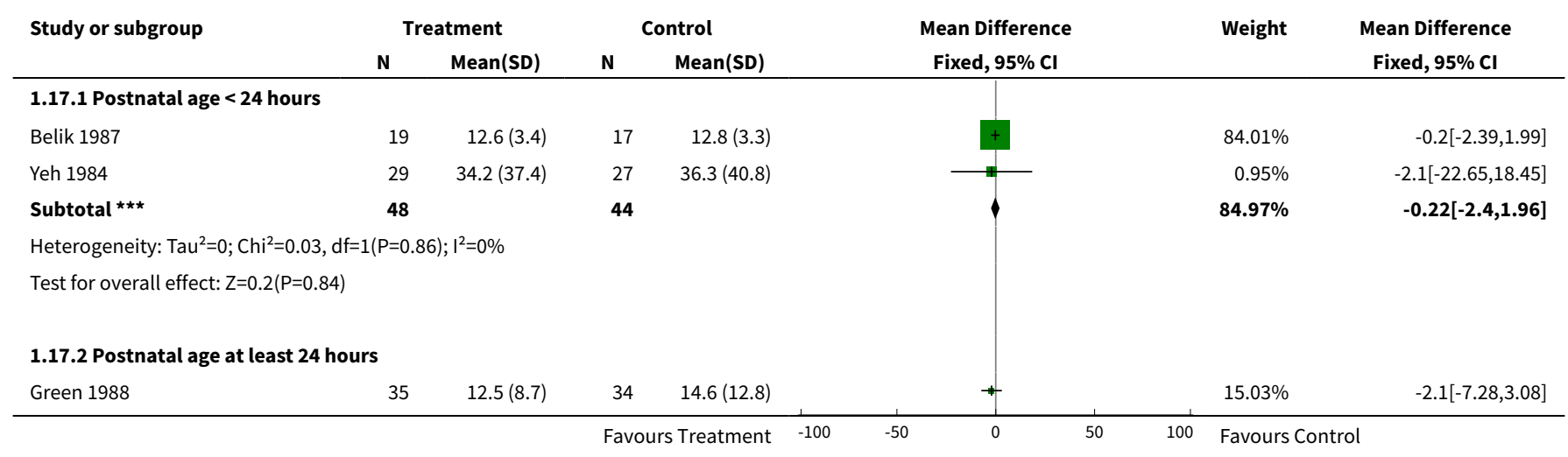




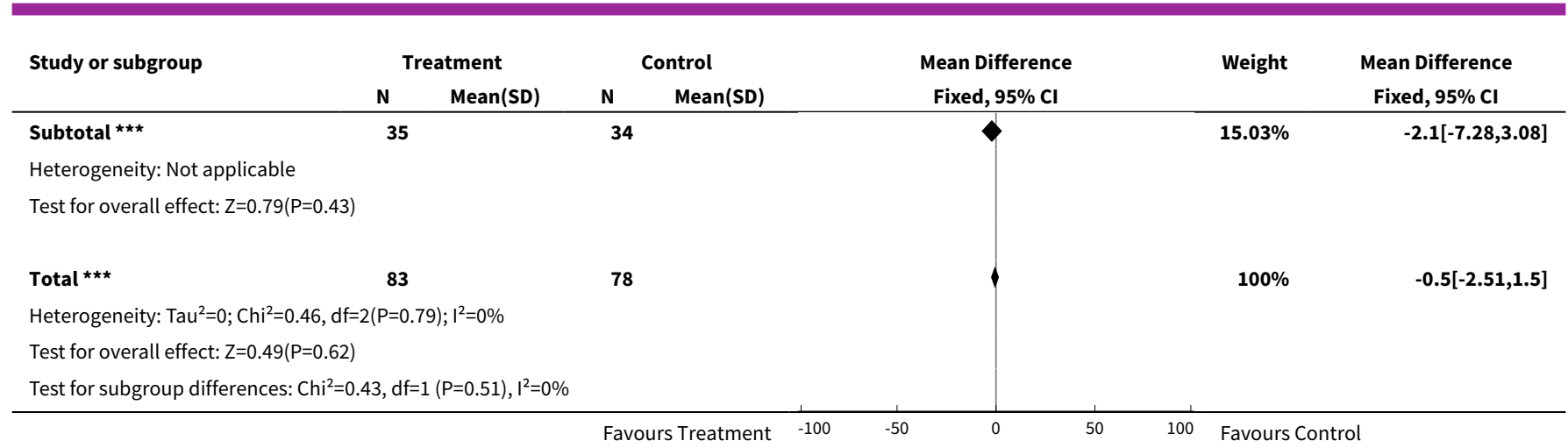

Analysis 1.18. Comparison 1 Routine diuretic administration versus placebo, no treatment or PRN diuretic administration, Outcome 18 IVH.

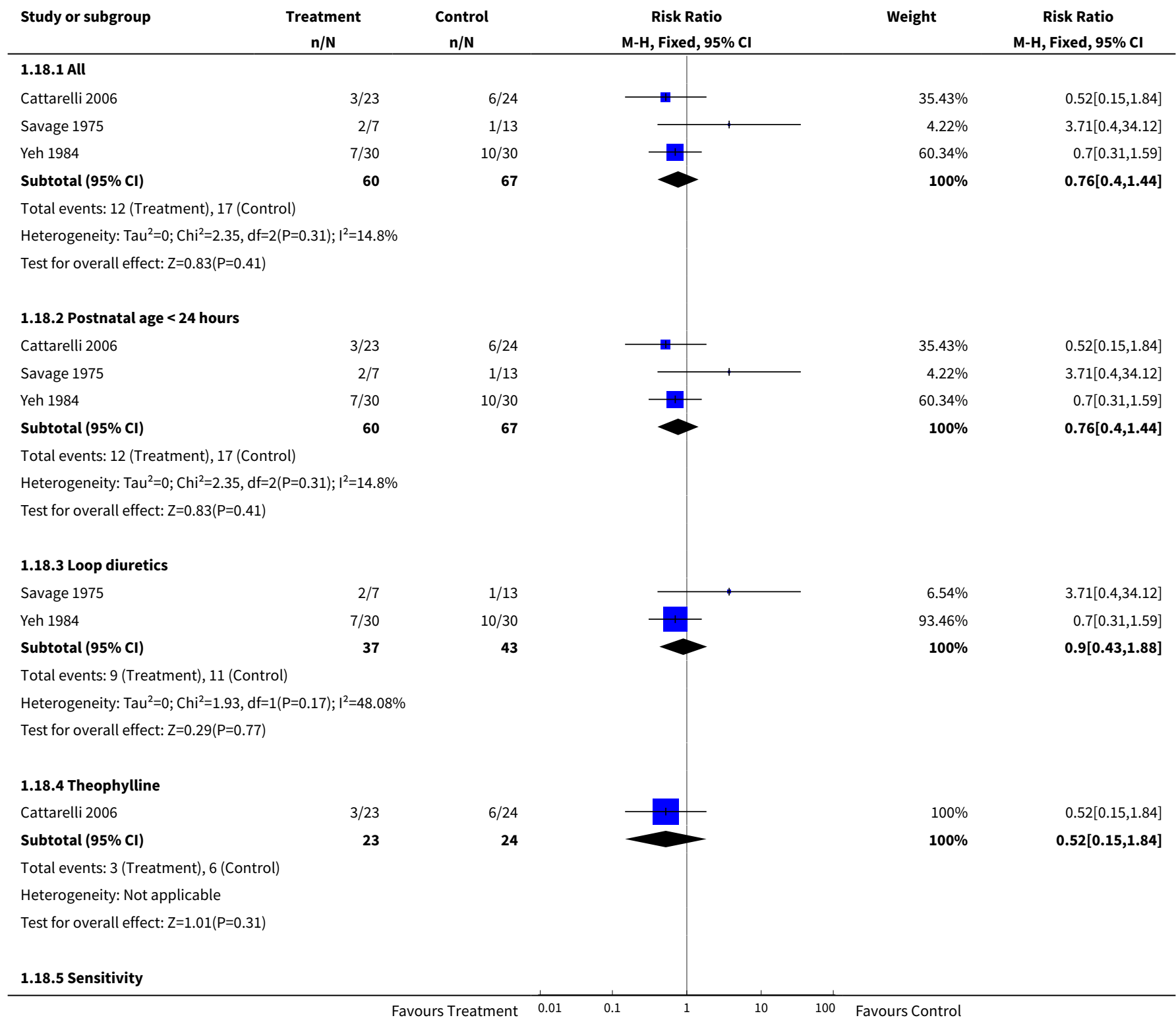




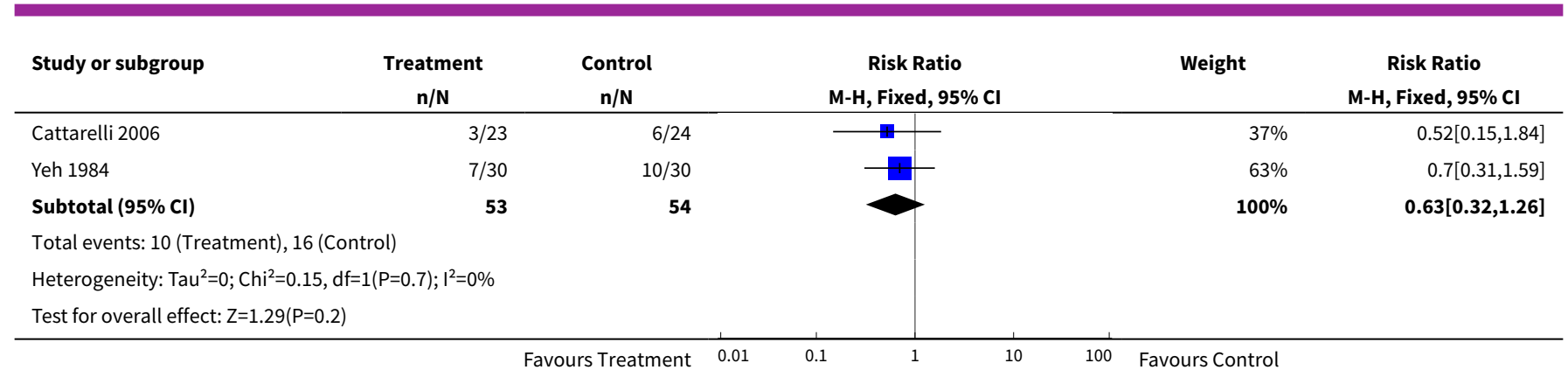

Analysis 1.19. Comparison 1 Routine diuretic administration versus placebo, no treatment or PRN diuretic administration, Outcome 19 Severe IVH (grade III or IV).

\begin{tabular}{|c|c|c|c|c|c|}
\hline Study or subgroup & $\begin{array}{c}\text { Treatment } \\
\mathrm{n} / \mathrm{N}\end{array}$ & $\begin{array}{c}\text { Control } \\
n / N\end{array}$ & $\begin{array}{c}\text { Risk Ratio } \\
\text { M-H, Fixed, 95\% Cl }\end{array}$ & Weight & $\begin{array}{c}\text { Risk Ratio } \\
\text { M-H, Fixed, 95\% Cl }\end{array}$ \\
\hline \multicolumn{6}{|l|}{ 1.19.1 All studies } \\
\hline Cattarelli 2006 & $1 / 23$ & $1 / 24$ & & $100 \%$ & $1.04[0.07,15.72]$ \\
\hline Subtotal $(95 \% \mathrm{CI})$ & 23 & 24 & & $100 \%$ & $1.04[0.07,15.72]$ \\
\hline \multicolumn{6}{|c|}{ Total events: 1 (Treatment), 1 (Control) } \\
\hline \multicolumn{6}{|c|}{ Heterogeneity: Not applicable } \\
\hline \multicolumn{6}{|c|}{ Test for overall effect: $Z=0.03(P=0.98)$} \\
\hline Total $(95 \% \mathrm{Cl})$ & 23 & 24 & & $100 \%$ & $1.04[0.07,15.72]$ \\
\hline \multicolumn{6}{|c|}{ Total events: 1 (Treatment), 1 (Control) } \\
\hline \multicolumn{6}{|c|}{ Heterogeneity: Not applicable } \\
\hline Test for overall effect & & & & & \\
\hline
\end{tabular}

Analysis 1.20. Comparison 1 Routine diuretic administration versus placebo, no treatment or PRN diuretic administration, Outcome 20 Duration of hospitalization (days).

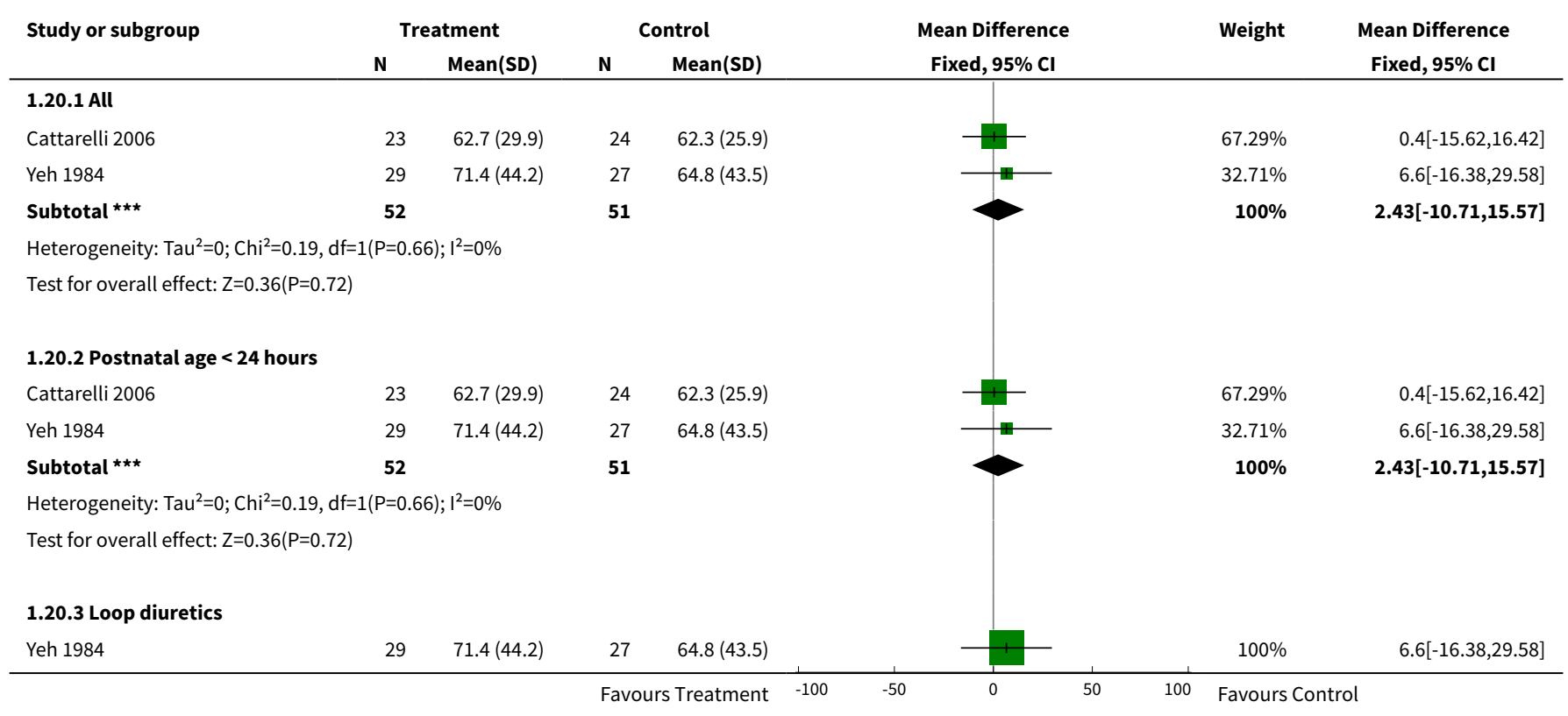




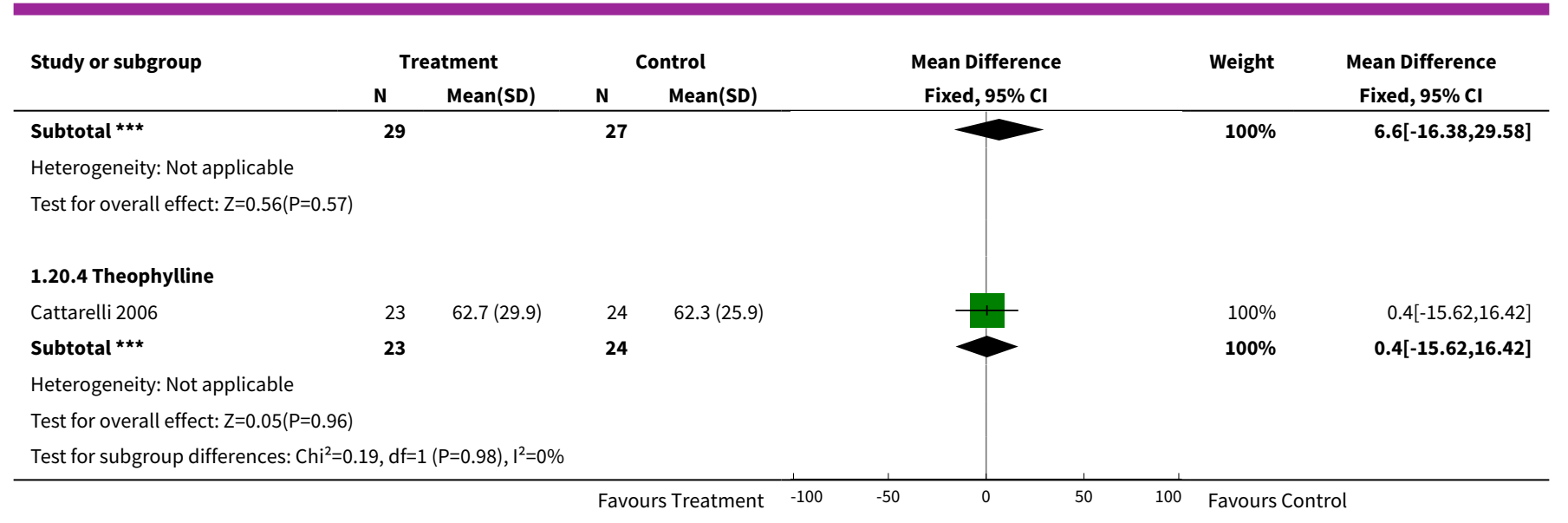

Analysis 1.21. Comparison 1 Routine diuretic administration versus placebo, no treatment or PRN diuretic administration, Outcome 21 Significant handicap at one year (major neurologic defect and/or MDI/PDI <50).

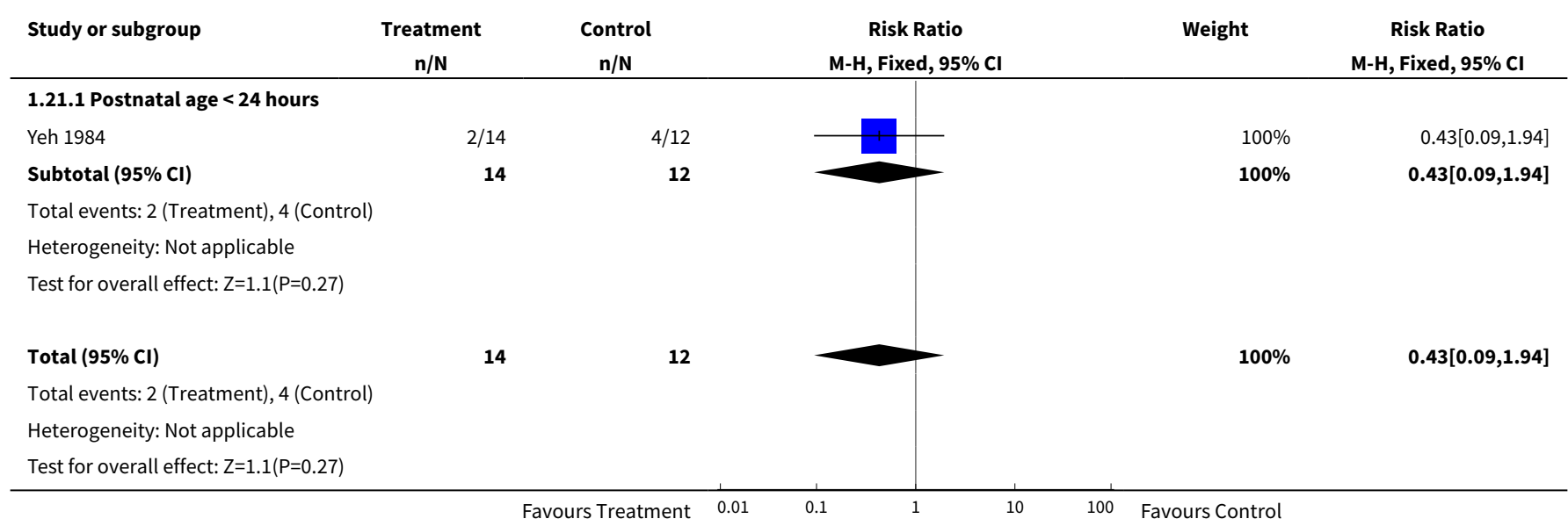

\section{Analysis 1.22. Comparison 1 Routine diuretic administration versus placebo, no treatment or PRN diuretic administration, Outcome 22 Oligoanuria (urine output $<1 \mathrm{ml} / \mathrm{kg} / \mathrm{hour}$ ).}

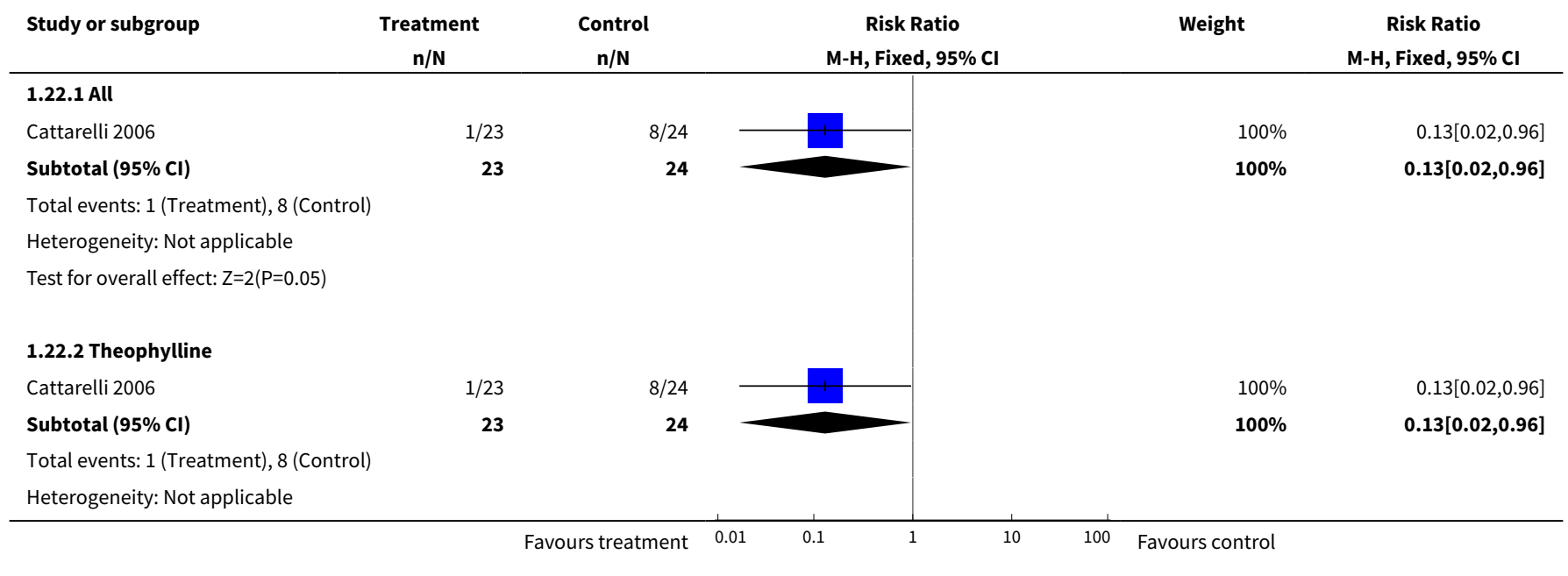




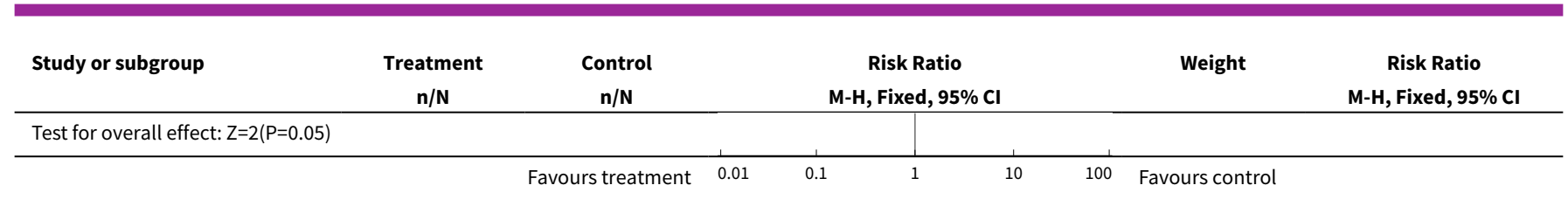

Analysis 1.23. Comparison 1 Routine diuretic administration versus placebo, no treatment or PRN diuretic administration, Outcome 23 Hyponatremia (sodium $<130 \mathrm{mM} / \mathrm{L}$ ).

\begin{tabular}{|c|c|c|c|c|c|}
\hline Study or subgroup & $\begin{array}{c}\text { Treatment } \\
\mathrm{n} / \mathrm{N}\end{array}$ & $\begin{array}{c}\text { Control } \\
\mathrm{n} / \mathrm{N}\end{array}$ & $\begin{array}{c}\text { Risk Ratio } \\
\text { M-H, Fixed, } 95 \% \mathrm{Cl} \\
\end{array}$ & Weight & $\begin{array}{c}\text { Risk Ratio } \\
\text { M-H, Fixed, } 95 \% \mathrm{Cl} \\
\end{array}$ \\
\hline \multicolumn{6}{|l|}{ 1.23.1 All } \\
\hline Cattarelli 2006 & $2 / 23$ & $2 / 24$ & 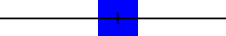 & $100 \%$ & $1.04[0.16,6.8]$ \\
\hline Subtotal $(95 \% \mathrm{Cl})$ & 23 & 24 & & $100 \%$ & $1.04[0.16,6.8]$ \\
\hline \multicolumn{6}{|c|}{ Total events: 2 (Treatment), 2 (Control) } \\
\hline \multicolumn{6}{|c|}{ Heterogeneity: Not applicable } \\
\hline \multicolumn{6}{|c|}{ Test for overall effect: $Z=0.04(P=0.96)$} \\
\hline Total $(95 \% \mathrm{Cl})$ & 23 & 24 & & $100 \%$ & $1.04[0.16,6.8]$ \\
\hline \multicolumn{6}{|c|}{ Total events: 2 (Treatment), 2 (Control) } \\
\hline \multicolumn{6}{|c|}{ Heterogeneity: Not applicable } \\
\hline Test for overall effect & & & & & \\
\hline
\end{tabular}

Analysis 1.24. Comparison 1 Routine diuretic administration versus placebo, no treatment or PRN diuretic administration, Outcome 24 Hyperkalemia (potassium $>6.5 \mathrm{mM} / \mathrm{L}$ ).

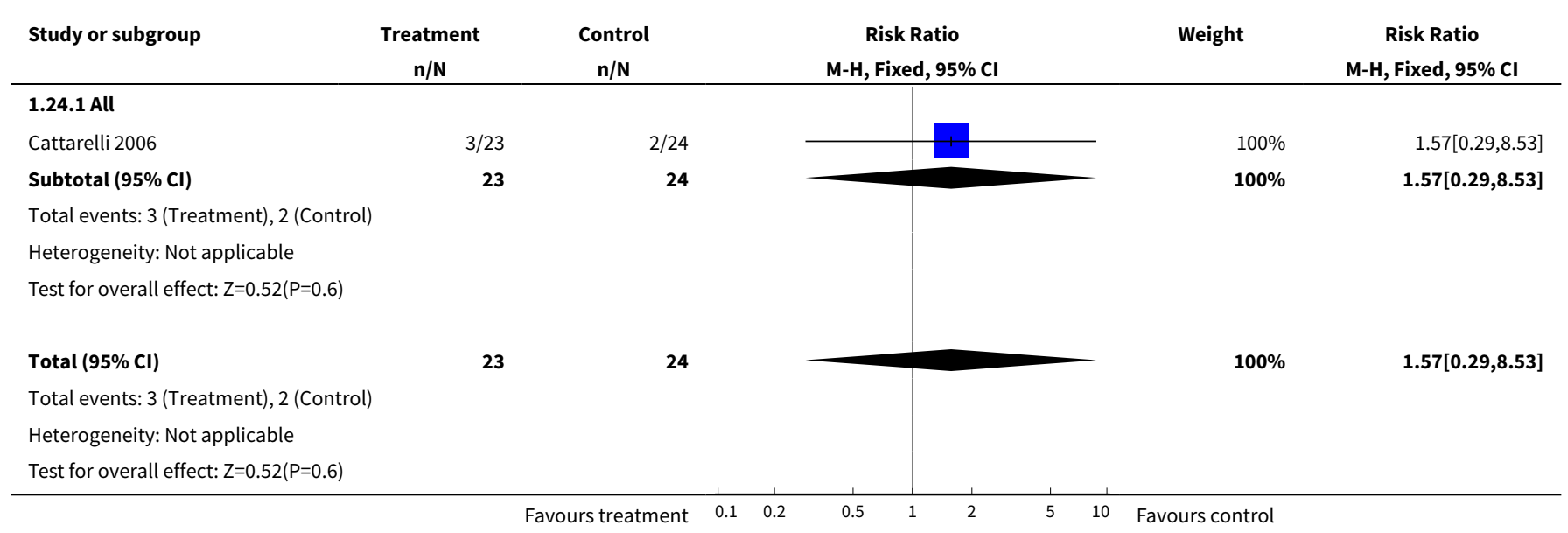


Comparison 2. Routine diuretic administration versus placebo or no treatment

\begin{tabular}{|c|c|c|c|c|}
\hline Outcome or subgroup title & $\begin{array}{l}\text { No. of } \\
\text { studies }\end{array}$ & $\begin{array}{l}\text { No. of } \\
\text { partici- } \\
\text { pants }\end{array}$ & Statistical method & Effect size \\
\hline 1 Death & 5 & & Risk Ratio (M-H, Fixed, 95\% Cl) & Subtotals only \\
\hline 1.1 All & 5 & 179 & Risk Ratio (M-H, Fixed, 95\% Cl) & $1.47[0.72,2.97]$ \\
\hline 1.2 Postnatal age $<24$ hours & 4 & 167 & Risk Ratio (M-H, Fixed, 95\% Cl) & $1.47[0.72,2.97]$ \\
\hline 1.3 Postnatal age at least 24 hours & 1 & 12 & Risk Ratio (M-H, Fixed, 95\% Cl) & $0.0[0.0,0.0]$ \\
\hline 1.4 Loop diuretics & 4 & 129 & Risk Ratio (M-H, Fixed, 95\% Cl) & $1.41[0.67,2.95]$ \\
\hline 1.5 Theophylline & 1 & 50 & Risk Ratio (M-H, Fixed, 95\% Cl) & $2.0[0.19,20.67]$ \\
\hline 2 Clinically significant PDA & 3 & & Risk Ratio (M-H, Fixed, 95\% Cl) & Subtotals only \\
\hline 2.1 All & 3 & 139 & Risk Ratio (M-H, Fixed, 95\% Cl) & $0.86[0.50,1.48]$ \\
\hline 2.2 Postnatal age $<24$ hours & 3 & 139 & Risk Ratio (M-H, Fixed, 95\% Cl) & $0.86[0.50,1.48]$ \\
\hline 2.3 Loop diuretics & 2 & 92 & Risk Ratio (M-H, Fixed, 95\% Cl) & $0.72[0.38,1.38]$ \\
\hline 2.4 Theophylline & 1 & 47 & Risk Ratio (M-H, Fixed, 95\% Cl) & $1.25[0.44,3.54]$ \\
\hline 3 Hypovolemic shock & 1 & 12 & Risk Ratio (M-H, Fixed, 95\% Cl) & $4.0[0.20,82.01]$ \\
\hline 3.1 Postnatal age at least 24 hours & 1 & 12 & Risk Ratio (M-H, Fixed, 95\% Cl) & $4.0[0.20,82.01]$ \\
\hline $\begin{array}{l}4 \text { Failure to extubate within } 3 \text { days after } \\
\text { study entry }\end{array}$ & 1 & 56 & Risk Ratio (M-H, Fixed, 95\% Cl) & $0.65[0.45,0.93]$ \\
\hline 4.1 Postnatal age $<24$ hours & 1 & 56 & Risk Ratio (M-H, Fixed, 95\% Cl) & $0.65[0.45,0.93]$ \\
\hline $\begin{array}{l}5 \text { Change in peak inspiratory pressure }(\mathrm{cm} \\
\mathrm{H} 2 \mathrm{O}) \text { during treatment }\end{array}$ & 1 & 36 & $\begin{array}{l}\text { Mean Difference (IV, Fixed, 95\% } \\
\mathrm{Cl})\end{array}$ & $-6.62[-14.74,1.50]$ \\
\hline 5.1 Postnatal age $<24$ hours & 1 & 36 & $\begin{array}{l}\text { Mean Difference (IV, Fixed, 95\% } \\
\mathrm{CI} \text { ) }\end{array}$ & $-6.62[-14.74,1.50]$ \\
\hline $\begin{array}{l}6 \text { Change in mean airway pressure }(\mathrm{cm} \\
\mathrm{H} 2 \mathrm{O}) \text { during treatment }\end{array}$ & 1 & 56 & $\begin{array}{l}\text { Mean Difference (IV, Fixed, 95\% } \\
\mathrm{CI} \text { ) }\end{array}$ & $-1.30[-2.81,0.21]$ \\
\hline 6.1 Postnatal age $<24$ hours & 1 & 56 & $\begin{array}{l}\text { Mean Difference (IV, Fixed, 95\% } \\
\mathrm{Cl})\end{array}$ & $-1.30[-2.81,0.21]$ \\
\hline $\begin{array}{l}7 \text { Duration of mechanical ventilation } \\
\text { (days) }\end{array}$ & 1 & 36 & $\begin{array}{l}\text { Mean Difference (IV, Fixed, 95\% } \\
\mathrm{Cl})\end{array}$ & $-5.0[-7.06,-2.94]$ \\
\hline 7.1 Postnatal age $<24$ hours & 1 & 36 & $\begin{array}{l}\text { Mean Difference (IV, Fixed, 95\% } \\
\mathrm{CI} \text { ) }\end{array}$ & $-5.0[-7.06,-2.94]$ \\
\hline 8 Change in $\mathrm{FiO} 2$ during treatment & 2 & 92 & $\begin{array}{l}\text { Mean Difference (IV, Fixed, 95\% } \\
\text { Cl) }\end{array}$ & $-0.05[-0.13,0.03]$ \\
\hline
\end{tabular}




\begin{tabular}{|c|c|c|c|c|}
\hline Outcome or subgroup title & $\begin{array}{l}\text { No. of } \\
\text { studies }\end{array}$ & $\begin{array}{l}\text { No. of } \\
\text { partici- } \\
\text { pants }\end{array}$ & Statistical method & Effect size \\
\hline 8.1 Postnatal age $<24$ hours & 2 & 92 & $\begin{array}{l}\text { Mean Difference (IV, Fixed, 95\% } \\
\mathrm{CI})\end{array}$ & $-0.05[-0.13,0.03]$ \\
\hline $\begin{array}{l}9 \text { Change in alveolar-arterial } 02 \text { gradient } \\
(\mathrm{mm} \mathrm{Hg}) \text { during treatment }\end{array}$ & 2 & 92 & $\begin{array}{l}\text { Mean Difference (IV, Fixed, 95\% } \\
\mathrm{CI} \text { ) }\end{array}$ & $-66.81[-131.24,-2.37]$ \\
\hline 9.1 Postnatal age $<24$ hours & 2 & 92 & $\begin{array}{l}\text { Mean Difference (IV, Fixed, 95\% } \\
\mathrm{CI} \text { ) }\end{array}$ & $-66.81[-131.24,-2.37]$ \\
\hline $10 \mathrm{BPD}$ & 3 & & Risk Ratio (M-H, Fixed, 95\% Cl) & Subtotals only \\
\hline 10.1 All & 3 & 139 & Risk Ratio (M-H, Fixed, 95\% Cl) & $0.81[0.41,1.59]$ \\
\hline 10.2 Postnatal age $<24$ hours & 3 & 139 & Risk Ratio (M-H, Fixed, 95\% Cl) & $0.81[0.41,1.59]$ \\
\hline 10.3 Loop diuretics & 2 & 92 & Risk Ratio (M-H, Fixed, 95\% Cl) & $1.02[0.49,2.10]$ \\
\hline 10.4 Theophylline & 1 & 47 & Risk Ratio (M-H, Fixed, 95\% Cl) & $0.26[0.03,2.16]$ \\
\hline 11 Death or BPD & 2 & & Risk Ratio (M-H, Fixed, 95\% Cl) & Subtotals only \\
\hline 11.1 All & 2 & 87 & Risk Ratio (M-H, Fixed, 95\% Cl) & $0.95[0.32,2.76]$ \\
\hline 11.2 Postnatal age $<24$ hours & 2 & 87 & Risk Ratio (M-H, Fixed, 95\% Cl) & $0.95[0.32,2.76]$ \\
\hline 11.3 Loop diuretics & 1 & 37 & Risk Ratio (M-H, Fixed, 95\% Cl) & $2.55[0.29,22.31]$ \\
\hline 11.4 Theophylline & 1 & 50 & Risk Ratio (M-H, Fixed, 95\% Cl) & $0.6[0.16,2.25]$ \\
\hline $\begin{array}{l}12 \text { Duration of oxygen supplementation } \\
\text { (days) }\end{array}$ & 2 & 92 & $\begin{array}{l}\text { Mean Difference (IV, Fixed, 95\% } \\
\mathrm{CI})\end{array}$ & $-0.22[-2.40,1.96]$ \\
\hline 12.1 Postnatal age $<24$ hours & 2 & 92 & $\begin{array}{l}\text { Mean Difference (IV, Fixed, 95\% } \\
\mathrm{CI} \text { ) }\end{array}$ & $-0.22[-2.40,1.96]$ \\
\hline $13 \mathrm{IVH}$ & 3 & & Risk Ratio (M-H, Fixed, 95\% Cl) & Subtotals only \\
\hline 13.1 All & 3 & 127 & Risk Ratio (M-H, Fixed, 95\% Cl) & $0.76[0.40,1.44]$ \\
\hline 13.2 Postnatal age $<24$ hours & 3 & 127 & Risk Ratio (M-H, Fixed, 95\% Cl) & $0.76[0.40,1.44]$ \\
\hline 13.3 Loop diuretics & 2 & 80 & Risk Ratio (M-H, Fixed, 95\% Cl) & $0.90[0.43,1.88]$ \\
\hline 13.4 Theophylline & 1 & 47 & Risk Ratio (M-H, Fixed, 95\% Cl) & $0.52[0.15,1.84]$ \\
\hline 14 Severe IVH (grade III or IV) & 1 & 47 & Risk Ratio (M-H, Fixed, 95\% Cl) & $1.04[0.07,15.72]$ \\
\hline 14.1 All & 1 & 47 & Risk Ratio (M-H, Fixed, 95\% Cl) & $1.04[0.07,15.72]$ \\
\hline 15 Duration of hospitalization (days) & 2 & & $\begin{array}{l}\text { Mean Difference (IV, Fixed, 95\% } \\
\mathrm{Cl} \text { ) }\end{array}$ & Subtotals only \\
\hline
\end{tabular}




\begin{tabular}{|c|c|c|c|c|}
\hline Outcome or subgroup title & $\begin{array}{l}\text { No. of } \\
\text { studies }\end{array}$ & $\begin{array}{l}\text { No. of } \\
\text { partici- } \\
\text { pants }\end{array}$ & Statistical method & Effect size \\
\hline 15.1 All & 2 & 103 & $\begin{array}{l}\text { Mean Difference (IV, Fixed, 95\% } \\
\mathrm{CI})\end{array}$ & $2.43[-10.71,15.57]$ \\
\hline 15.2 Postnatal age $<24$ hours & 2 & 103 & $\begin{array}{l}\text { Mean Difference (IV, Fixed, 95\% } \\
\mathrm{Cl} \text { ) }\end{array}$ & $2.43[-10.71,15.57]$ \\
\hline 15.3 Loop diuretics & 1 & 56 & $\begin{array}{l}\text { Mean Difference (IV, Fixed, 95\% } \\
\mathrm{CI} \text { ) }\end{array}$ & $6.60[-16.38,29.58]$ \\
\hline 15.4 Theophylline & 1 & 47 & $\begin{array}{l}\text { Mean Difference (IV, Fixed, 95\% } \\
\mathrm{CI} \text { ) }\end{array}$ & $0.40[-15.62,16.42]$ \\
\hline $\begin{array}{l}16 \text { Significant handicap at one year (ma- } \\
\text { jor neurologic defect and/or MDI/PDI <50) }\end{array}$ & 1 & 26 & Risk Ratio (M-H, Fixed, 95\% Cl) & $0.43[0.09,1.94]$ \\
\hline 16.1 Postnatal age $<24$ hours & 1 & 26 & Risk Ratio (M-H, Fixed, 95\% Cl) & $0.43[0.09,1.94]$ \\
\hline $\begin{array}{l}17 \text { Oligoanuria (urine output }<1 \mathrm{ml} / \mathrm{kg} \text { / } \\
\text { hour) }\end{array}$ & 1 & & Risk Ratio (M-H, Fixed, 95\% Cl) & Subtotals only \\
\hline 17.1 All & 1 & 47 & Risk Ratio (M-H, Fixed, 95\% Cl) & $0.13[0.02,0.96]$ \\
\hline 17.2 Theophylline & 1 & 47 & Risk Ratio (M-H, Fixed, 95\% Cl) & $0.13[0.02,0.96]$ \\
\hline 18 Hyponatremia (sodium < $130 \mathrm{mM} / \mathrm{L}$ ) & 1 & 47 & Risk Ratio (M-H, Fixed, 95\% Cl) & $1.04[0.16,6.80]$ \\
\hline 18.1 All & 1 & 47 & Risk Ratio (M-H, Fixed, 95\% Cl) & $1.04[0.16,6.80]$ \\
\hline 19 Hyperkalemia (potassium > 6.5 mM/L) & 1 & 47 & Risk Ratio (M-H, Fixed, 95\% Cl) & $1.57[0.29,8.53]$ \\
\hline 19.1 All & 1 & 47 & Risk Ratio (M-H, Fixed, 95\% Cl) & $1.57[0.29,8.53]$ \\
\hline
\end{tabular}

\section{Analysis 2.1. Comparison 2 Routine diuretic administration versus placebo or no treatment, Outcome 1 Death.}

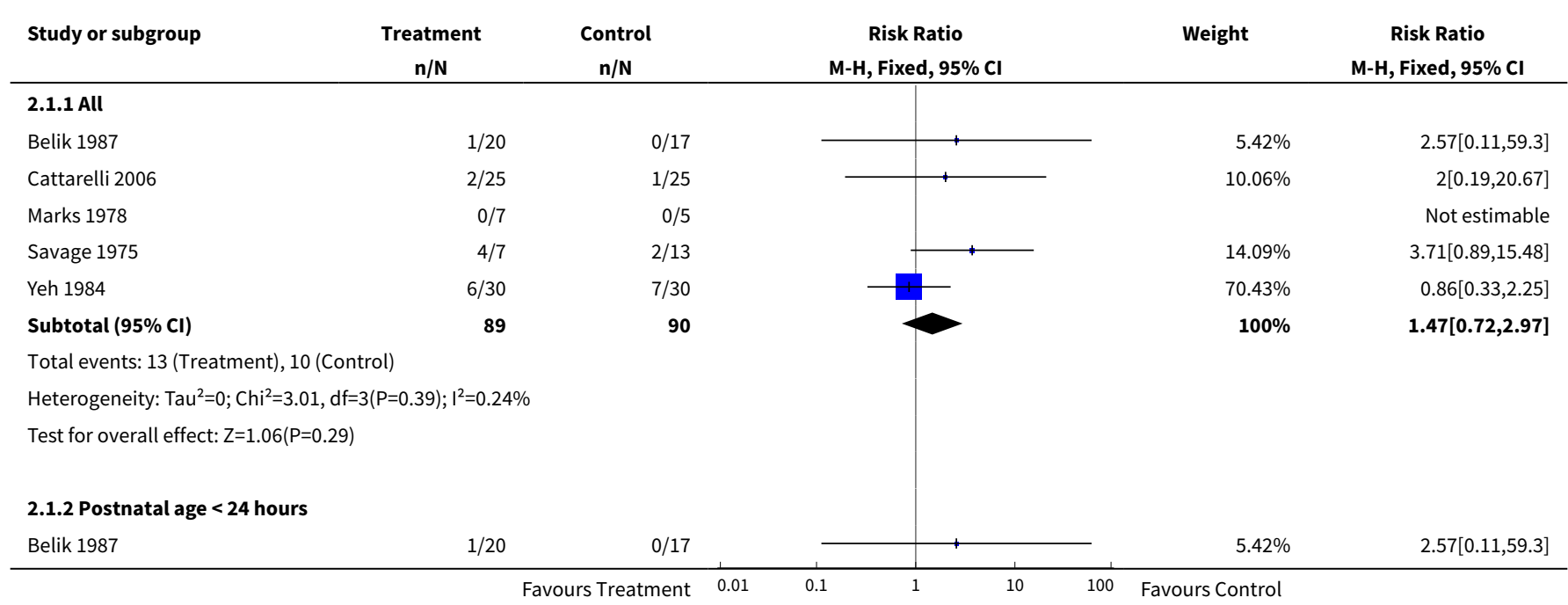




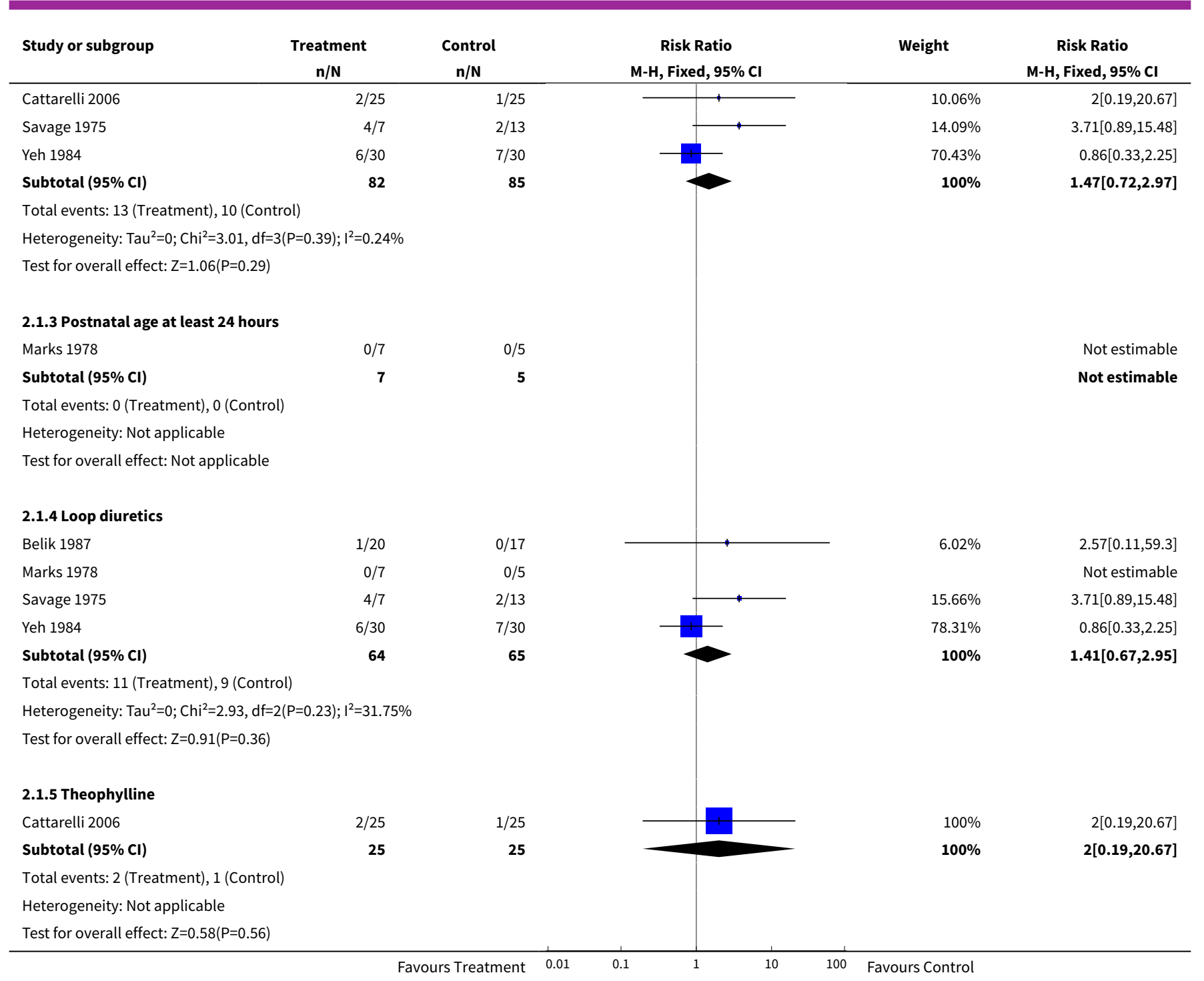

Analysis 2.2. Comparison 2 Routine diuretic administration versus placebo or no treatment, Outcome 2 Clinically significant PDA.

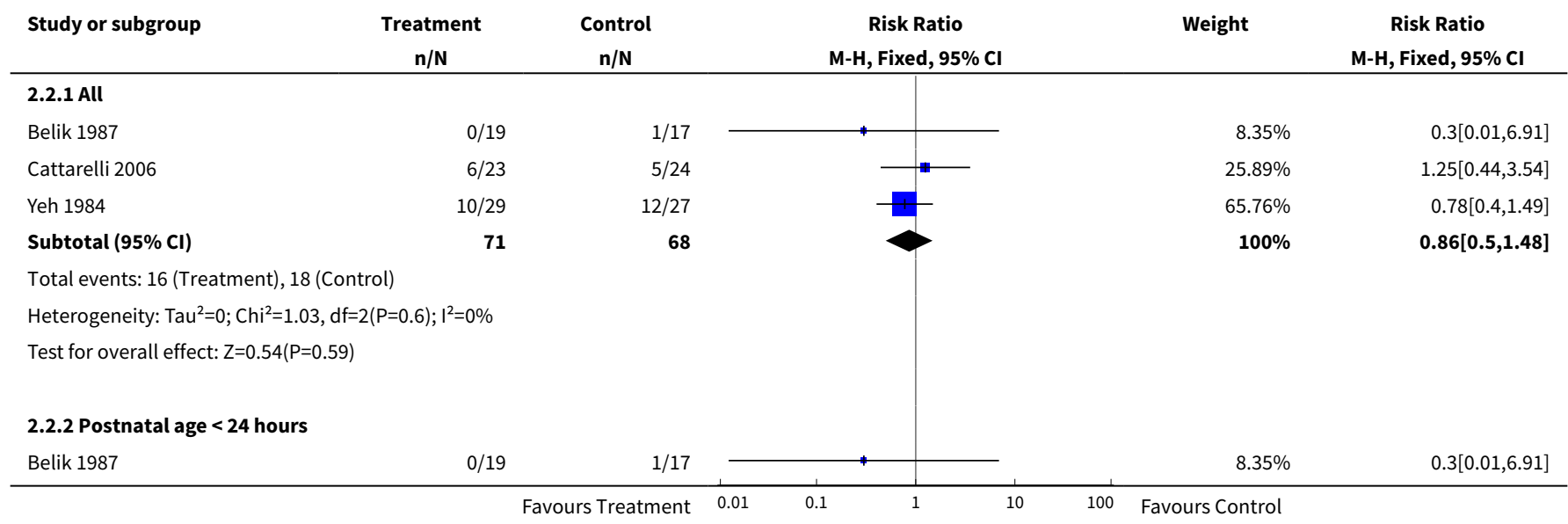




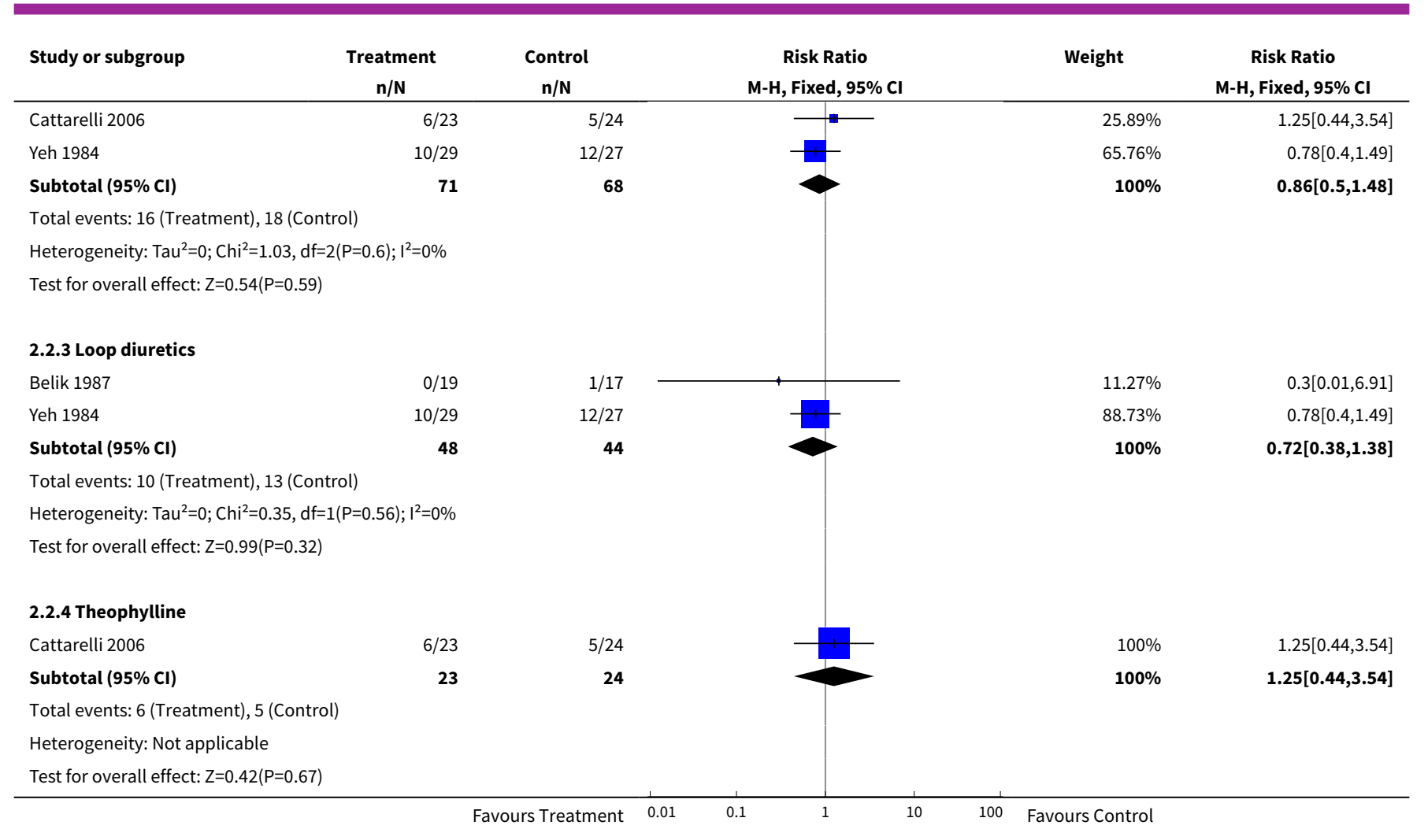

Analysis 2.3. Comparison 2 Routine diuretic administration versus placebo or no treatment, Outcome 3 Hypovolemic shock.

\begin{tabular}{|c|c|c|c|c|c|}
\hline Study or subgroup & $\begin{array}{l}\text { Treatment } \\
\mathrm{n} / \mathrm{N}\end{array}$ & $\begin{array}{c}\text { Control } \\
n / N\end{array}$ & $\begin{array}{c}\text { Risk Ratio } \\
\text { M-H, Fixed, } 95 \% \mathrm{Cl}\end{array}$ & Weight & $\begin{array}{c}\text { Risk Ratio } \\
\text { M-H, Fixed, 95\% Cl }\end{array}$ \\
\hline \multicolumn{6}{|c|}{ 2.3.1 Postnatal age at least 24 hours } \\
\hline Marks 1978 & $1 / 5$ & $0 / 7$ & & $100 \%$ & $4[0.2,82.01]$ \\
\hline Subtotal $(95 \% \mathrm{Cl})$ & 5 & 7 & & $100 \%$ & $4[0.2,82.01]$ \\
\hline \multicolumn{6}{|c|}{ Total events: 1 (Treatment), 0 (Control) } \\
\hline \multicolumn{6}{|c|}{ Heterogeneity: Not applicable } \\
\hline \multicolumn{6}{|c|}{ Test for overall effect: $Z=0.9(P=0.37)$} \\
\hline Total $(95 \% \mathrm{Cl})$ & 5 & 7 & & $100 \%$ & $4[0.2,82.01]$ \\
\hline \multicolumn{6}{|c|}{ Total events: 1 (Treatment), 0 (Control) } \\
\hline \multicolumn{6}{|c|}{ Heterogeneity: Not applicable } \\
\hline Test for overall effect & & & & & \\
\hline
\end{tabular}

Analysis 2.4. Comparison 2 Routine diuretic administration versus placebo or no treatment, Outcome 4 Failure to extubate within 3 days after study entry.

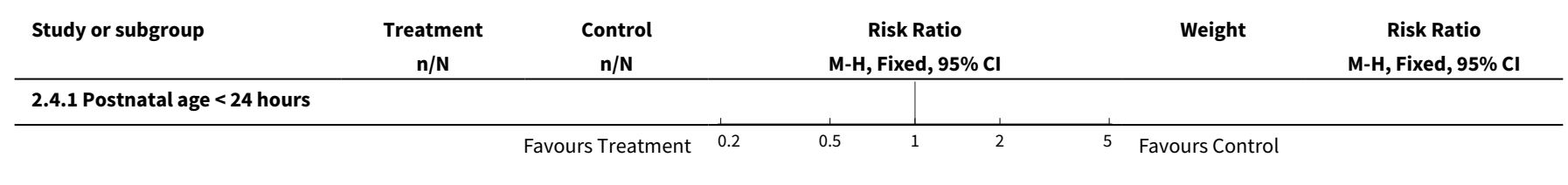




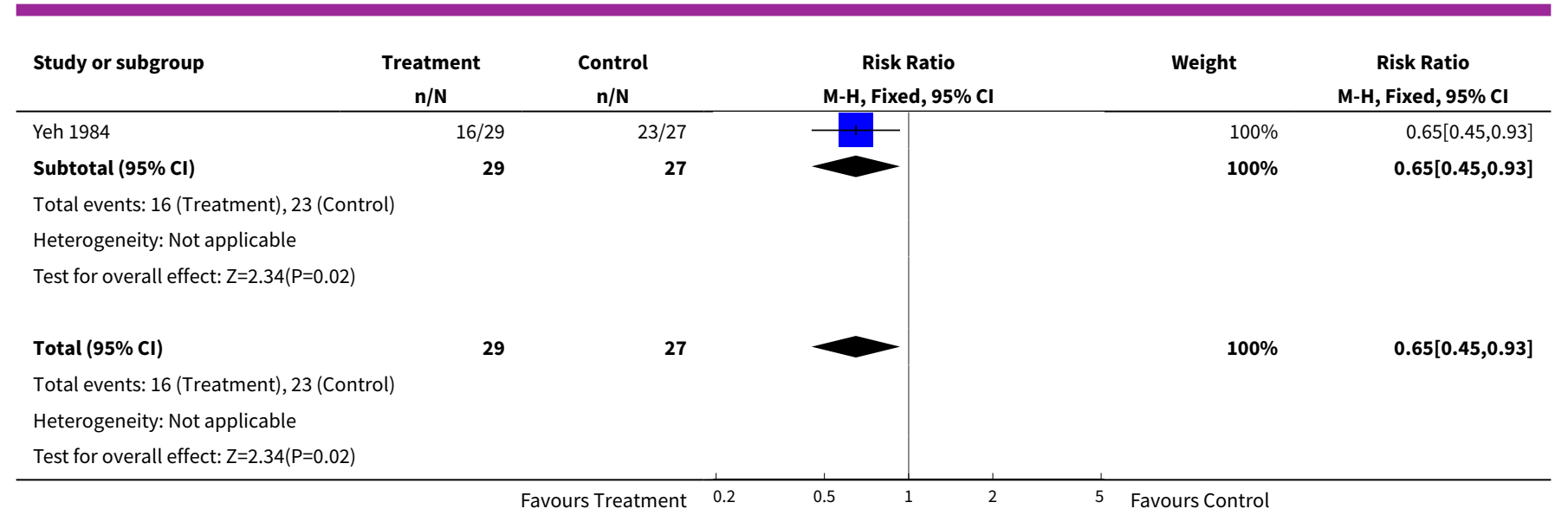

Analysis 2.5. Comparison 2 Routine diuretic administration versus placebo or no treatment, Outcome 5 Change in peak inspiratory pressure $(\mathrm{cm} \mathrm{H2O})$ during treatment.

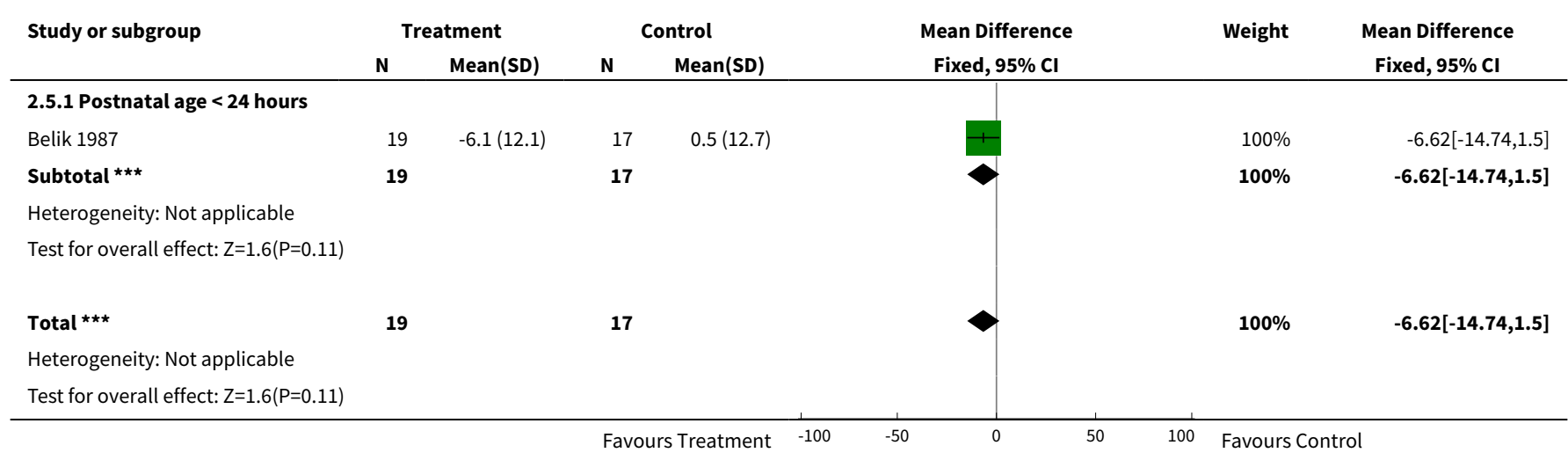

Analysis 2.6. Comparison 2 Routine diuretic administration versus placebo or no treatment, Outcome 6 Change in mean airway pressure $(\mathrm{cm} \mathrm{H2O})$ during treatment.

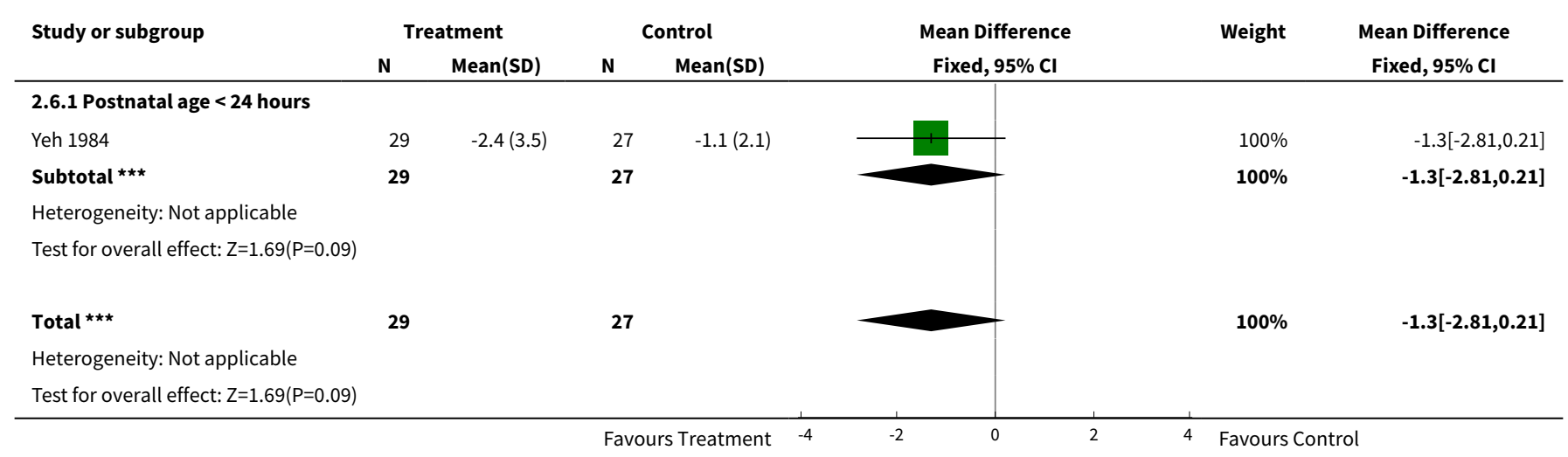


Analysis 2.7. Comparison 2 Routine diuretic administration versus placebo or no treatment, Outcome 7 Duration of mechanical ventilation (days).

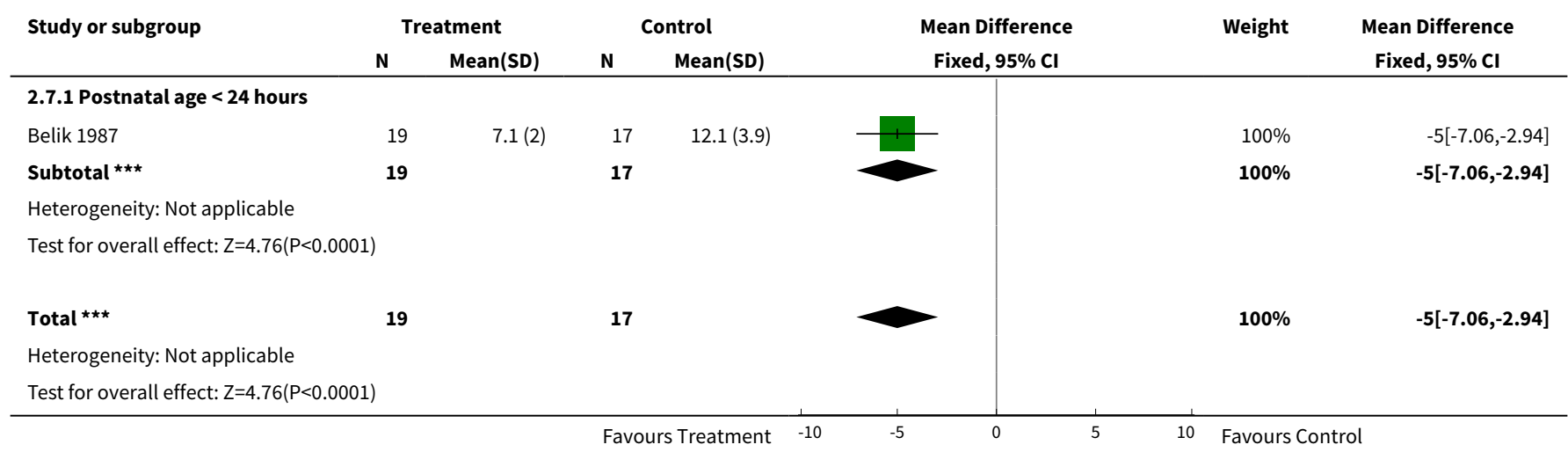

Analysis 2.8. Comparison 2 Routine diuretic administration versus placebo or no treatment, Outcome 8 Change in FiO2 during treatment.

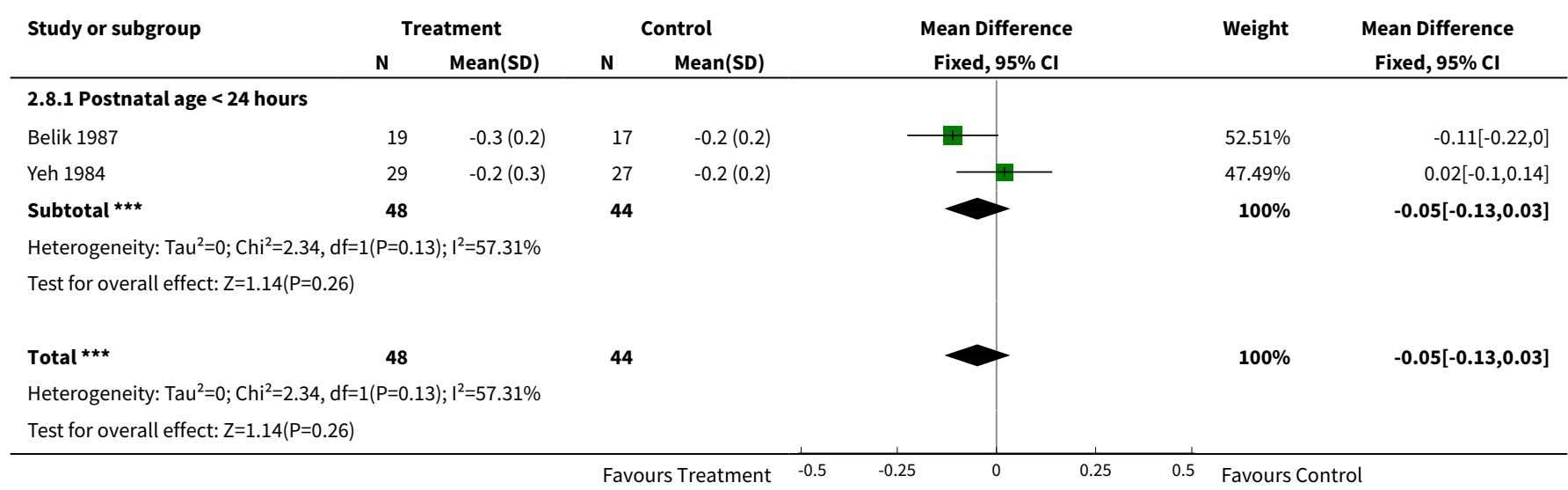

Analysis 2.9. Comparison 2 Routine diuretic administration versus placebo or no treatment, Outcome 9 Change in alveolar-arterial 02 gradient $(\mathrm{mm} \mathrm{Hg})$ during treatment.

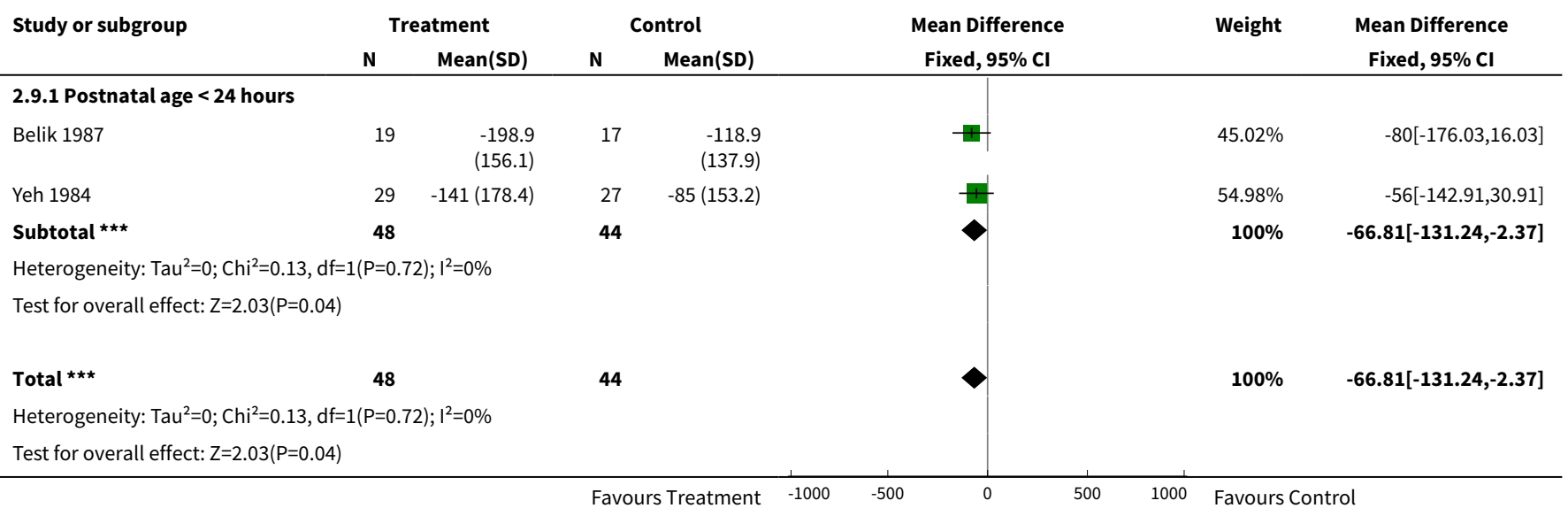


Analysis 2.10. Comparison 2 Routine diuretic administration versus placebo or no treatment, Outcome 10 BPD.

\begin{tabular}{|c|c|c|c|c|c|}
\hline Study or subgroup & $\begin{array}{c}\text { Treatment } \\
\mathrm{n} / \mathrm{N}\end{array}$ & $\begin{array}{c}\text { Control } \\
\mathrm{n} / \mathrm{N}\end{array}$ & $\begin{array}{c}\text { Risk Ratio } \\
\text { M-H, Fixed, } 95 \% \mathrm{Cl}\end{array}$ & Weight & $\begin{array}{c}\text { Risk Ratio } \\
\text { M-H, Fixed, } 95 \% \mathrm{Cl} \\
\end{array}$ \\
\hline \multicolumn{6}{|l|}{ 2.10.1 All } \\
\hline Belik 1987 & $2 / 19$ & $1 / 17$ & $\rightarrow$ & $7.39 \%$ & $1.79[0.18,18.02]$ \\
\hline Cattarelli 2006 & $1 / 23$ & $4 / 24$ & $\longrightarrow$ & $27.39 \%$ & $0.26[0.03,2.16]$ \\
\hline Yeh 1984 & $9 / 29$ & $9 / 27$ & & $65.22 \%$ & $0.93[0.44,1.99]$ \\
\hline Subtotal $(95 \% \mathrm{Cl})$ & 71 & 68 & & $100 \%$ & $0.81[0.41,1.59]$ \\
\hline \multicolumn{6}{|c|}{ Total events: 12 (Treatment), 14 (Control) } \\
\hline \multicolumn{6}{|c|}{ Heterogeneity: Tau $^{2}=0 ; \mathrm{Chi}^{2}=1.68, \mathrm{df}=2(\mathrm{P}=0.43) ; \mathrm{I}^{2}=0 \%$} \\
\hline \multicolumn{6}{|c|}{ Test for overall effect: $Z=0.61(P=0.54)$} \\
\hline \multicolumn{6}{|c|}{ 2.10.2 Postnatal age $<24$ hours } \\
\hline Belik 1987 & $2 / 19$ & $1 / 17$ & . & $7.39 \%$ & $1.79[0.18,18.02]$ \\
\hline Cattarelli 2006 & $1 / 23$ & $4 / 24$ & & $27.39 \%$ & $0.26[0.03,2.16]$ \\
\hline Yeh 1984 & $9 / 29$ & 9/27 & & $65.22 \%$ & $0.93[0.44,1.99]$ \\
\hline Subtotal $(95 \% \mathrm{Cl})$ & 71 & 68 & & $100 \%$ & $0.81[0.41,1.59]$ \\
\hline \multicolumn{6}{|c|}{ Total events: 12 (Treatment), 14 (Control) } \\
\hline \multicolumn{6}{|c|}{ Heterogeneity: $\operatorname{Tau}^{2}=0 ; \mathrm{Chi}^{2}=1.68, \mathrm{df}=2(\mathrm{P}=0.43) ; 1^{2}=0 \%$} \\
\hline \multicolumn{6}{|c|}{ Test for overall effect: $Z=0.61(P=0.54)$} \\
\hline \multicolumn{6}{|c|}{ 2.10.3 Loop diuretics } \\
\hline Belik 1987 & $2 / 19$ & $1 / 17$ & ' & $10.17 \%$ & $1.79[0.18,18.02]$ \\
\hline Yeh 1984 & $9 / 29$ & $9 / 27$ & $\vdash$ & $89.83 \%$ & $0.93[0.44,1.99]$ \\
\hline Subtotal $(95 \% \mathrm{Cl})$ & 48 & 44 & $>$ & $100 \%$ & $1.02[0.49,2.1]$ \\
\hline \multicolumn{6}{|c|}{ Total events: 11 (Treatment), 10 (Control) } \\
\hline \multicolumn{6}{|c|}{ Heterogeneity: Tau $^{2}=0 ; \mathrm{Chi}^{2}=0.28, \mathrm{df}=1(\mathrm{P}=0.6) ; I^{2}=0 \%$} \\
\hline \multicolumn{6}{|c|}{ Test for overall effect: $Z=0.05(P=0.96)$} \\
\hline \multicolumn{6}{|l|}{ 2.10.4 Theophylline } \\
\hline Cattarelli 2006 & $1 / 23$ & $4 / 24$ & & $100 \%$ & $0.26[0.03,2.16]$ \\
\hline Subtotal $(95 \% \mathrm{Cl})$ & 23 & 24 & & $100 \%$ & $0.26[0.03,2.16]$ \\
\hline \multicolumn{6}{|c|}{ Total events: 1 (Treatment), 4 (Control) } \\
\hline \multicolumn{6}{|c|}{ Heterogeneity: Not applicable } \\
\hline Test for overall effec & & & & & \\
\hline
\end{tabular}

Analysis 2.11. Comparison 2 Routine diuretic administration versus placebo or no treatment, Outcome 11 Death or BPD.

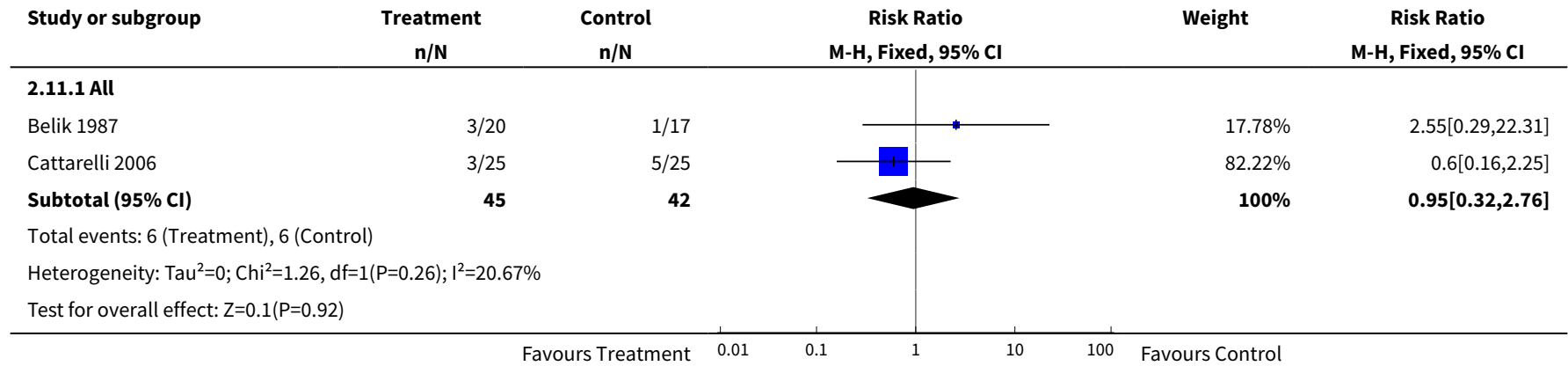




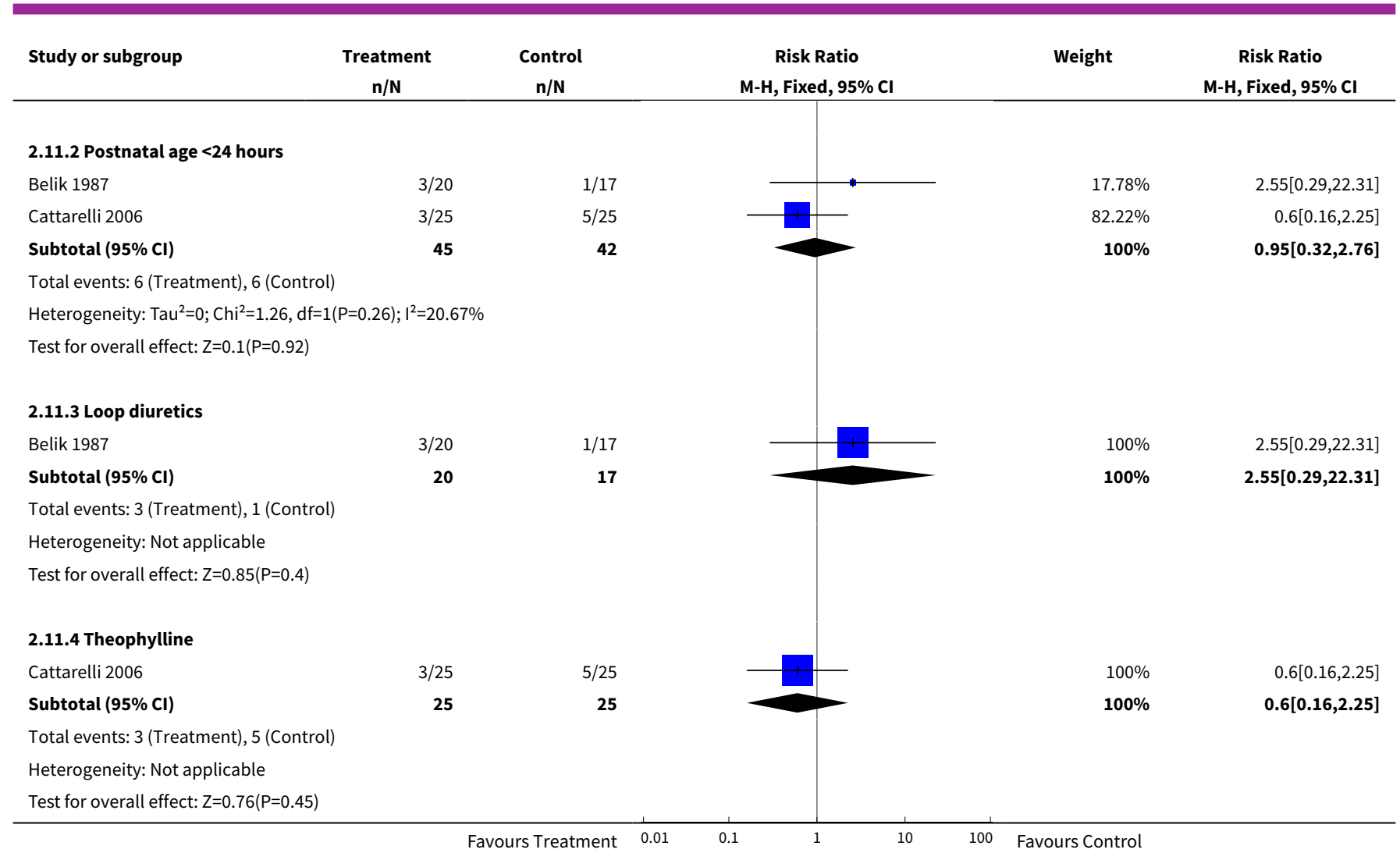

Analysis 2.12. Comparison 2 Routine diuretic administration versus placebo or no treatment, Outcome 12 Duration of oxygen supplementation (days).

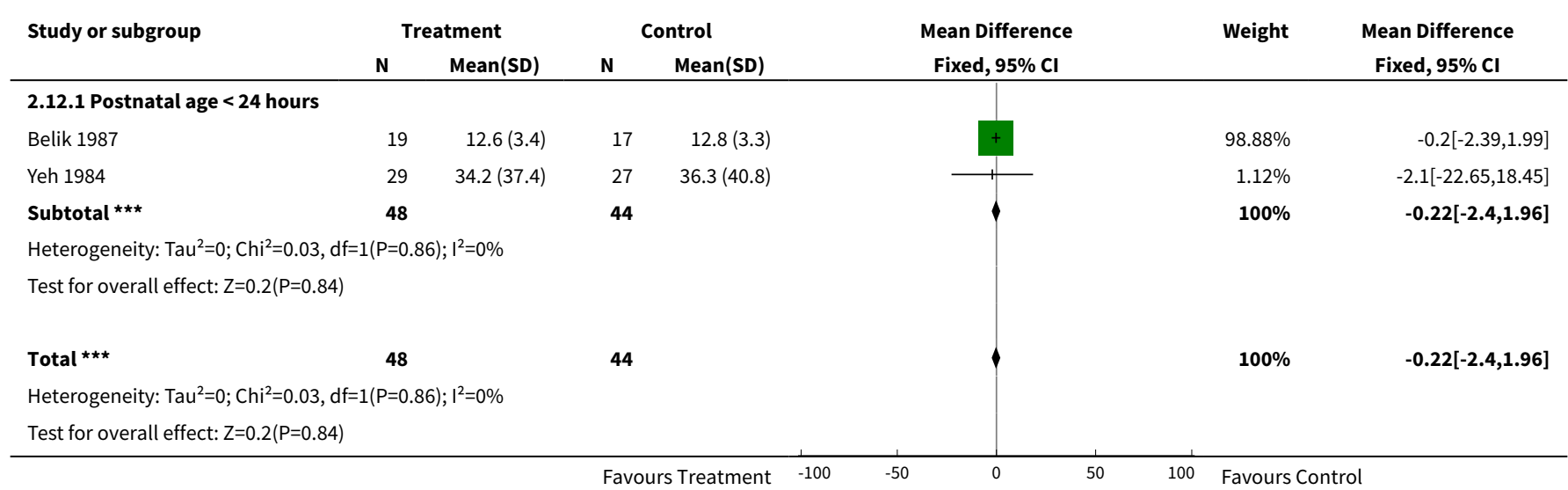

Analysis 2.13. Comparison 2 Routine diuretic administration versus placebo or no treatment, Outcome 13 IVH.

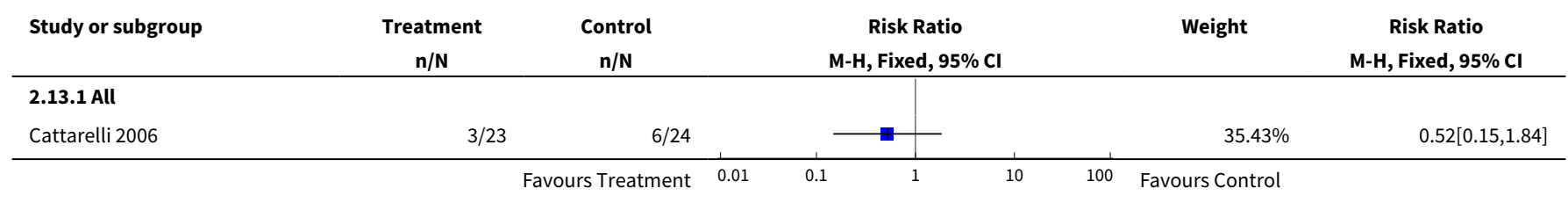




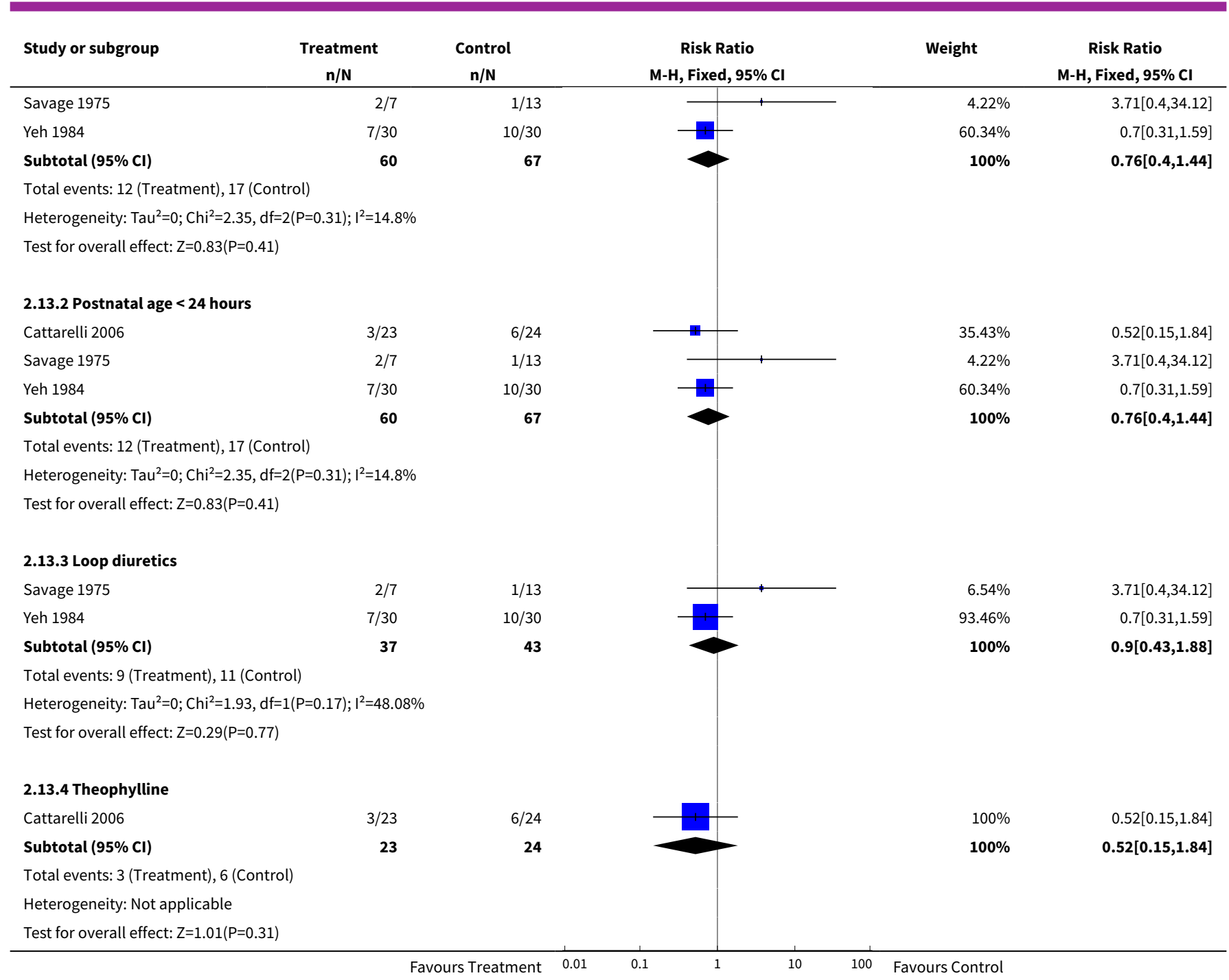

Analysis 2.14. Comparison 2 Routine diuretic administration versus placebo or no treatment, Outcome 14 Severe IVH (grade III or IV).

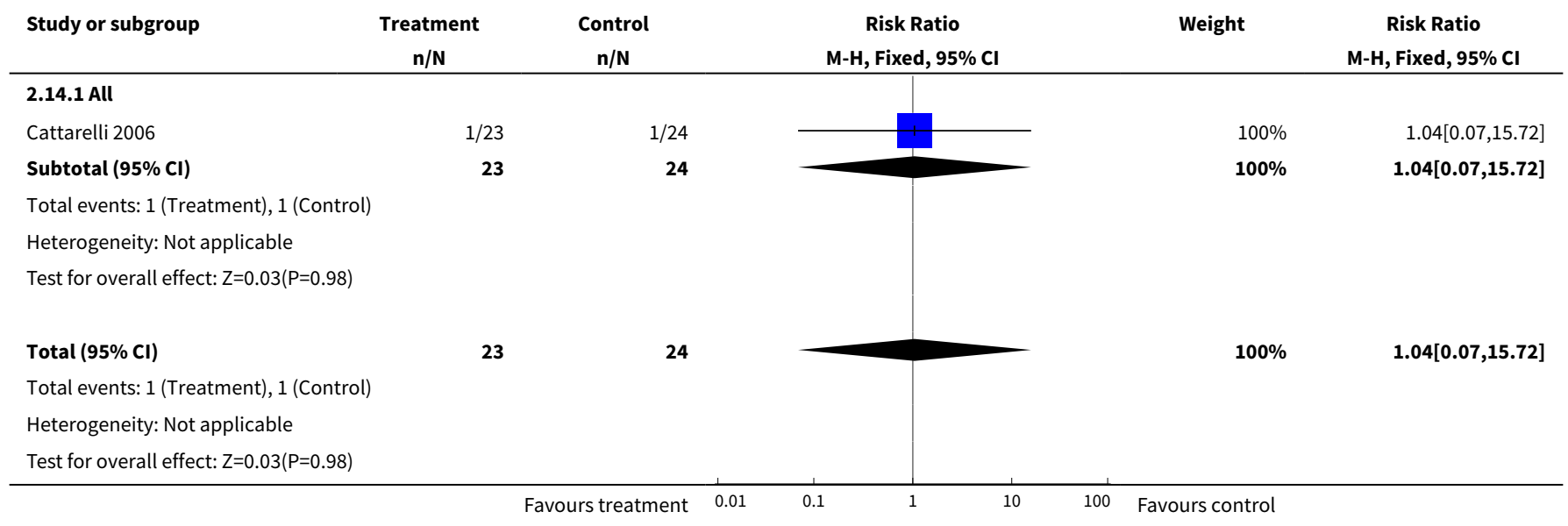


Analysis 2.15. Comparison 2 Routine diuretic administration versus placebo or no treatment, Outcome 15 Duration of hospitalization (days).

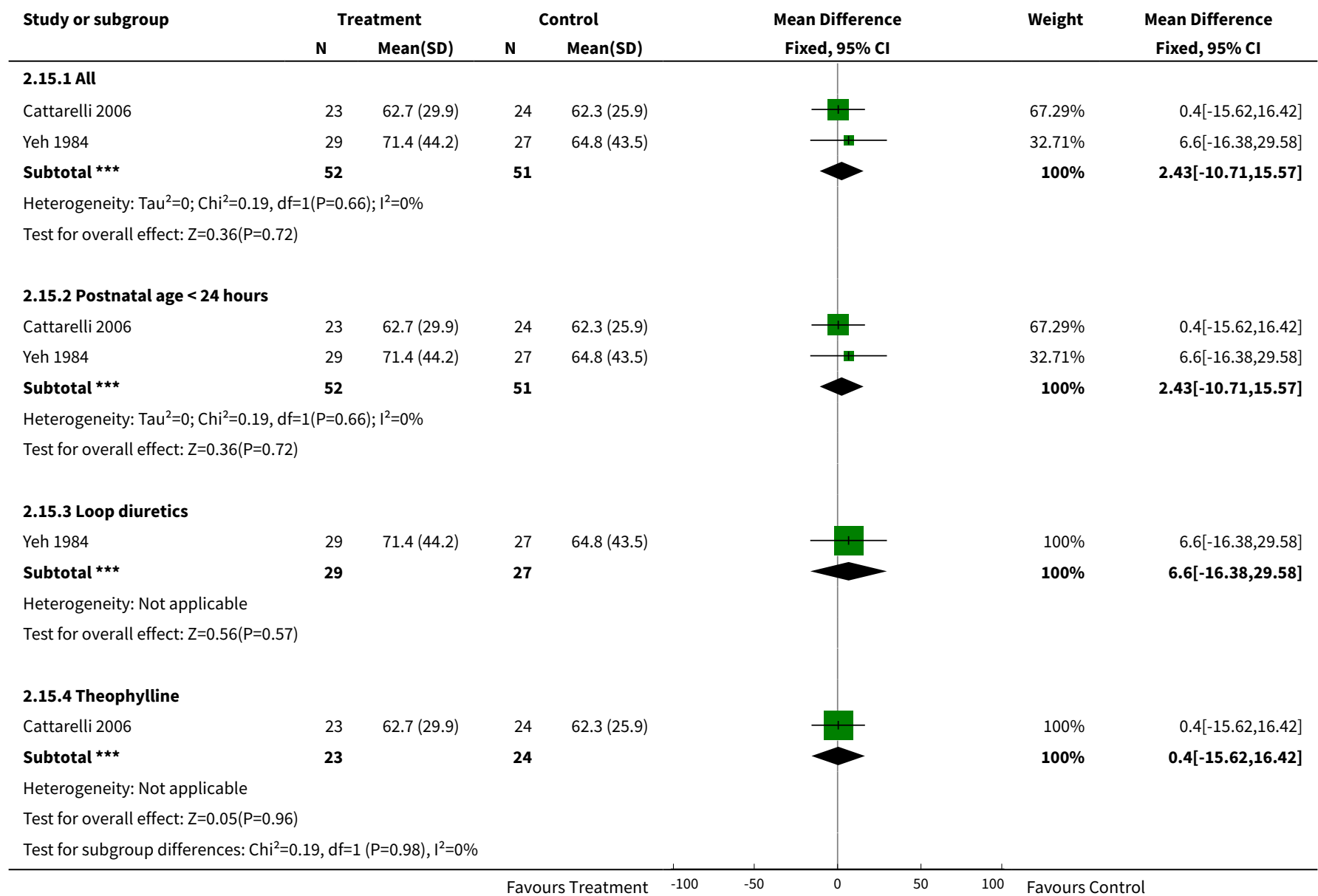

\section{Analysis 2.16. Comparison 2 Routine diuretic administration versus placebo or no treatment, Outcome 16 Significant handicap at one year (major neurologic defect and/or MDI/PDI <50).}

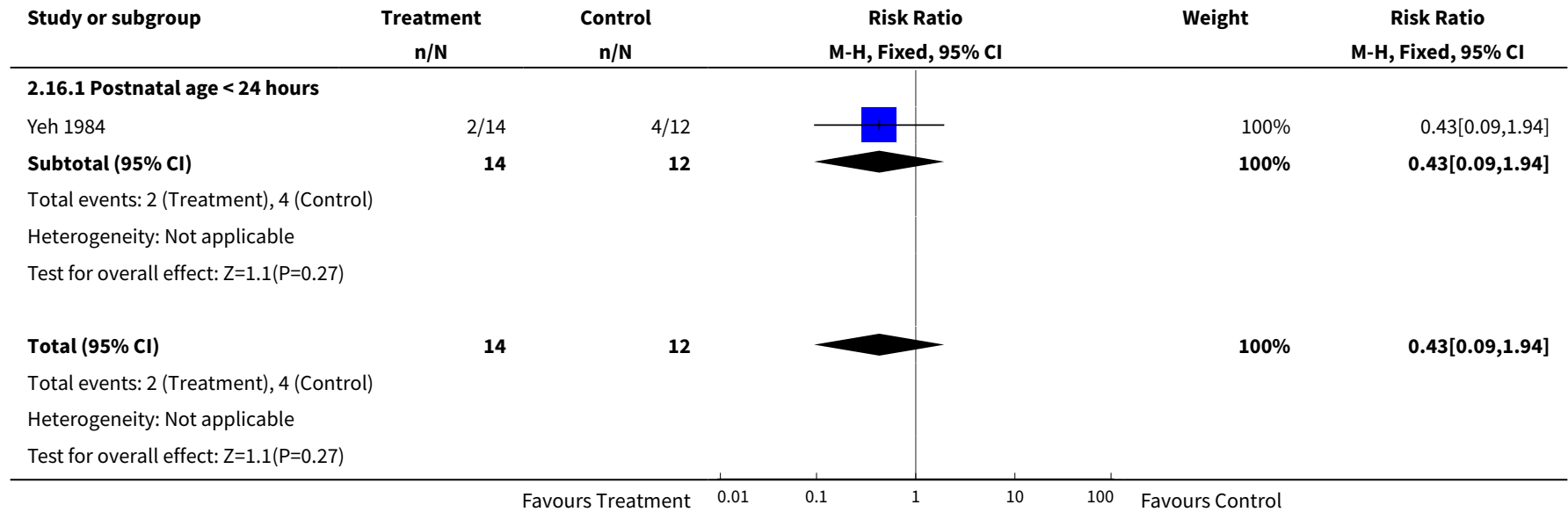


Analysis 2.17. Comparison 2 Routine diuretic administration versus placebo or no treatment, Outcome 17 Oligoanuria (urine output $<1 \mathrm{ml} / \mathrm{kg} /$ hour).

\begin{tabular}{|c|c|c|c|c|c|}
\hline Study or subgroup & $\begin{array}{c}\text { Treatment } \\
\mathbf{n} / \mathbf{N}\end{array}$ & $\begin{array}{c}\text { Control } \\
n / N\end{array}$ & $\begin{array}{c}\text { Risk Ratio } \\
\text { M-H, Fixed, 95\% Cl }\end{array}$ & Weight & $\begin{array}{c}\text { Risk Ratio } \\
\text { M-H, Fixed, } 95 \% \mathrm{Cl}\end{array}$ \\
\hline \multicolumn{6}{|l|}{ 2.17.1 All } \\
\hline Cattarelli 2006 & $1 / 23$ & $8 / 24$ & & $100 \%$ & $0.13[0.02,0.96]$ \\
\hline Subtotal $(95 \% \mathrm{Cl})$ & 23 & 24 & & $100 \%$ & $0.13[0.02,0.96]$ \\
\hline \multicolumn{6}{|c|}{ Total events: 1 (Treatment), 8 (Control) } \\
\hline \multicolumn{6}{|c|}{ Heterogeneity: Not applicable } \\
\hline \multicolumn{6}{|l|}{ 2.17.2 Theophylline } \\
\hline Cattarelli 2006 & $1 / 23$ & $8 / 24$ & & $100 \%$ & $0.13[0.02,0.96]$ \\
\hline Subtotal $(95 \% \mathrm{Cl})$ & 23 & 24 & & $100 \%$ & $0.13[0.02,0.96]$ \\
\hline \multicolumn{6}{|c|}{ Total events: 1 (Treatment), 8 (Control) } \\
\hline \multicolumn{6}{|c|}{ Heterogeneity: Not applicable } \\
\hline
\end{tabular}

Analysis 2.18. Comparison 2 Routine diuretic administration versus placebo or no treatment, Outcome 18 Hyponatremia (sodium < $130 \mathrm{mM} / \mathrm{L}$ ).

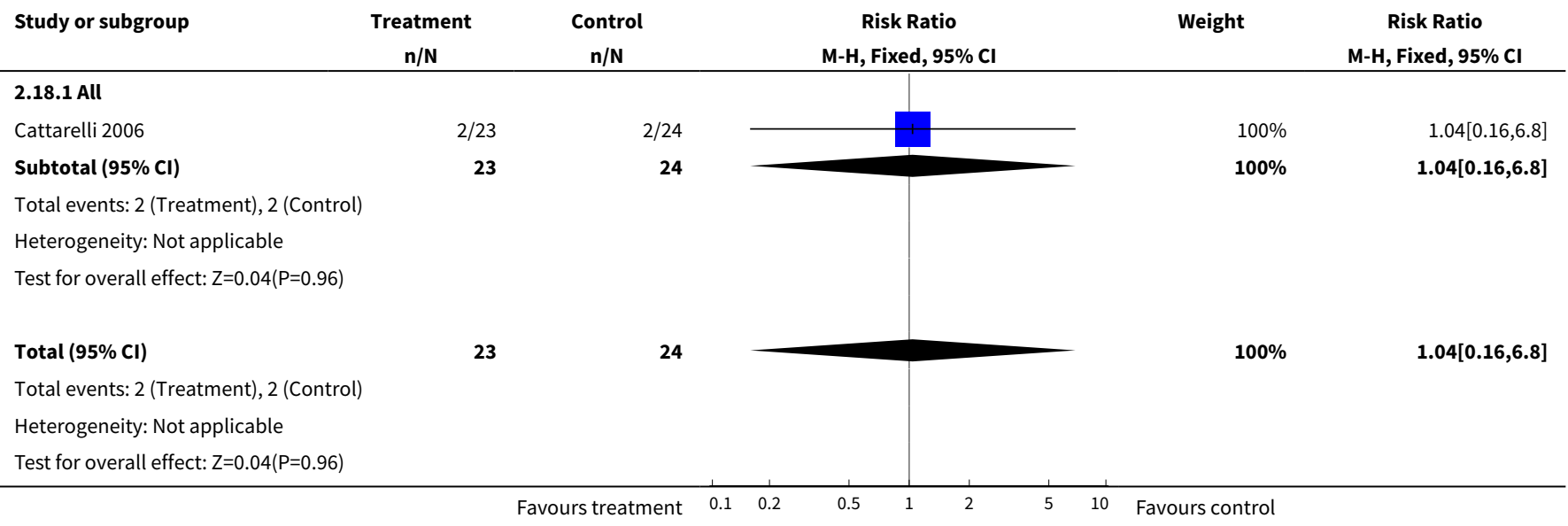

Analysis 2.19. Comparison 2 Routine diuretic administration versus placebo or no treatment, Outcome 19 Hyperkalemia (potassium $>6.5 \mathrm{mM} / \mathrm{L}$ ).

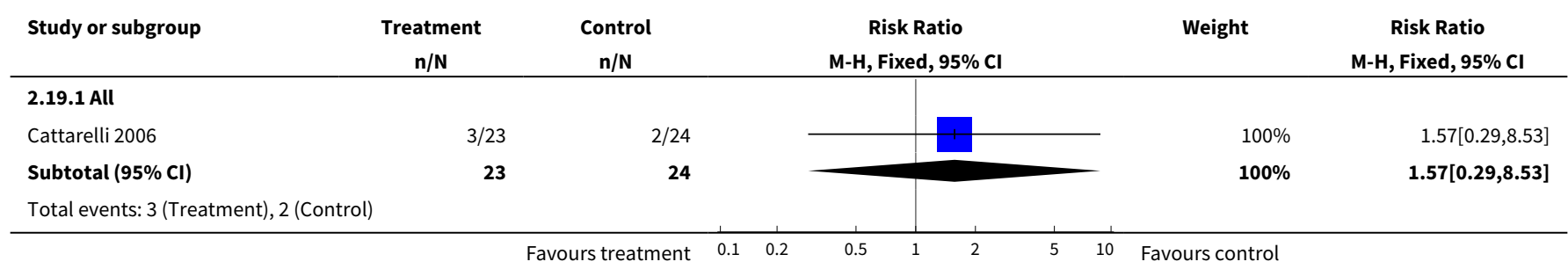




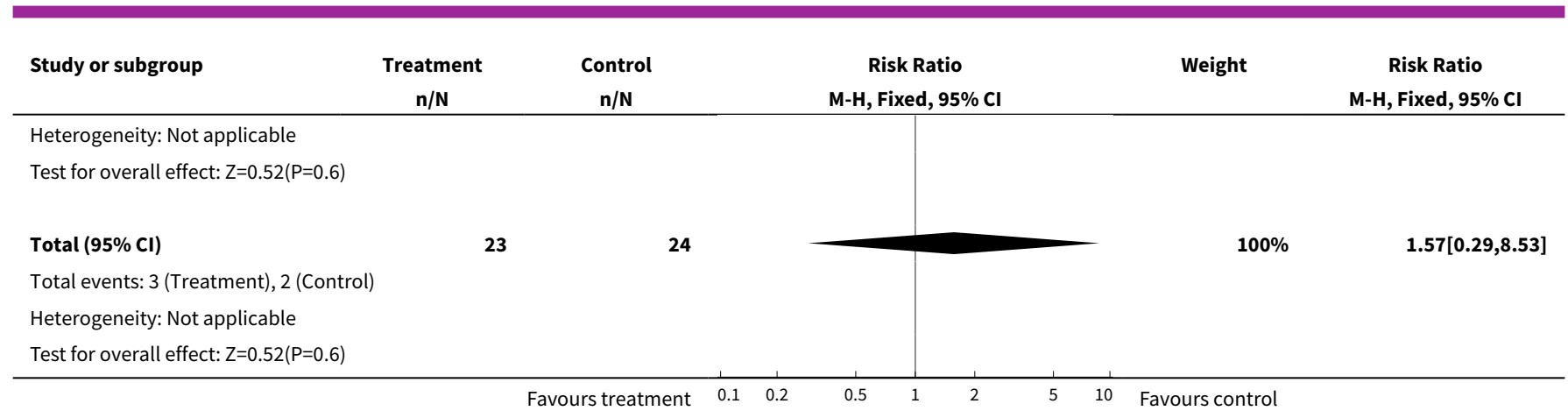

\section{Comparison 3. PRN furosemide versus PRN chlorothiazide}

\begin{tabular}{|c|c|c|c|c|}
\hline Outcome or subgroup title & $\begin{array}{l}\text { No. of } \\
\text { studies }\end{array}$ & $\begin{array}{l}\text { No. of } \\
\text { partici- } \\
\text { pants }\end{array}$ & Statistical method & Effect size \\
\hline 1 Death & 1 & 66 & Risk Ratio (M-H, Fixed, 95\% Cl) & $0.62[0.29,1.29]$ \\
\hline 2 Clinical diagnosis of PDA during the study & 1 & 66 & Risk Ratio (M-H, Fixed, 95\% Cl) & $2.25[1.14,4.44]$ \\
\hline $\begin{array}{l}3 \text { Clinical diagnosis of PDA (during the } \\
\text { study or later) }\end{array}$ & 1 & 66 & Risk Ratio (M-H, Fixed, 95\% Cl) & $3.0[1.58,5.68]$ \\
\hline 4 BPD & 1 & 45 & Risk Ratio (M-H, Fixed, 95\% Cl) & $0.8[0.18,3.54]$ \\
\hline 5 Death or BPD & 1 & 66 & Risk Ratio (M-H, Fixed, 95\% Cl) & $0.69[0.38,1.25]$ \\
\hline $6 \mathrm{IVH}$ & 1 & 66 & Risk Ratio (M-H, Fixed, 95\% Cl) & $1.18[0.62,2.25]$ \\
\hline $\begin{array}{l}7 \text { Duration of mechanical ventilation in sur- } \\
\text { vivors (days) }\end{array}$ & 1 & 45 & $\begin{array}{l}\text { Mean Difference (IV, Fixed, 95\% } \\
\mathrm{CI})\end{array}$ & $3.20[-1.31,7.71]$ \\
\hline 8 Duration of hospitalization (days) & 1 & 45 & $\begin{array}{l}\text { Mean Difference (IV, Fixed, 95\% } \\
\mathrm{CI} \text { ) }\end{array}$ & $-8.0[-33.33,17.33]$ \\
\hline
\end{tabular}

Analysis 3.1. Comparison 3 PRN furosemide versus PRN chlorothiazide, Outcome 1 Death.

\begin{tabular}{|c|c|c|c|c|c|}
\hline Study or subgroup & $\begin{array}{c}\text { Treatment } \\
\mathrm{n} / \mathrm{N}\end{array}$ & $\begin{array}{c}\text { Control } \\
n / N\end{array}$ & $\begin{array}{c}\text { Risk Ratio } \\
\text { M-H, Fixed, 95\% Cl }\end{array}$ & Weight & $\begin{array}{c}\text { Risk Ratio } \\
\text { M-H, Fixed, 95\% Cl }\end{array}$ \\
\hline Green 1983 & $8 / 33$ & $13 / 33$ & \begin{tabular}{l|l}
+1 & \\
\end{tabular} & $100 \%$ & $0.62[0.29,1.29]$ \\
\hline Total $(95 \% \mathrm{CI})$ & 33 & 33 & - & $100 \%$ & $0.62[0.29,1.29]$ \\
\hline \multicolumn{6}{|c|}{ Total events: 8 (Treatment), 13 (Control) } \\
\hline \multicolumn{6}{|c|}{ Heterogeneity: Not applicable } \\
\hline \multicolumn{6}{|c|}{ Test for overall effect: $Z=1.29(P=0.2)$} \\
\hline
\end{tabular}


Analysis 3.2. Comparison 3 PRN furosemide versus PRN

chlorothiazide, Outcome 2 Clinical diagnosis of PDA during the study.

\begin{tabular}{|c|c|c|c|c|c|}
\hline Study or subgroup & $\begin{array}{c}\text { Treatment } \\
\mathrm{n} / \mathrm{N}\end{array}$ & $\begin{array}{c}\text { Control } \\
n / N\end{array}$ & $\begin{array}{c}\text { Risk Ratio } \\
\text { M-H, Fixed, 95\% Cl }\end{array}$ & Weight & $\begin{array}{c}\text { Risk Ratio } \\
\text { M-H, Fixed, } 95 \% \mathrm{Cl}\end{array}$ \\
\hline Green 1983 & $18 / 33$ & $8 / 33$ & & $100 \%$ & $2.25[1.14,4.44]$ \\
\hline Total $(95 \% \mathrm{Cl})$ & 33 & 33 & & $100 \%$ & $2.25[1.14,4.44]$ \\
\hline \multicolumn{6}{|c|}{ Total events: 18 (Treatment), 8 (Control) } \\
\hline \multicolumn{6}{|c|}{ Heterogeneity: Not applicable } \\
\hline \multicolumn{6}{|c|}{ Test for overall effect: $Z=2.34(P=0.02)$} \\
\hline
\end{tabular}

Analysis 3.3. Comparison 3 PRN furosemide versus PRN chlorothiazide, Outcome 3 Clinical diagnosis of PDA (during the study or later).

\begin{tabular}{|c|c|c|c|c|c|}
\hline Study or subgroup & $\begin{array}{c}\text { Treatment } \\
\mathrm{n} / \mathrm{N}\end{array}$ & $\begin{array}{c}\text { Control } \\
\mathrm{n} / \mathrm{N}\end{array}$ & $\begin{array}{c}\text { Risk Ratio } \\
\text { M-H, Fixed, } 95 \% \mathrm{Cl}\end{array}$ & Weight & $\begin{array}{c}\text { Risk Ratio } \\
\text { M-H, Fixed, } 95 \% \mathrm{Cl} \\
\end{array}$ \\
\hline Green 1983 & $24 / 33$ & $8 / 33$ & 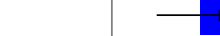 & $100 \%$ & $3[1.58,5.68]$ \\
\hline Total $(95 \% \mathrm{Cl})$ & 33 & 33 & & $100 \%$ & $3[1.58,5.68]$ \\
\hline \multicolumn{6}{|c|}{ Total events: 24 (Treatment), 8 (Control) } \\
\hline \multicolumn{6}{|c|}{ Heterogeneity: Not applicable } \\
\hline Test for overall effec & & & & & \\
\hline
\end{tabular}

Analysis 3.4. Comparison 3 PRN furosemide versus PRN chlorothiazide, Outcome 4 BPD.

\begin{tabular}{|c|c|c|c|c|c|}
\hline Study or subgroup & $\begin{array}{l}\text { Treatment } \\
n / \mathrm{N}\end{array}$ & $\begin{array}{l}\text { Control } \\
\mathrm{n} / \mathrm{N}\end{array}$ & $\begin{array}{c}\text { Risk Ratio } \\
\text { M-H, Fixed, } 95 \% \text { CI }\end{array}$ & Weight & $\begin{array}{c}\text { Risk Ratio } \\
\text { M-H, Fixed, } 95 \% \mathrm{Cl}\end{array}$ \\
\hline Green 1983 & $3 / 25$ & $3 / 20$ & & $100 \%$ & $0.8[0.18,3.54]$ \\
\hline Total $(95 \% \mathrm{Cl})$ & 25 & 20 & & $100 \%$ & $0.8[0.18,3.54]$ \\
\hline \multicolumn{6}{|c|}{ Total events: 3 (Treatment), 3 (Control) } \\
\hline \multicolumn{6}{|c|}{ Heterogeneity: Not applicable } \\
\hline \multicolumn{6}{|c|}{ Test for overall effect: $Z=0.29(P=0.77)$} \\
\hline
\end{tabular}

Analysis 3.5. Comparison 3 PRN furosemide versus PRN chlorothiazide, Outcome 5 Death or BPD.

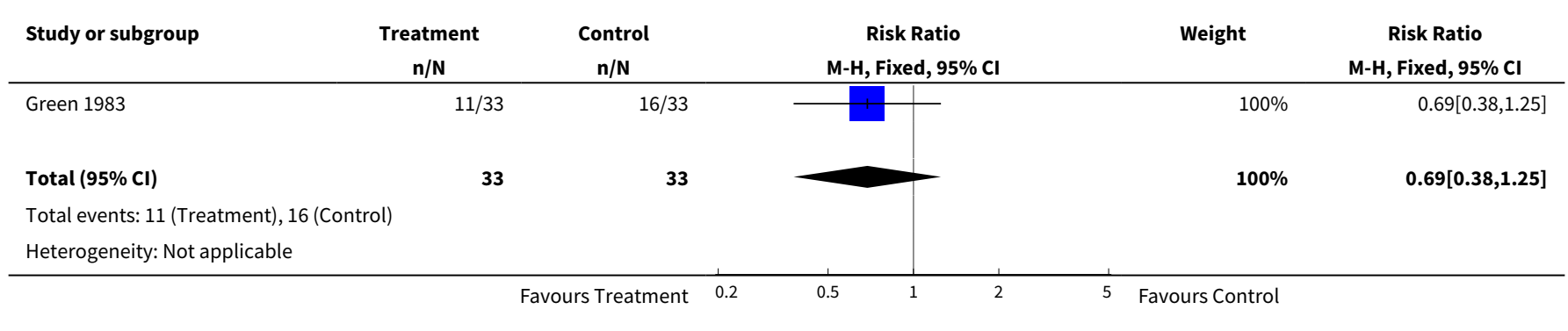




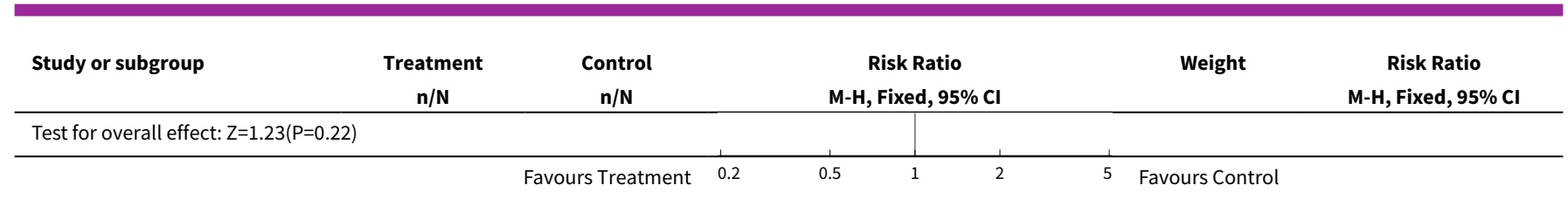

Analysis 3.6. Comparison 3 PRN furosemide versus PRN chlorothiazide, Outcome 6 IVH.

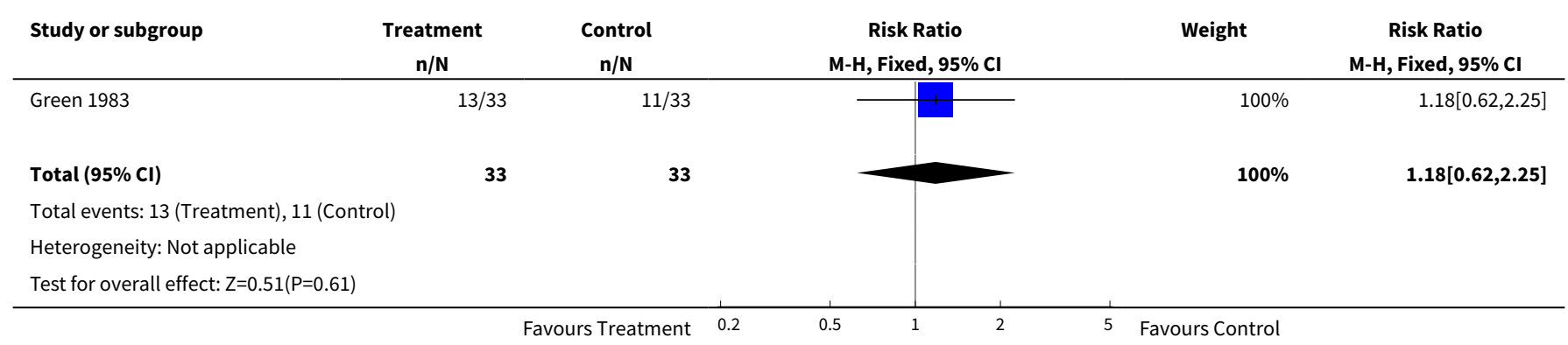

Analysis 3.7. Comparison 3 PRN furosemide versus PRN chlorothiazide, Outcome 7 Duration of mechanical ventilation in survivors (days).

\begin{tabular}{|c|c|c|c|c|c|c|c|}
\hline \multirow{3}{*}{$\begin{array}{l}\text { Study or subgroup } \\
\text { Green } 1983\end{array}$} & \multicolumn{2}{|c|}{ Treatment } & \multicolumn{2}{|c|}{ Control } & \multirow{2}{*}{$\begin{array}{c}\text { Mean Difference } \\
\text { Fixed, } 95 \% \mathrm{Cl}\end{array}$} & \multirow[t]{2}{*}{ Weight } & \multirow{2}{*}{$\begin{array}{c}\text { Mean Difference } \\
\text { Fixed, } 95 \% \mathrm{Cl}\end{array}$} \\
\hline & $\mathbf{N}$ & Mean(SD) & $\mathbf{N}$ & $\operatorname{Mean}(S D)$ & & & \\
\hline & 25 & $10.5(10.3)$ & 20 & $7.3(4.6)$ & 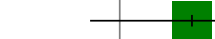 & $100 \%$ & $3.2[-1.31,7.71]$ \\
\hline Total ${ }^{\star \star \star}$ & 25 & & 20 & & & $100 \%$ & $3.2[-1.31,7.71]$ \\
\hline \multicolumn{8}{|c|}{ Heterogeneity: $\mathrm{Tau}^{2}=0 ; \mathrm{Chi}^{2}=0, \mathrm{df}=0(\mathrm{P}<0.0001) ; \mathrm{I}^{2}=100 \%$} \\
\hline \multicolumn{3}{|c|}{ Test for overall effect: $Z=1.39(P=0.16)$} & & & & & \\
\hline
\end{tabular}

Analysis 3.8. Comparison 3 PRN furosemide versus PRN chlorothiazide, Outcome 8 Duration of hospitalization (days).

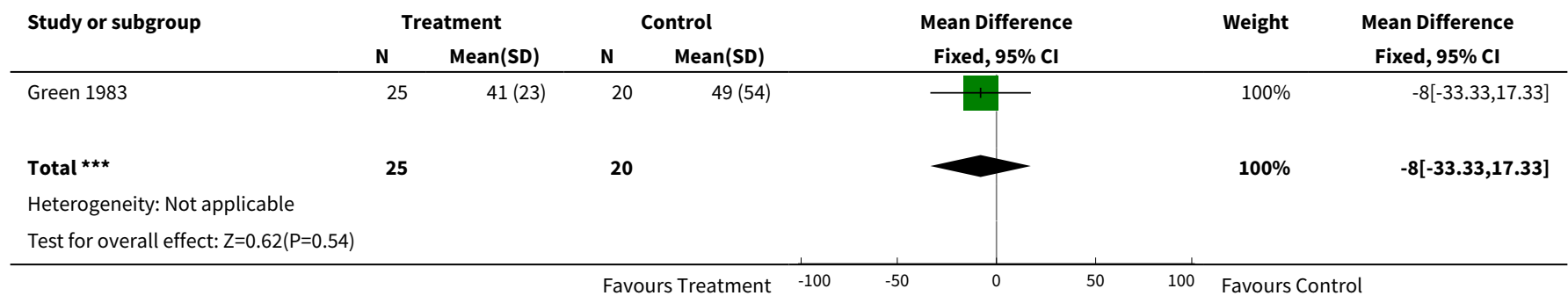

WHAT'S NEW 


\begin{tabular}{lll}
\hline Date & Event & Description \\
\hline 20 September 2011 & $\begin{array}{l}\text { New citation required but conclusions } \\
\text { have not changed }\end{array}$ & New lead author: Dr. Audra Stewart \\
\hline 14 January 2011 & New search has been performed & $\begin{array}{l}\text { This is an update of the review "Diuretics for respiratory distress } \\
\text { syndrome in preterm infants", published in The Cochrane Li- } \\
\text { brary, Issue 1, 2008 (Brion 2008). }\end{array}$ \\
& $\begin{array}{l}\text { A search of MEDLINE through August 2011 yielded one additional } \\
\text { trial which was not included in the analysis (Greenough 1985). } \\
\text { Additional searches in Cochrane Central Register of Controlled } \\
\text { Trials (CENTRAL, The Cochrane Library), EMBASE, controlled-tri- } \\
\text { als.com and clinicaltrials.gov did not yield additional studies. }\end{array}$ \\
\end{tabular}

\section{HISTORY}

Protocol first published: Issue 3, 1999

Review first published: Issue 3, 1999

\begin{tabular}{lll}
\hline Date & Event & Description \\
\hline 3 June 2008 & Amended & Converted to new review format. \\
\hline 7 November 2007 & New search has been performed & $\begin{array}{l}\text { This is an update of the review "Diuretics for respiratory distress } \\
\text { syndrome in preterm infants", published in The Cochrane Li- } \\
\text { brary, Issue 2, 2001 (Brion 2001). }\end{array}$ \\
& $\begin{array}{l}\text { A search of MEDLINE in April 2003 and of the Cochrane Central } \\
\text { Register of Controlled Trials (CENTRAL, The Cochrane Library, Is- } \\
\text { sue 1, 2003) did not yield any additional eligible studies. }\end{array}$ \\
& $\begin{array}{l}\text { Based on recent expansion of the classification of diuretics } \\
\text { (Guignard 2005), the background and search strategy have } \\
\text { been updated. A search of MEDLINE in March 2007 and of The } \\
\text { Cochrane Central Register of Controlled Trials (CENTRAL, The } \\
\text { Cochrane Library, Issue 1, 2007) yielded two additional trials, one } \\
\text { of which was included in the analysis (Cattarelli 2005). }\end{array}$ \\
\hline 7 November 2007 & $\begin{array}{l}\text { New citation required but conclusions } \\
\text { have not changed }\end{array}$ & \begin{tabular}{l} 
Substantive amendment \\
\hline
\end{tabular} \\
\hline
\end{tabular}

\section{CONTRIBUTIONS OF AUTHORS}

Michael C. McQueen was a co-author of the first version of this systematic review (Soll 1992).

LPB and RS performed the searches, wrote the review and revised prior reviews.

ALS, LPB and RS revised the most recent review update (2011).

\section{DECLARATIONS OF INTEREST}

None 


\section{SOURCES OF SUPPORT}

\section{Internal sources}

- No sources of support supplied

\section{External sources}

- Grant-in-Aid 9650445N of the American Heart Association (LPB), USA.

- NICHD Grant for the Neonatal Collaborative Group NO1-MD-6-3523, USA.

\section{INDEX TERMS}

\section{Medical Subject Headings (MeSH)}

Bronchodilator Agents [therapeutic use]; Chlorothiazide [therapeutic use]; Diuretics [adverse effects] [ ${ }^{\star}$ therapeutic use]; Furosemide [adverse effects] [therapeutic use]; Infant, Premature; Randomized Controlled Trials as Topic; Respiratory Distress Syndrome, Newborn [*drug therapy] [mortality]; Theophylline [therapeutic use]

\section{MeSH check words}

Humans; Infant, Newborn 